INSTITUTO DE PESQUISAS ENERGÉTICAS E NUCLEARES

Autarquia associada à Universidade de São Paulo

INFLUÊNCIA DA CONFIGURAÇÃO DE BOBINAGEM NO COMPORTAMENTO MECÂNICO DE CILINDROS DE COMPÓSITO POLIMÉRICO

OSNI DE CARVALHO

Dissertação apresentada como parte dos requisitos para a obtenção do Grau de Mestre em Ciências na Área de Tecnologia Nuclear - Materiais.

Orientador:

Dr. Gerson Marinucci 
À minha esposa, Rosimeri. Aos meus filhos, Felipe e Henrique. Aos meus pais, Juracy e Agostinho. 


\section{AGRADECIMENTOS}

A Deus, por permitir que eu conquistasse mais uma vitória.

Ao meu orientador, Dr. Gerson Marinucci, por ter me incentivado a iniciar este trabalho, por ter acreditado na minha capacidade e pela participação direta em todas as etapas.

Ao Dr. Jesualdo Luiz Rossi, pelo apoio nas etapas iniciais, permitindo a viabilidade do trabalho.

Ao Centro Tecnológico da Marinha em São Paulo - CTMSP, pelo uso de suas instalações para obtenção dos corpos-de-prova e realização de ensaios.

Ao Superintende Industrial do CTMSP, CMG (EN-RRm) Germano de Freitas, pelo apoio no decorrer do trabalho.

Ao Chefe do Departamento de Fabricação do CTMSP, Dr. Tadeu Antônio da Silva Martins, pelo apoio no decorrer do trabalho.

Aos colegas da OFCOMP do CTMSP, João Claudino de Godois Netto, Lúcio Alves Pinto, Daniel Bina e Reinaldo do Nascimento Júnior, pela participação nas etapas de produção dos cilindros.

Aos colegas do LACAM do CTMSP, Dra. Patrícia, Dra. Cláudia, Marcos Augusto, José Ferreira, Carlos, Cláudio Brasil e Álvaro, pela participação nas etapas de caracterização e ensaios.

Aos colegas do LABMAT do CTMSP, Gomide, Ana Elis e Carina, pela utilização do equipamento analisador de imagens.

Ao colega César Kodama, pela participação na etapa de análise de tensões e deformações.

Aos colegas da Informática do CTMSP, Oscar e Vanessa, pela utilização dos equipamentos de informática.

Aos demais colegas do CTMSP, que participaram direta ou indiretamente do trabalho.

Ao Instituto de Pesquisas Energéticas e Nucleares - IPEN, por tornar possível a realização deste estudo.

Aos funcionários da biblioteca do IPEN, pela ajuda no decorrer deste trabalho. 


\title{
INFLUÊNCIA DA CONFIGURAÇÃO DE BOBINAGEM NO COMPORTAMENTO MECÂNICO DE CILINDROS DE COMPÓSITO POLIMÉRICO
}

\author{
Osni de Carvalho
}

\section{RESUMO}

Neste trabalho avaliou-se experimentalmente a influência da configuração de bobinagem no comportamento mecânico de cilindros de compósito polimérico com bobinagem simétrica e assimétrica. Para tanto, foram fabricados pelo processo de bobinamento filamentar (filament winding) dois grupos de cilindros com extremidades abertas, que apresentaram alteração no posicionamento das camadas em relação ao plano médio, caracterizando laminados simétrico e assimétrico. No compósito deste estudo, utilizou-se uma matriz com sistema tricomponente com resina epoxídica e reforço de fibra de carbono. Para avaliação da resistência mecânica, os cilindros foram submetidos a ensaio hidrostático que consistiu da pressurização interna em dispositivo apropriado mediante a utilização de um fluido até que ocorresse o colapso. Adicionalmente, as deformações e os modos de falha dos dois grupos de cilindros foram analisados e comparados. A utilização de um programa de cálculo de elementos finitos permitiu concluir que esta ferramenta, muito usada em projeto, não consegue identificar tensões na orientação da fibra em cada uma das camadas do compósito, bem como tensões de cisalhamento interlaminares que surgem nos cilindros com configuração assimétrica. Os resultados dos ensaios mostraram que as configurações de bobinagem exercem influência no comportamento mecânico dos cilindros de material compósito, favorecendo a construção do tipo simétrica. 


\title{
INFLUENCE OF THE STACKING SEQUENCE OF LAYERS ON THE MECHANICAL BEHAVIOR OF POLYMERIC COMPOSITE CYLINDERS
}

\section{Osni de Carvalho}

\begin{abstract}
This work evaluated experimentally the influence of the stacking sequence of layers symmetrical and asymmetrical on the mechanical behavior of polymeric composite cylinders. For so much, two open-ended cylinders groups were manufactured by filament winding process, which had different stacking sequence related to the laminate midplane, characterizing symmetrical and asymmetrical laminates. The composite cylinders were made with epoxy matrix and carbon fiber as reinforcement. For evaluation of the mechanical strength, the cylinders were tested hydrostatically, which consisted of internal pressurization in a hydrostatic device through the utilization of a fluid until the cylinders burst. Additionally, were compared the strains and failure modes between the cylinders groups. The utilization of a finite element program allowed to conclude that this tool, very used in design, does not get to identify tensions in the fiber direction in each composite layer, as well as interlaminar shear stress, that appears in the cylinders with asymmetrical stacking sequence. The tests results showed that the stacking sequence had influence in the mechanical behavior of the composite cylinders, favoring the symmetrical construction.
\end{abstract}




\section{SUMÁRIO}

Página

1 INTRODUÇÃO

2 OBJETIVO

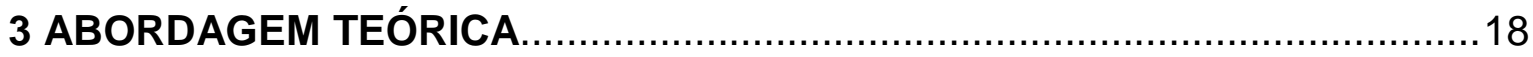

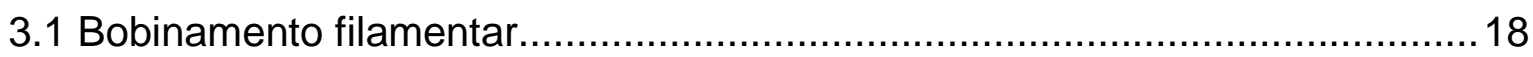

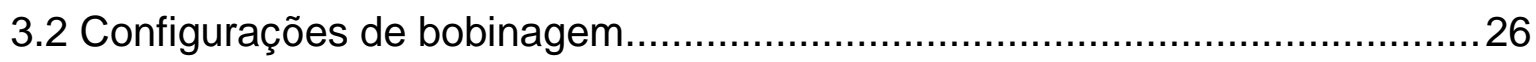

4 MATERIAIS E MÉTODOS

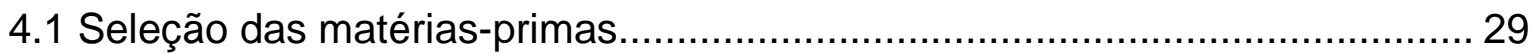

4.2 Definição das configurações de bobinagem.................................................

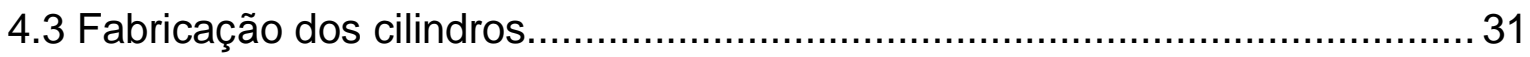

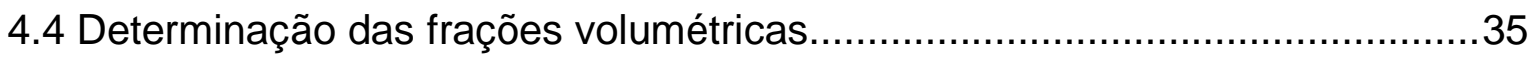

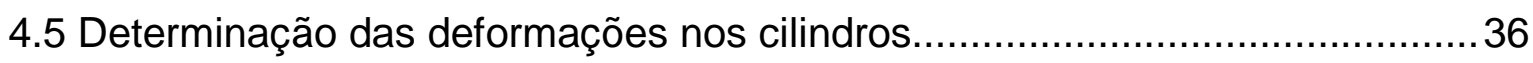

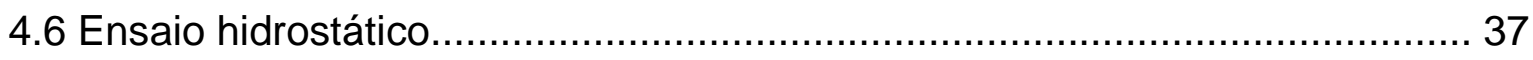

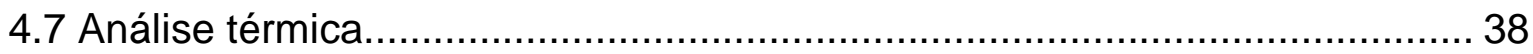

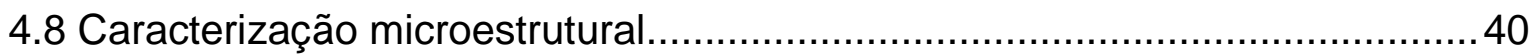

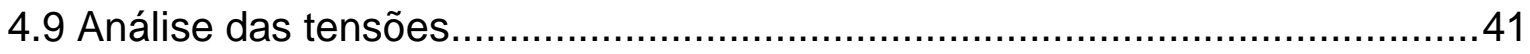

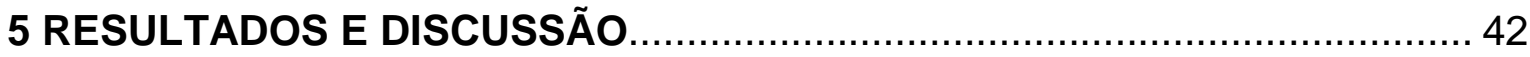

5.1 Frações volumétricas dos cilindros com bobinagem simétrica e assimétrica. 42

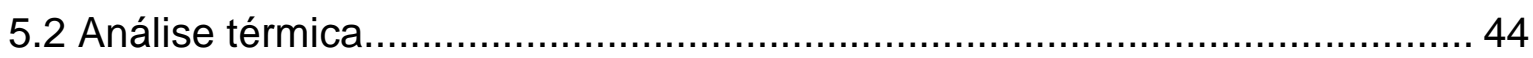

5.3 Relação entre pressão e deformações circunferencial e longitudinal............. 45

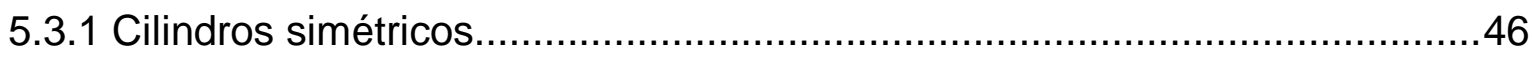

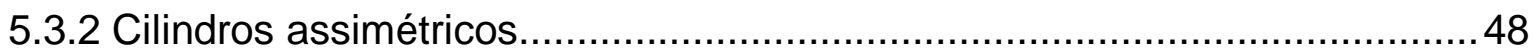

5.3.3 Comparação entre pressão e deformações circunferencial e longitudinal nos cilindros simétricos e assimétricos........................................................

5.4 Relação entre deformações circunferencial e longitudinal............................. 53

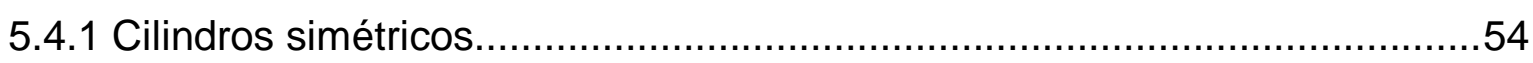

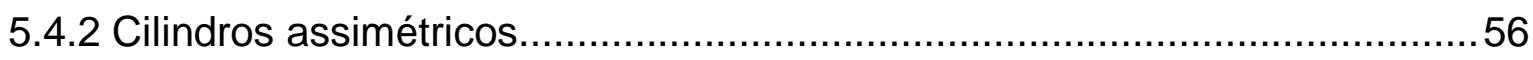


5.4.3 Comparação entre deformações circunferencial e longitudinal nos

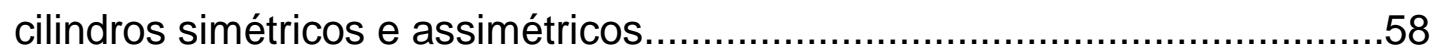

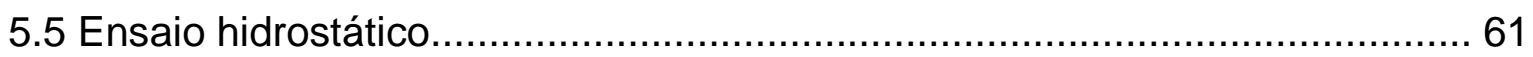

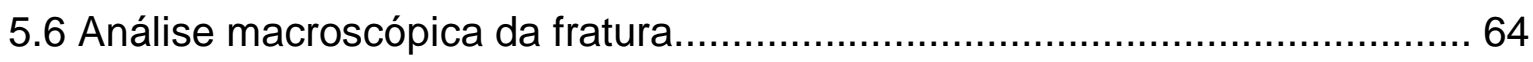

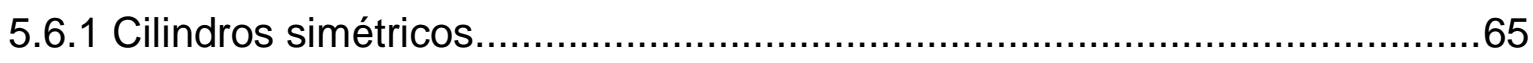

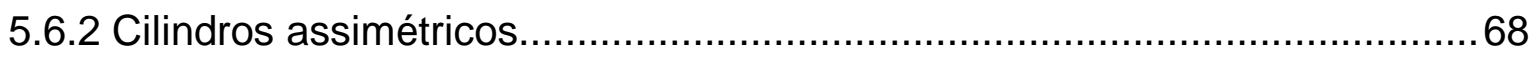

5.6.3 Comparação macroscópica das fraturas................................................. 70

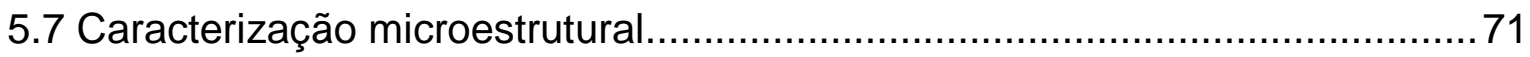

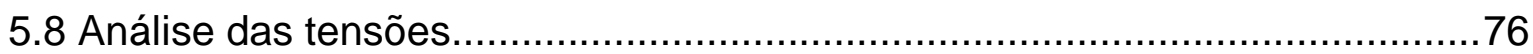

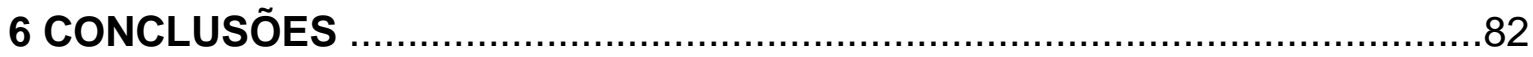

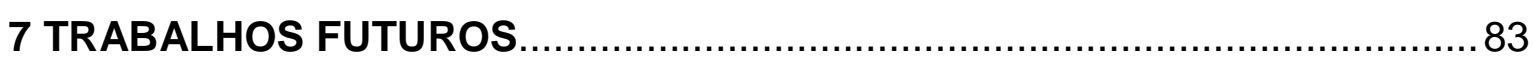

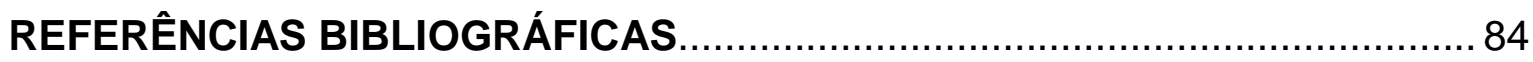




\section{INTRODUÇÃO}

Há uma crescente demanda mundial pela utilização de estruturas cilíndricas de material compósito, uma vez que estas podem ser empregadas em uma grande variedade de aplicações na indústria. A elevada resistência mecânica e a baixa massa específica tornam o material compósito atrativo para áreas tais como a nuclear, a aeroespacial, a petrolífera, a automotiva e a esportiva.

Um material compósito pode ser definido como uma combinação macroscópica de dois ou mais materiais distintos que podem ser fisicamente identificados e exibem uma interface bem definida entre eles. Contudo, como os compósitos são utilizados por causa das suas propriedades estruturais, a definição pode ser restringida para incluir somente aqueles materiais que contêm um reforço, tais como fibras ou partículas, sustentado por uma matriz que pode ser polimérica, cerâmica ou metálica (ASM, 1987).

Os materiais compósitos poliméricos possuem inúmeras vantagens quando comparados aos materiais tradicionalmente utilizados na engenharia, como por exemplo, aço e alumínio. Graças ao elevado desempenho e seu aspecto multifuncional, os compósitos são capazes de atender a diversos requisitos de projeto. A resistência à tração específica desses materiais (razão entre a resistência à tração e a massa específica) é aproximadamente quatro a seis vezes maior que a do aço ou alumínio. O módulo de elasticidade específico (razão entre o módulo de elasticidade e a massa específica) é de três e meio a cinco vezes maior que a do aço ou alumínio (Strong, 1989). A redução de peso é significativa e freqüentemente pode variar de 25 a $50 \%$ do peso de componentes em material metálico de aplicação geral. Outras vantagens que podem ser atribuídas aos compósitos poliméricos são a elevada resistência à fadiga, ao impacto, elevada resistência química, além da possibilidade de eliminar diversas juntas, evitando pontos críticos estruturais e reduzindo o custo.

Os processos de fabricação de compósitos são caracterizados pela forma com que o reforço e a matriz polimérica são depositados sobre o molde, o qual dará a forma final ao componente estrutural desejado. A técnica mais simples, de 
menor custo e provavelmente a mais utilizada, é a laminação manual (hand lay-up), na qual os materiais de reforço, tais como fibras picadas, véus, mantas ou tecidos são depositados manualmente sobre um molde, previamente coberto com desmoldante. O reforço é aplicado em várias camadas e a cada camada as fibras são impregnadas pela matriz polimérica com o auxílio de pincéis e rolos. Durante a laminação é feita a operação de roletagem, que consiste em passar um rolete sobre as camadas laminadas para compactar o material e retirar eventuais bolhas de ar. Este processo utiliza na maioria das aplicações reforço de fibras de vidro e resinas de poliéster insaturadas de cura ambiente.

O processo de laminação por projeção (spray-up) é caracterizado pela utilização de uma pistola que projeta um jato da matriz e simultaneamente corta a fibra em pequenos pedaços, com o auxílio de um picador acoplado à pistola. $\mathrm{A}$ fibra picotada é lançada sobre o jato da matriz e direcionado para a superfície do molde, permitindo um método de fabricação contínuo com baixo investimento em equipamentos. Neste processo, a espessura do laminado depende da habilidade do operador da pistola e a compactação do compósito e retirada de bolhas de ar também é feita por roletagem como na laminação manual.

O processo de fabricação que utiliza o reforço pré-impregnado é visto como uma extensão do método de laminação manual descrito anteriormente. Neste processo, o reforço está geralmente na forma de tecido, contendo a matriz em proporções que atendem especificações rigorosas do transformador. Este método é muito mais preciso e quase sempre necessita de uma bolsa de vácuo (vacuum bag) e autoclave. A resina mais utilizada na impregnação do reforço é a epóxi, cuja cura ocorre a temperaturas acima da temperatura ambiente.

No processo que utiliza o reforço na forma pré-impregnada, a autoclave é o equipamento que proporciona a consolidação das camadas de compósito através da aplicação de pressões superiores à atmosférica. O material compósito arranjado sobre o molde em camadas é colocado dentro da autoclave envolvido em uma bolsa de vácuo. Pressão e vácuo são aplicados, além de temperatura para a cura da matriz. Este é um processo caro e utilizado em aplicações nas quais os requisitos para o compósito exigem alto desempenho, tais como na indústria aeronáutica.

No processo que utiliza apenas bolsa de vácuo (vacuum bag), o molde, após a deposição do material compósito, é envolvido em uma bolsa na qual é 
aplicado vácuo. Esta técnica explora a ação da pressão atmosférica para assegurar o contato do compósito com o molde, consolidando as camadas, expelindo o ar e os voláteis da resina durante a cura (Ashbee, 1989).

Outro processo bastante empregado na fabricação de estruturas em compósito é a bobinagem filamentar (filament winding), na qual filamentos contínuos de reforço impregnados pela matriz são bobinados sobre um molde em rotação. Para a execução do processo, utiliza-se uma bobinadeira que é o equipamento que torna possível a fabricação do componente em compósito. A bobinagem dos filamentos é feita utilizando-se recursos de softwares específicos, que tornam possível a fabricação de estruturas de baixo peso e elevadas resistências mecânica e química. Apesar do alto investimento em equipamento, este processo permite a produção em larga escala de componentes cilíndricos e esféricos.

Além dos processos de moldagem em molde aberto descritos anteriormente, existem os processos de moldagem em molde fechado, tais como o BMC (Bulk Molding Compound), o SMC (Sheet Molding Compound) e o RTM (Resin Transfer Molding).

O BMC é o processo no qual a matéria-prima composta de resina, fibra de vidro picada, cargas minerais e aditivos é moldada por compressão em um molde previamente aquecido. A quantidade de matéria-prima necessária para a peça é depositada na parte inferior do molde que é fechado em seguida pela parte superior, em uma prensa de alta capacidade de carga. A temperatura do molde cura a peça em poucos minutos, permitindo a alta produção exigida na indústria automobilística (Strong, 1989).

O SMC é um processo semelhante ao BMC, porém a matéria-prima previamente preparada tem a forma de uma chapa fina e é fornecida em rolos. Esta chapa é recortada próxima às dimensões da peça a ser produzida e então é posicionada sobre o molde que é fechado por uma prensa. A cura ocorre pelo aquecimento do molde em reduzido intervalo de tempo (Strong, 1989).

No processo de RTM, o molde preenchido com o material de reforço é fechado e colocado sob vácuo. O vácuo retira o ar retido na cavidade do molde e auxilia na etapa de injeção de resina. Um dos requisitos para o material de reforço é que ele mantenha a sua preforma durante a injeção. A escolha correta dos pontos de injeção é um dos requisitos importantes na construção do molde 
porque a resina necessita atingir todas as áreas da peça em tempo inferior ao início da etapa de gel para garantir uma boa impregnação das fibras (Strong, 1989).

Uma alternativa ao RTM que apresenta custo mais baixo é o processo RTM Light, no qual a pressão de injeção é menor que 1 bar, permitindo que os moldes sejam mais simples, podendo inclusive substituir os moldes metálicos por moldes de material compósito. Os custos são inferiores ao custo do RTM convencional, podendo chegar à metade, com a redução da velocidade de produção na mesma proporção, porém, a produtividade é de duas a três vezes superior a dos processos de molde aberto.

Para a fabricação dos exemplares deste estudo foi utilizado o processo de bobinamento filamentar. Este processo, conforme anteriormente citado, pode ser definido como uma técnica para fabricação de estruturas de compósito polimérico na qual reforços contínuos de carbono, vidro ou aramida (Kevlar), já previamente impregnados com a matriz polimérica ou impregnados durante o bobinamento (wet winding), são depositados sobre um mandril em rotação obedecendo orientações preestabelecidas. O mandril é fabricado utilizando-se aço ou alumínio e deve apresentar ótimo acabamento superficial e tolerâncias dimensionais de acordo com os critérios de projeto do componente. A peça gerada é uma superfície de revolução e pode ou não incluir fechamentos nas extremidades. Quando o número requerido de camadas é atingido, a bobinagem é finalizada e a matriz polimérica é curada com a posterior retirada do mandril (Peters, 1989).

No projeto de um componente estrutural em compósito polimérico é importante considerar o posicionamento das camadas na configuração de bobinagem, uma vez que a posição relativa de cada uma das lâminas em relação ao plano médio da espessura pode introduzir tensões que causam um efeito indesejado na estrutura e muitas vezes podem ser desconsideradas no cálculo estrutural. Assim, não só os ângulos de bobinagem e as propriedades mecânicas de cada uma das camadas devem ser conhecidas, mas também a seqüência com que as camadas são bobinadas na fabricação do compósito (Carvalho et al., 2004).

Um compósito laminado cuja seqüência de camadas abaixo do plano médio da espessura é uma imagem de espelho da seqüência empilhada acima do mesmo plano é denominado de laminado simétrico. Um laminado que possui uma 
seqüência arbitrária de empilhamento, não possuindo um plano médio de simetria é denominado laminado assimétrico (ASM, 1987).

Estudos sobre a influência dos parâmetros do processo de bobinamento filamentar na resistência e qualidade dos cilindros foram realizados em ensaios hidrostáticos (Cohen, 1997) e variáveis como a fração volumétrica de fibra e a seqüência de empilhamento das camadas mostraram exercer influência nos resultados obtidos. Segundo o autor, a resistência mecânica do cilindro aumentou com a elevação da fração volumétrica de fibra. A fração volumétrica no compósito foi afetada pela tensão aplicada aos filamentos e pelo tempo de impregnação da fibra durante o processo de bobinamento. Frações volumétricas mais elevadas foram obtidas com maiores tensões nos filamentos e também tempos de impregnação menores produziram frações volumétricas mais elevadas.

Ainda segundo Cohen, a seqüência de empilhamento merece destaque especial devido à influência nos resultados de fração volumétrica de fibra. Duas seqüências diferentes de empilhamento com os mesmos ângulos e mesmo número de camadas foram analisadas. Cilindros fabricados com a seqüência de empilhamento cujas camadas de fibra a $90^{\circ}$ ficaram adjacentes obtiveram média de fração volumétrica de fibra $4,8 \%$ maior que os cilindros fabricados com a seqüência de empilhamento, cujas camadas de fibra a $90^{\circ}$ ficaram dispersas entre as camadas helicoidais, conseqüentemente, a pressão média de ruptura da primeira seqüência de cilindros foi superior.

$\mathrm{Na}$ mesma linha de estudo, Cohen et al. (2001) desenvolveram um modelo computacional que utiliza os parâmetros do processo de bobinamento filamentar para estimar a fração volumétrica de fibra em cilindros e assim calcular a pressão de ruptura. Resultados de fração volumétrica de fibra obtidos entre o modelo desenvolvido e um analisador de imagens foram comparados e mostraram pequena variação. Paralelamente, cilindros testados hidrostaticamente comparados com o cálculo do modelo mostraram erro de $5 \%$ para valores de pressão de ruptura. Finalizando o estudo, uma das conclusões dos autores foi que entre os cilindros analisados, os que possuíam elevada fração volumétrica de fibra e baixo volume de vazio exibiram resultados superiores de resistência quando submetidos ao ensaio hidrostático.

Vazios presentes em compósitos produzem efeitos negativos sobre as propriedades mecânicas do material e colaboram na diminuição da resistência à 
tração, à flexão, à compressão e ao cisalhamento (Hagstrand et al., 2005). Deste modo, é importante que as técnicas de fabricação possibilitem minimizar o volume de vazio. Os vazios podem se formar durante o processo pelas presenças de ar, umidade, solventes ou produtos da polimerização.

De acordo com Hagstrand et al. (2005), o efeito do volume de vazio sobre as propriedades mecânicas é dependente de sua morfologia. Por exemplo, um compósito com as fibras apresentando uma boa impregnação e com vazios distribuídos uniformemente pela matriz possui uma morfologia vantajosa do ponto de vista mecânico, uma vez que, a transferência de carga para as fibras deverá ser relativamente boa apesar da presença de vazios, se comparado com um compósito de mesmo volume de vazio com morfologia de vazios na interface fibra/matriz. O compósito estudado pelos autores foi fabricado com matriz termoplástica de polipropileno.

Segundo Mertiny et al. (2003), artigos que abordam estruturas multiângulos produzidas pelo processo de bobinamento filamentar são limitados e raramente apresentam os mecanismos responsáveis pelos modos de falha observados. No trabalho dos autores, a influência da seqüência de empilhamento na resistência de cilindros produzidos pelo processo de bobinamento filamentar em camadas multi-ângulos foi testada e um dos ensaios utilizados foi o ensaio hidrostático em cilindros de extremidades abertas.

Neste estudo realizado por Mertiny, foram comparados cilindros com dois tipos de bobinagem assimétrica, sendo uma seqüência de empilhamento $\left[ \pm 45^{\circ} / \pm 60^{\circ}\right]_{\mathrm{T}}$ e a outra seqüência, denominada de seqüência invertida $\left[ \pm 60^{\circ} / \pm 45^{\circ}\right]_{T}$. Resultados obtidos evidenciaram que a seqüência $\left[ \pm 45^{\circ} / \pm 60^{\circ}\right]_{T}$ possuía resistência superior à seqüência $\left[ \pm 60^{\circ} \underline{ }^{\circ} 45^{\circ}\right]_{\mathrm{T}}$ no carregamento circunferencial puro, apenas com a inversão da ordem de deposição das camadas. Para justificar este comportamento por intermédio de experimentos e de análise elástico-linear foi mostrado que a deformação das camadas $\pm 45^{\circ}$ eram maiores que a das camadas $\pm 60^{\circ}$. No caso da seqüência $\left[ \pm 45^{\circ} / \pm 60^{\circ}\right]_{T}$ as camadas $\pm 60^{\circ}$ agiram como um limitador para as camadas $\pm 45^{\circ}$. Ao contrário para a seqüência $\left[ \pm 60^{\circ} \pm 45^{\circ}\right]_{\mathrm{T}}$, a ação limitadora não pôde ser executada, já que as camadas externas deformaram mais que as camadas internas. Esta situação seria minimizada se as camadas posicionadas a $\pm 45^{\circ}$ permanecessem 
perfeitamente aderidas às camadas de $\pm 60^{\circ}$. Entretanto, com o início e progressão das falhas na matriz durante o carregamento, ocorreram delaminações localizadas que permitiram a penetração do fluido de pressurização nas zonas de delaminação, sendo mais prováveis na seqüência $\left[ \pm 60^{\circ} \pm 45^{\circ}\right]_{\mathrm{T}}$. Tal comportamento foi considerado a razão para o desempenho superior da seqüência $\left[ \pm 45^{\circ} / \pm 60^{\circ}\right]_{\mathrm{T}}$. O estudo não focou as propriedades do material, mas sim o desempenho da estrutura tubular e também concluiu que as deformações axiais e longitudinais obtidas durante os ensaios não revelaram uma diferença significativa entre as duas seqüências de empilhamento das camadas.

No processo de bobinamento filamentar, cada camada helicoidal consiste de um número de passes da fibra com ângulo de orientação $+\theta$ e com o mesmo número de passes com orientação $-\theta$ (Wild \& Vickers, 1997). Estes passes geram diversos cruzamentos entre as fibras e a deposição simultânea de duas camadas de mesmo ângulo e sinais opostos $[ \pm \theta]$. A forma como estes cruzamentos ocorrem é denominada de padrão de bobinagem, no qual o processo permite que para um mesmo ângulo, vários padrões sejam gerados apenas com a manipulação adequada dos parâmetros utilizados na programação do equipamento de bobinagem.

A influência do padrão de bobinagem no comportamento de falha de cilindros sob vários carregamentos foi estudada por Rousseau et al. (1999), incluindo o teste hidrostático em cilindros de extremidades abertas. Para os autores, apesar da dificuldade em determinar precisamente as principais causas da ocorrência de danos, estima-se que os cruzamentos na bobinagem helicoidal representam defeitos internos que facilitam o surgimento de trincas. Portanto, segundo conclusão dos autores, a quantidade de cruzamentos deve ser minimizada na fabricação de cilindros utilizando este processo.

No bobinamento filamentar, a bobinagem helicoidal mais comum é aquela em que duas camadas de fibra são depositadas simultaneamente com ângulos de deposição iguais e sinais opostos. Contudo, é possível haver a deposição das fibras sobre o molde sem a ocorrência de cruzamento entre camadas helicoidais, porque cada camada pode ser depositada de forma independente segundo a técnica de superposição de camadas. Esta técnica utiliza recursos especiais que 
permitem que a fibra seja depositada com o mesmo ângulo de bobinagem no percurso de um mesmo ciclo de bobinagem.

Bobinagens helicoidais cruzadas e superpostas estão descritas em Marinucci (2001), no qual estruturas cilíndricas fabricadas por essas duas técnicas foram comparadas por meio de ensaio hidrostático. No estudo feito pelo autor, cilindros com a mesma configuração assimétrica divididos em dois grupos, um deles com camadas helicoidais cruzadas e o outro com camadas helicoidais superpostas, apresentaram resultados similares de resistência mecânica, como também nos modos e tipos de falha obtidos, indicando que os métodos de fabricação dos cilindros não exerceram influência no desempenho da estrutura.

Um estudo realizado por Al-Salehi et al. (2001) com cilindros de extremidades abertas submetidos à pressão interna produzidos pelo processo de bobinagem filamentar, com ângulos de bobinagem cruzada de $\pm 25^{\circ}, \pm 55^{\circ} \mathrm{e} \pm 75^{\circ}$, foi realizado nas temperaturas de $-46^{\circ} \mathrm{C},+20^{\circ} \mathrm{C}$ e $70^{\circ} \mathrm{C}$. Como parte da análise, foram obtidos os valores de deformação circunferencial e longitudinal mediante a colagem de strain gauges na superfície externa dos cilindros. A aquisição de dados foi feita durante os ensaios até que ocorresse o colapso. Resultados mostraram que os cilindros com ângulos de bobinagem de $\pm 25^{\circ}, \pm 55^{\circ}$ e $\pm 75^{\circ}$, respectivamente, obtiveram resistência ao carregamento hidrostático crescentes. As deformações foram crescentes para os ângulos $\pm 25^{\circ}, \pm 75^{\circ}$ e $\pm 55^{\circ}$, respectivamente. Os três ângulos testados nas temperaturas de $-46^{\circ} \mathrm{C},+20^{\circ} \mathrm{C} \mathrm{e}$ $70^{\circ} \mathrm{C}$, respectivamente, obtiveram resistência ao carregamento hidrostático decrescentes.

Uma análise dos modos de falha em cilindros bobinados submetidos à pressão interna, com e sem dano localizado, foi investigada experimentalmente por Chang, (2003) para determinar a diminuição da pressão máxima de ruptura associada com o dano preexistente. Os cilindros com um corte longitudinal superficial localizado na parte central tiveram três diferentes modos de falha, todas iniciadas na trinca preexistente e redução da pressão máxima de ruptura de $15 \%$ quando comparada com cilindros sem dano. Os cilindros com dano causado pelo impacto de carga de $823 \mathrm{~N}$ e $1492 \mathrm{~N}$, respectivamente, tiveram redução de $24 \%$ e $32 \%$ quando comparados com os cilindros sem dano. Este tipo de análise 
permite entender a dinâmica das falhas e compará-las às falhas catastróficas que ocorrem em componentes em serviço. 


\section{OBJETIVO}

O objetivo deste trabalho foi avaliar experimentalmente a influência da configuração de bobinagem no comportamento mecânico de cilindros de compósito polimérico com bobinagem simétrica e assimétrica mediante um carregamento com pressão hidrostática até a ocorrência do colapso dos cilindros.

Simulações foram realizadas utilizando o programa de elementos finitos ANSYS para avaliar as tensões causadas pela pressão interna e relacioná-las com os modos de fratura apresentados pelos cilindros nas duas configurações estudadas.

Os cilindros foram fabricados pelo processo de bobinagem filamentar (filament winding) utilizando fibra de carbono da alta resistência mecânica (HT) e sistema de matriz epoxídica com endurecedor de ácido anidrido. Os cilindros foram divididos em dois grupos de acordo com a seqüência de empilhamento das camadas utilizada na fabricação, ou seja, simétrica ou assimétrica. 


\section{ABORDAGEM TEÓRICA}

\subsection{Bobinamento filamentar}

As práticas modernas de bobinamento filamentar (filament winding) iniciaram-se por volta de 1947, em razão da necessidade do governo americano de desenvolver vasos de pressão de baixo peso para os programas de foguetes e mísseis. Contudo, o bobinamento filamentar não era algo novo. Na Idade Média, canhões feitos de ferro fundido eram enrolados com fios de aço. Ainda durante a II Guerra Mundial, uma técnica similar foi usada em cilindros de oxigênio de alta pressão que eram feitos de alumínio e enroladas com fios de aço. Os fios de aço minimizavam a probabilidade de ocorrer uma explosão, caso eventualmente um projétil atingisse o cilindro. Com o surgimento da fibra de vidro contínua (desenvolvida no final de 1930) houve uma nova dimensão para a prática do bobinamento filamentar. Um outro fator que contribuiu de forma decisiva para o sucesso da tecnologia do bobinamento filamentar foi o desenvolvimento de resinas termofixas líquidas, tais como poliéster e epóxi (Bader et al., 1990).

O processo de bobinamento filamentar consiste na deposição de filamentos contínuos, previamente impregnados, com alta velocidade e precisão sobre um molde em rotação. A principal vantagem do processo, que permite que a fibra seja impregnada durante a fabricação, é o custo, porque associa uma fibra de custo relativamente elevado a uma resina de custo baixo se comparado ao processo que utiliza o material pré-impregnado, além da possibilidade de redução do custo de fabricação de componentes graças à elevada velocidade de deposição do material sobre o molde (ASM, 1987).

Outras vantagens do processo de bobinamento filamentar que podem ser citadas são: a alta repetitividade do ângulo de bobinagem das fibras de camada para camada, como também de componente para componente; a capacidade de utilizar filamentos contínuos em toda a extensão da superfície de um componente (sem emendas); a facilidade de orientar as fibras na direção do carregamento e a possibilidade de se obter altas frações volumétricas de fibra. 
Algumas desvantagens associadas ao bobinamento filamentar que podem ser citadas são: a forma do componente produzido, que deve ser tal que permita a remoção do molde, a não ser que o molde seja utilizado como liner ; a necessidade de molde, que pode ser complexo e caro; a dificuldade de programação do equipamento de bobinagem e a quantidade de parâmetros que devem ser controlados no processo.

O tipo de máquina de bobinamento filamentar mais utilizado e o mais versátil é o que fixa o mandril na posição horizontal e cujo carro, contendo o sistema de impregnação do fio, movimenta-se sobre um eixo paralelo à direção longitudinal do mandril. O uso de CNC (comando numérico computadorizado) permite que este tipo de equipamento possua múltiplos eixos, tornando possível a fabricação de componentes com geometrias complexas e proporcionando a deposição do reforço sobre o molde com alta precisão (Bader et al., 1990).

Durante o processo de fabricação, sucessivas camadas de fibra são depositadas sobre o mandril. A deposição de fibra em cada uma das camadas pode ser feita empregando-se apenas uma determinada orientação ou variando-se o ângulo de camada para camada, permitindo orientar as direções principais das camadas para as direções de carregamento. $\mathrm{O}$ tipo de fibra e o número de camadas para construir o compósito é uma decisão que envolve o tipo de aplicação que será dado à estrutura.

A limitação dimensional de um componente produzido pelo processo de bobinamento filamentar está ligada às características geométricas do equipamento utilizado na sua produção. Apesar da grande flexibilidade que este processo oferece, permitindo que a fibra seja depositada numa ampla faixa de ângulos que varia de $0^{\circ}$ a próximo de $90^{\circ}$, um componente não poderá ultrapassar as dimensões úteis de comprimento e diâmetro e a capacidade de carga do equipamento de bobinagem.

A superfície externa do mandril ou molde utilizado no processo de bobinamento filamentar é reproduzida na superfície interna do componente gerado. Os principais tipos de moldes usados são os solúveis, os não removíveis e os desmontáveis ou removíveis. Os moldes solúveis fabricados com areia, são usados na fabricação de componentes que apresentam baixa escala de produção e podem ser usados, por exemplo, na fabricação de tanques de combustível de foguetes. A remoção deste tipo de mandril ocorre mediante a injeção de água 
pela extremidade aberta da peça cujo diâmetro é inferior ao diâmetro do corpo e tem a função de dissolver o material aglutinante. Os moldes não removíveis (liners) são fabricados com metal ou plástico e possuem também a função de evitar o vazamento do material contido nos vasos de pressão. Os moldes desmontáveis ou removíveis são fabricados geralmente com metal e são usados na produção em larga escala de componentes que têm como requisitos alto grau de precisão dimensional e acabamento.

Na Fig. 3.1.1 é mostrada a ilustração de uma máquina de bobinamento filamentar horizontal de dois eixos (Strong, 1989), sendo um eixo o que corresponde a rotação do mandril e o outro eixo no qual o carro se desloca paralelo ao molde. Nesta figura também podem ser observados dois exemplos de bobinagem, a circunferencial e a helicoidal, bem como componentes que pertencem ao equipamento, tais como o recipiente que deve conter a matriz e o porta-bobinas de fibra. O recipiente que contém a matriz tem a função de impregnar os filamentos de fibra antes de serem depositados sobre o mandril, enquanto que o porta-bobinas tem a função de fixar as bobinas de fibra e tensionar os filamentos garantindo tanto uma boa impregnação da fibra pela matriz como uma boa ancoragem sobre o mandril durante a execução da bobinagem.

Equipamentos de bobinamento filamentar com apenas dois eixos (dois graus de liberdade) são na verdade os mais simples utilizados neste processo e executam as funções básicas de enrolamento. Existem estruturas que para serem fabricadas, no entanto, requerem bobinadeiras com elevados recursos tecnológicos, podendo ter até cinco ou seis eixos (graus de liberdade). Isto faz com que seja possível produzir componentes de geometrias complexas, no qual a fibra é depositada sobre o mandril na mesma condição para qualquer ângulo de bobinagem e que permite ancorar a fibra em um domo na extremidade do mandril, quando este recurso geométrico é necessário. 


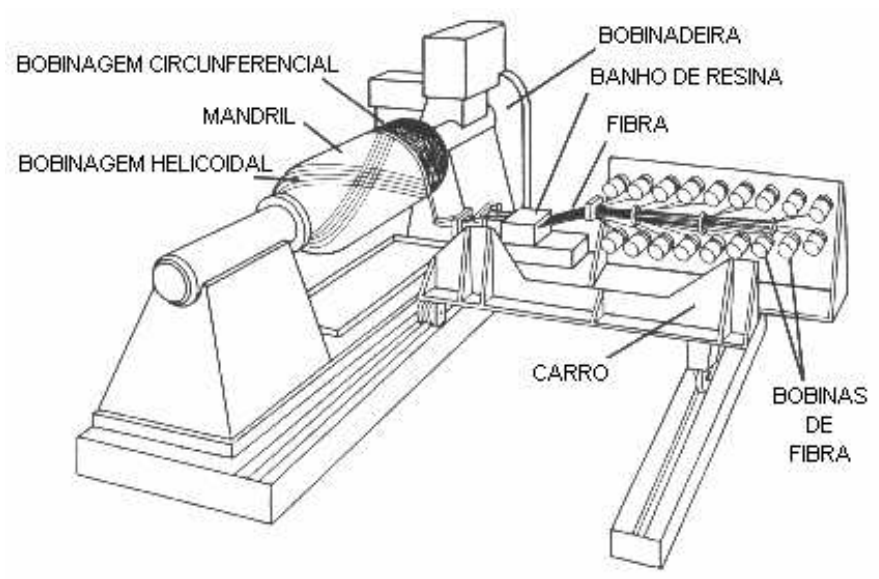

Figura 3.1.1 - Máquina de bobinamento filamentar (Strong, 1989).

O ângulo que a fibra forma com o eixo longitudinal do mandril é obtido com a programação adequada entre a rotação do mandril e a velocidade do carro. Dependendo de como estes dois movimentos ocorrem, pode-se determinar qual tipo de bobinagem será realizada. Dentre os tipos existentes, destacam-se os dois principais, que são o circunferencial e o helicoidal.

$\mathrm{Na}$ bobinagem circunferencial (hoop), o molde gira continuamente, enquanto o carro avança lentamente, permitindo que a fibra seja depositada perpendicularmente ao eixo longitudinal do molde. Nesse tipo de bobinagem, o deslocamento do carro é bastante lento, enquanto que a rotação do mandril é proporcionalmente mais elevada para permitir a correta deposição do fio, que é próxima de $90^{\circ}$. Este ângulo é obtido mediante o avanço do carro correspondente a uma largura, abertura ou banda da fibra a cada volta completa do molde, conforme ilustrado na Fig. 3.1.2, sendo B a indicação da banda da fibra.

Na Fig. 3.1.2 é possível observar também que à esquerda do ponto no qual a fibra está sendo depositada há uma região do mandril que já está envolvida pela fibra e à direita o aspecto do acabamento do mandril. Nota-se, com clara evidência, que a fibra é bobinada com ângulo próximo a $90^{\circ}$ em relação a uma linha horizontal imaginária representando o eixo longitudinal do mandril. 


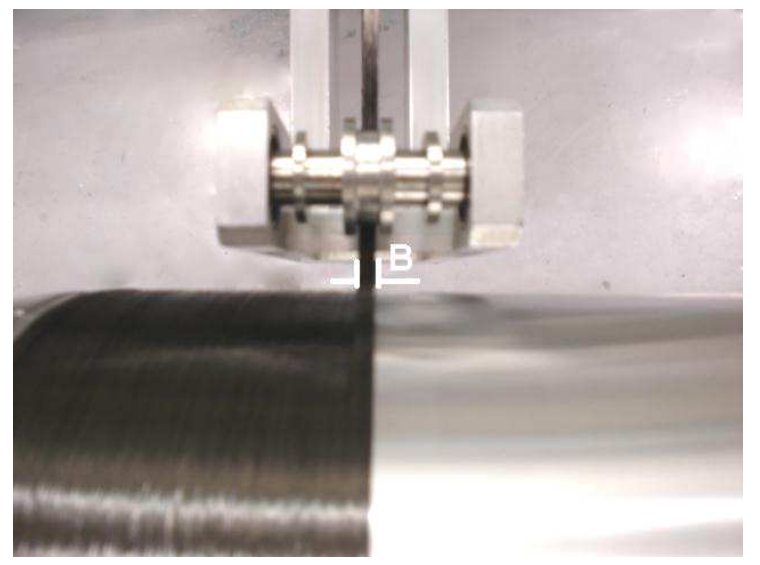

Figura 3.1.2 - Detalhe da bobinagem circunferencial na qual o avanço do carro corresponde a uma banda da fibra, indicada como B.

$\mathrm{Na}$ bobinagem helicoidal, o molde gira continuamente, enquanto o carro transversal movimenta-se de forma sincronizada com eixo de rotação do mandril, gerando o ângulo helicoidal desejado, conforme representado na Fig. 3.1.1. A cobertura completa do mandril ocorre após a execução total de um número de ciclos programados. Um ciclo corresponde ao movimento completo de ida e volta do carro transversal, desde o ponto de partida, numa das extremidades do mandril, até o retorno à mesma posição inicial. A cada novo ciclo, a fibra depositada pode ou não ficar adjacente à fibra do ciclo anterior, que dependerá do padrão de bobinagem utilizado (Corrêa, 1979).

O padrão de bobinagem é definido como o número de ciclos executados sobre o mandril antes que um ciclo seja iniciado na posição adjacente ao primeiro ciclo depositado. Para melhor esclarecer esta definição, considere-se uma bobinagem na qual o segundo ciclo de deposição da fibra é posicionado adjacente ao primeiro, nesse caso tem-se o padrão de bobinagem denominado primário, que caracteriza-se pela formação de apenas um cruzamento sobre o mandril.

Um padrão de bobinagem primário é mostrado na Fig. 3.1.3. Observa-se que o segundo ciclo de bobinagem foi iniciado sobre o domo e que neste ocorre a deposição de uma fibra adjacente à anteriormente depositada (primeiro ciclo), estabelecendo assim o conceito de padrão primário de bobinagem. Na Fig. 3.1.4 está mostrada uma vista geral de um mandril com padrão de bobinagem primário, no qual ocorre apenas um cruzamento entre as fibras de ângulos $+\theta$ e $-\theta$ posicionado na metade do comprimento. Além do cruzamento central sobre o 
mandril, esse padrão de bobinagem possui ainda uma forma característica de cobrir a superfície dos domos nas extremidades do mandril, conforme está ilustrado na Fig. 3.1.5.

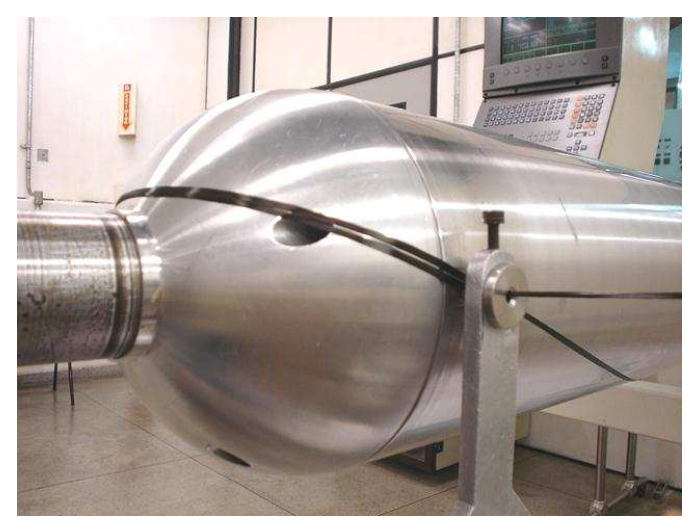

Figura 3.1.3 - Detalhe da fibra no segundo ciclo sendo depositada adjacente à fibra do primeiro ciclo no padrão de bobinagem primário.

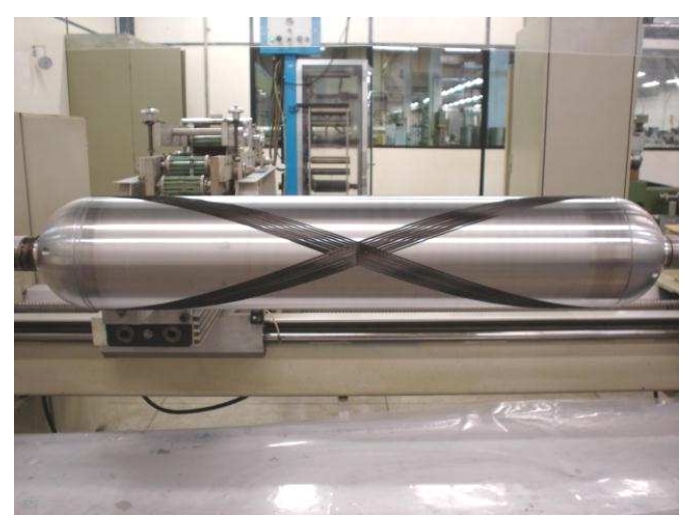

Figura 3.1.4 - Vista geral de um mandril com padrão de bobinagem primário.

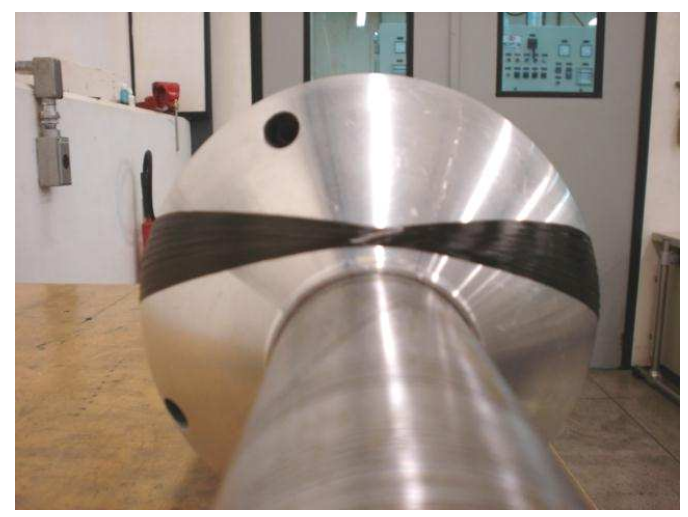

Figura 3.1.5 - Detalhe da fibra sobre o domo no padrão de bobinagem primário. 
Um outro padrão de bobinagem ocorre quando o terceiro ciclo de deposição da fibra é posicionado adjacente ao primeiro, neste caso tem-se o padrão de bobinagem denominado secundário. Na Fig. 3.1.6 é mostrado o detalhe da fibra no terceiro ciclo sendo depositada adjacente à fibra do primeiro ciclo. Na Fig. 3.1.7 está mostrada uma vista geral de um mandril com padrão de bobinagem secundário, no qual ocorrem dois cruzamentos entre as fibras de ângulos $+\theta$ e $-\theta$ dividindo o comprimento do mandril em três partes. Observa-se que os ângulos $+\theta$ e $-\theta$ são os mesmos, variando-se apenas o padrão de deposição. Outro detalhe desse padrão de bobinagem é a forma característica de cobertura sobre a superfície dos domos nas extremidades do mandril, conforme está ilustrado na Fig. 3.1.8. É interessante notar que ocorre a formação de dois cruzamentos, um à esquerda e outro à direita do eixo de sustentação do mandril.

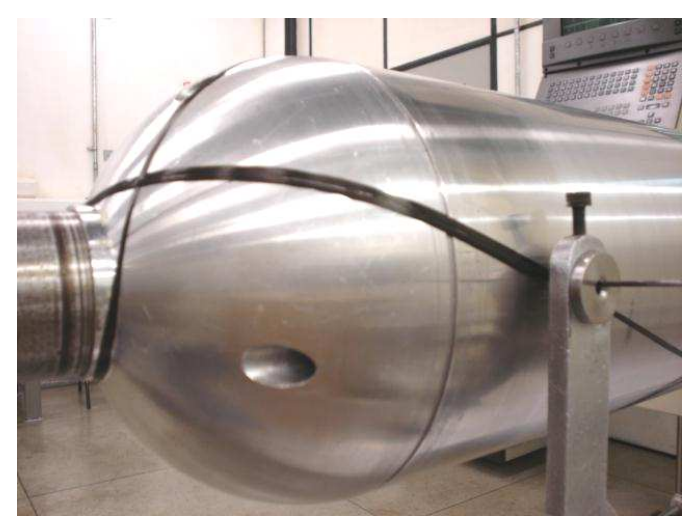

Figura 3.1.6 - Detalhe da fibra no terceiro ciclo sendo depositada adjacente à fibra do primeiro ciclo no padrão de bobinagem secundário.

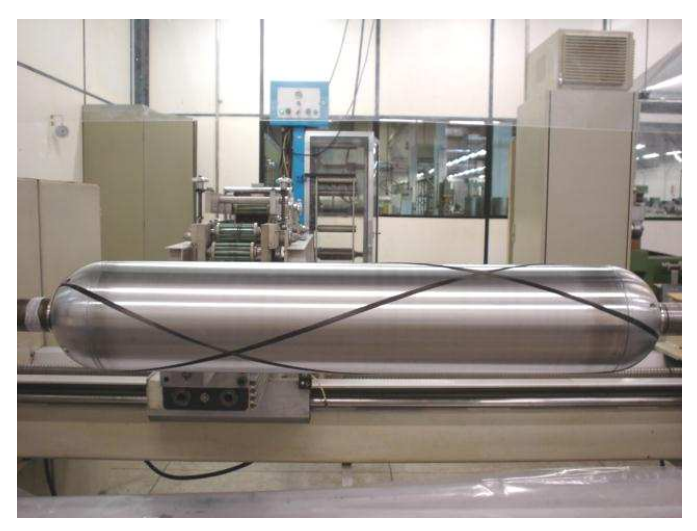

Figura 3.1.7 - Vista geral de um mandril com padrão de bobinagem secundário. 


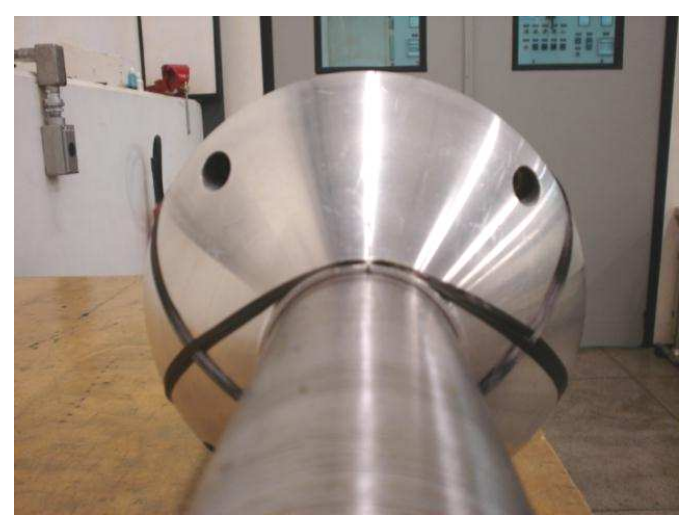

Figura 3.1.8 - Detalhe da fibra sobre o domo no padrão de bobinagem secundário.

Conforme descrito anteriormente, o número de cruzamentos sobre o mandril pode aumentar sucessivamente, gerando inúmeros padrões de bobinagem. A determinação do padrão de bobinagem a ser utilizado na bobinagem helicoidal cruzada depende da geometria do mandril, do ângulo de bobinagem desejado, da banda da fibra e de cálculos específicos que consideram todos esses parâmetros para determinar o caminho que a fibra percorrerá sobre o mandril.

A deposição da fibra numa camada helicoidal só é possível com a utilização de domos nas extremidades do mandril. Domos são elementos que além de permitir o fechamento das extremidades do mandril, possuem geometria que garante o ancoramento da fibra nas reversões de movimento do carro e inversões do ângulo de deposição que ocorrem durante a execução de cada ciclo de bobinagem. As formas mais utilizadas para os domos são: plana, cônica, esférica, geodésica e pinada.

A bobinagem helicoidal também pode ser feita de forma que cada camada seja depositada sobre o molde individualmente, ou seja, camadas com ângulos $+\theta$ e - $\theta$ são depositadas de forma superposta, sem a ocorrência de cruzamentos entre as fibras de cada camada (Rousseau et al., 1999; Marinucci, 2001), ao contrário da bobinagem cruzada em que ocorre a deposição de duas camadas simultâneas de ângulos $\pm \theta$. Para que isto seja possível, na bobinagem superposta é utilizada a técnica em que os domos são pinados e permitem, por exemplo, que a camada de ângulo $+\theta$ seja depositada totalmente sobre o mandril e em seguida sendo colocada a camada de ângulo $-\theta$. Nesse tipo de bobinagem, a 
programação do equipamento é feita de tal forma que a reversão no sentido de movimento do carro e de rotação do mandril na extremidade do molde, garantem que a fibra retorne com o mesmo ângulo de deposição no decorrer de cada ciclo. Na Fig. 3.1.9 é mostrado um detalhe da bobinagem helicoidal com domos pinados.

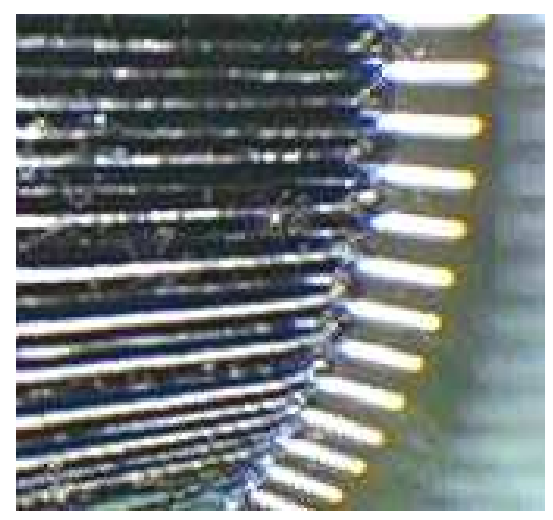

Figura 3.1.9 - Detalhe da bobinagem helicoidal com domos pinados.

\subsection{Configurações de bobinagem}

Os laminados de materiais compósitos recebem uma denominação específica de modo que possibilite a sua identificação adequada. A exemplo do que acontece com um aço SAE 1020, por exemplo, ou um alumínio AA 7075 T6, também nos compósitos é necessário estabelecer um código, que os caracterize, no qual a orientação de uma camada específica com relação aos eixos de referência possa ser claramente identificada.

Cada camada depositada sobre o molde é identificada por um ângulo e pelo material de reforço nela utilizado, sendo o ângulo de bobinagem definido como a medida, em graus, entre a direção da fibra e o eixo longitudinal do mandril. A representação de um bobinado, delimitada por colchetes que indicam a camada inicial e a final, é feita pela identificação das camadas com seus respectivos ângulos de bobinagem. A leitura é feita da esquerda para a direita, com a indicação da primeira camada junto ao colchete da esquerda. Camadas paralelas adjacentes com a mesma orientação são mostradas por um índice subscrito que quantifica o número de camadas. A existência de um índice subscrito $S$ ou $T$ ao colchete da direita, identifica, respectivamente, um laminado simétrico, neste caso somente metade das camadas é indicada entre colchetes, 
ou um laminado em que todas as camadas estão representadas no código (Ashbee,1989). A seguir estão ilustrados exemplos de laminado simétrico Fig. 3.2.1(a) e laminado em que há a representação do número total de camadas Fig. 3.2.1(b). As letras GI, C e K representam, respectivamente, fibras de vidro, carbono e aramida.

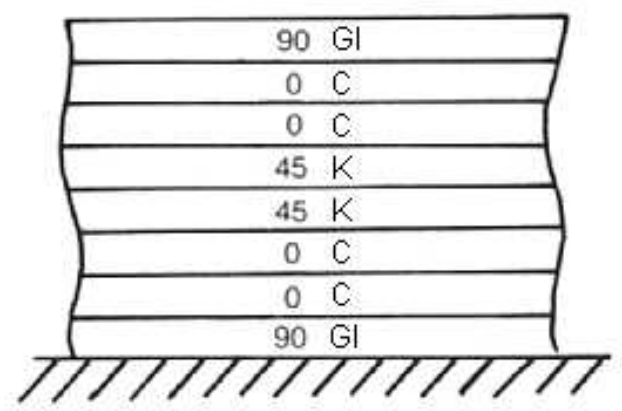

$$
\left[90_{\mathrm{Gl}} / 0_{2 \mathrm{C}} / 45_{\mathrm{K}}\right]_{\mathrm{S}}
$$

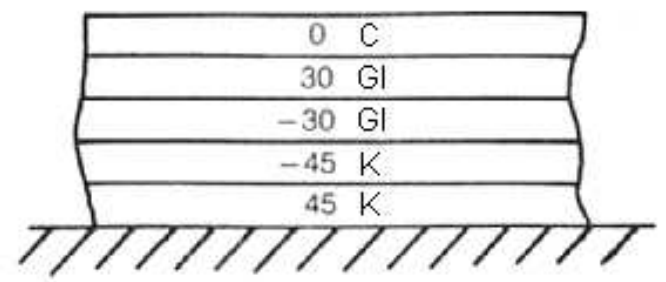

$\left[45_{K} /-45_{K} /-30_{G l} / 30_{G l} / 0_{C}\right]_{T}$

Figura 3.2.1 - Exemplos de laminados: (a) laminado simétrico, (b) laminado com representação do número total de camadas (Ashbee, 1989).

Um compósito laminado é denominado simétrico quando as camadas acima do plano médio de sua espessura são depositadas em seqüência inversa à seqüência depositada abaixo desse mesmo plano. Compósitos laminados que não possuem esta característica são denominados de assimétricos. Na Fig. 3.2.2 estão mostrados exemplos de laminados simétrico e assimétrico, respectivamente. Observa-se na Fig. 3.2.2(a) que a simetria existe no plano entre a sexta e a sétima camadas, indicada pela linha s-s, fabricadas com reforço de fibra de vidro e posicionadas à $90^{\circ}$ (perpendicular ao plano do papel). 


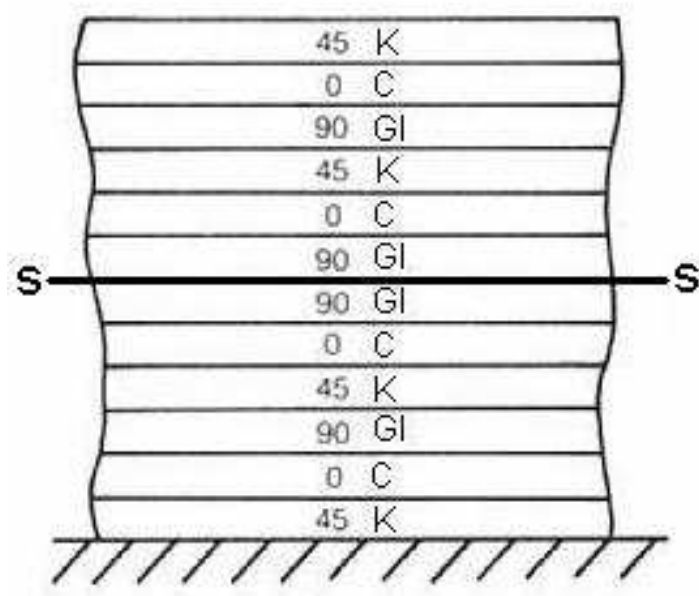

$$
\begin{aligned}
& {\left[\left(45_{K} / 0_{C} / 90_{G I}\right)_{2}\right]_{S}} \\
& \text { ou }\left[45_{K} / 0_{C} / 90_{G l}\right]_{2 S}
\end{aligned}
$$

$$
\left[45_{\mathrm{Gl}} / 0_{\mathrm{C}} /-60_{2 \mathrm{~K}} / 30_{\mathrm{C}}\right]_{\mathrm{T}}
$$

Figura 3.2.2 - Exemplos de laminados: (a) simétrico, (b) assimétrico (Ashbee, 1989). 


\section{MATERIAIS E MÉTODOS}

\subsection{Seleção das matérias-primas}

O material de reforço utilizado, levando-se em conta o comportamento estrutural, a disponibilidade e a técnica de bobinagem filamentar (filament winding) a ser empregada foi a fibra de carbono T 300. Esta fibra é fornecida na forma de fio contínuo, constituído por 6000 filamentos com diâmetro da ordem de $7 \mu \mathrm{m}$ por filamento.

A matriz, cuja viscosidade e tempo de trabalho (pot life) também devem ser adequados à fabricação de peças cilíndricas pelo processo de bobinamento filamentar, foi um sistema tricomponente constituído por uma resina epóxi, um endurecedor e um acelerador. Os constituintes da matriz polimérica e as proporções de mistura em massa foram: resina epóxi- éter diglicidílico de bisfenol A (100 partes em peso); endurecedor- metiltetrahidroftálico (100 partes em peso); e acelerador- benzildimetilamina (1,0 parte em peso).

Nas Tab. 4.1.1 e 4.1.2 são mostradas, respectivamente, as principais propriedades mecânicas e características da fibra de carbono (Tenax, 1991) e da matriz polimérica (Vântico, 2001) fornecidas pelos fabricantes.

Tabela 4.1.1 - Propriedades mecânicas e características da fibra de carbono.

\begin{tabular}{cc}
\hline Propriedades e características da fibra & T300 HT 6K \\
\hline Módulo de elasticidade (GPa) & 238 \\
Limite de resistência à tração (MPa) & 3400 \\
Alongamento até a ruptura $(\%)$ & 1,5 \\
Diâmetro do filamento $(\mu \mathrm{m})$ & 7 \\
Massa específica $\left(\mathrm{g} \cdot \mathrm{cm}^{-3}\right)$ & 1,77 \\
\hline
\end{tabular}


Tabela 4.1.2 - Propriedades do sistema com resina epóxi.

\begin{tabular}{cc}
\hline Propriedades do sistema de resina & GY260/HY905/DY062 \\
\hline Módulo de elasticidade (GPa) & 3,3 \\
Limite de resistência à tração (MPa) & 85 \\
Alongamento até a ruptura (\%) & 4,8 \\
Massa específica $\left(\mathrm{g} . \mathrm{cm}^{-3}\right)$ & 1,22 \\
\hline
\end{tabular}

\subsection{Definição das configurações de bobinagem}

Para definição do número de camadas dos cilindros fabricados para o presente estudo, utilizou-se como primeira aproximação a regra da mistura dada pela equação (4.2.1), assim como foi feito por Cohen et al. (2001), embora a equação tenha sido desenvolvida para laminados unidirecionais considerando as hipóteses feitas na Análise Micromecânica da Lâmina.

$$
\sigma_{c}=v_{f} \cdot \sigma_{f}+\left(1-v_{f}\right) \cdot \sigma_{m}
$$

na qual $\sigma_{c}, \sigma_{f}$ e $\sigma_{m}$ são os limites de resistência à tração do compósito, da fibra e da matriz, respectivamente e $v_{f}$ a fração volumétrica de fibra.

Outra equação que apoiou está decisão foi a que relaciona a tensão circunferencial em cilindros de parede fina submetidos à pressão interna às características geométricas do componente, tal como utilizada por Kaddour et al. (2003) e indicada na equação (4.2.2).

$$
\sigma_{\theta}=\mathrm{P} \cdot \mathrm{r} / \mathrm{t}
$$

na qual $\sigma_{\theta}$ é a tensão circunferencial no cilindro em virtude da pressão interna $P$, sendo "r" e "t" o raio e a espessura, respectivamente.

Para a determinação da configuração de bobinagem, foram consideradas também a capacidade e características dimensionais do dispositivo de ensaio hidrostático, definindo-se que uma pressão de ruptura $(\mathrm{P})$ de até $30 \mathrm{MPa}$ seria segura para a realização dos ensaios.

Portanto, considerando-se as propriedades da fibra de carbono e da matriz, conforme as tabelas Tab. 4.1.1 e 4.1.2 respectivamente e admitindo-se 
uma fração volumétrica de fibra no compósito de aproximadamente $65 \%$, tem-se da equação (4.2.1) que:

$$
\sigma_{c}=0,65.3400+(1-0,65) \cdot 85 \Rightarrow \sigma_{c}=2240 \mathrm{MPa}
$$

Considerando-se 0 ensaio hidrostático, no qual um cilindro de extremidades abertas é submetido somente ao carregamento circunferencial, é possível admitir que a tensão circunferencial máxima $\sigma{ }_{\theta}$ corresponda ao limite de resistência à tração $\sigma_{c}$, ou seja, $\sigma_{\theta}=\sigma_{c}$. Assim da equação (4.2.2) tem-se que:

$$
r / t=\sigma_{c} / P
$$

obtendo-se a relação entre o raio do cilindro e a espessura, dada em (4.2.3). Portanto:

$$
r / t=2240 / 30 \Rightarrow r / t=74,7
$$

Admitindo-se que cada camada bobinada possui uma espessura nominal de 0,15 mm e com base na relação $r / t$ de 74,7, definiu-se que os cilindros seriam fabricados com 10 camadas, sendo o ângulo das camadas helicoidais escolhido para este estudo de $30^{\circ}$. Portanto, as configurações de bobinagem simétrica e assimétrica seriam, respectivamente, [90\% $\left./-30 \%+30 \% / 90{ }^{\circ}\right]_{\mathrm{s}}$ e $[90 \% /-30 \% /+30 \% / 90 \% /+30 \% /-30 \% / 90 \% 4]_{\mathrm{T}}$.

\subsection{Fabricação dos cilindros}

O equipamento de bobinamento filamentar possui um comando numérico computadorizado para controle dos eixos ou graus de liberdade. A fixação do mandril é feita na posição horizontal e o carro, contendo o sistema de impregnação do fio, movimenta-se sobre um eixo paralelo à direção longitudinal do mandril.

A programação da máquina de bobinagem foi feita por intermédio da sincronização do movimento dos eixos de modo que a fibra fosse depositada nos 
ângulos de $-30^{\circ},+30^{\circ}$ e $90^{\circ}$ com relação ao eixo longitudinal do mandril, sendo utilizado um programa para cada ângulo de deposição.

Nos programas helicoidais, de ângulos $-30^{\circ} \mathrm{e}+30^{\circ}$, utilizou-se domos pinados fixados em cada extremidade do molde, para permitir o ancoramento da fibra no momento de reversão dos movimentos do carro e do molde. As camadas helicoidais foram depositadas de maneira superposta.

Para a execução dos ensaios hidrostáticos, foram fabricados dois grupos de cilindros com extremidades abertas, cada grupo com sete unidades. Os cilindros de cada grupo apresentaram alteração no posicionamento das camadas em relação ao plano médio, caracterizando bobinamento simétrico e assimétrico, conforme as duas configurações de bobinagem definidas no item 4.2.

$\mathrm{Na}$ fabricação dos cilindros foi utilizado um molde de alumínio de forma cilíndrica que apresenta um acabamento superficial adequado ao processo, sobre o qual foi aplicado um produto desmoldante à base de silicone antes de cada fabricação. O desmoldante utilizado foi o QZ-13 produzido pela empresa Huntsman.

A matriz polimérica foi preparada utilizando-se um sistema tricomponente, conforme as proporções indicadas no item 4.1 e obtidas com auxílio de uma balança analítica com precisão centesimal. Após a preparação e homogeneização, a matriz foi colocada na cuba do sistema de impregnação, que é fixada sobre o carro longitudinal da máquina de bobinagem. Há um controle de temperatura no sistema de impregnação de modo a manter a viscosidade da matriz dentro de limites determinados, permitindo uma impregnação efetiva dos filamentos.

As camadas de fibra foram depositadas sobre o mandril seguindo a seqüência de empilhamento definida para cada grupo de cilindros, até que todas as camadas previstas na configuração de bobinagem tivessem sido depositadas. Finalizado o processo, o molde foi retirado do equipamento e colocado sobre mancais rotativos na estufa de cura. $\mathrm{O}$ mandril foi acoplado a um redutor que 0 manteve em rotação para evitar o escorrimento da resina durante o processo de cura. Na Fig. 4.3.1 estão mostrados alguns detalhes da estufa de cura, observando-se no primeiro plano o sistema de apoio e ao fundo o sistema de fixação do mandril. 


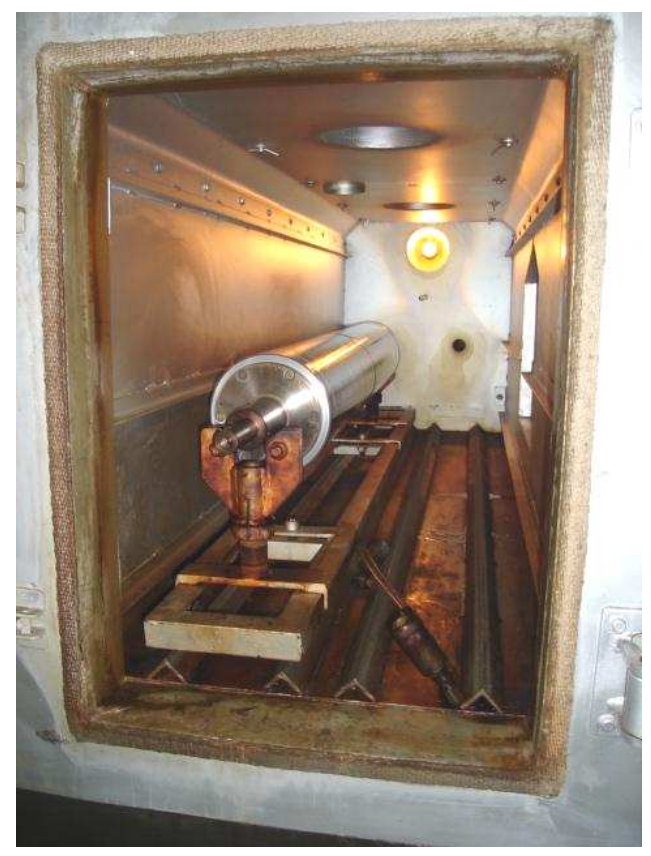

Figura 4.3.1 - Molde sobre mancais rotativos na estufa de cura.

As etapas do ciclo de cura da matriz seguiram a programação feita num controlador de processos e estão mostradas na Fig. 4.3.2.

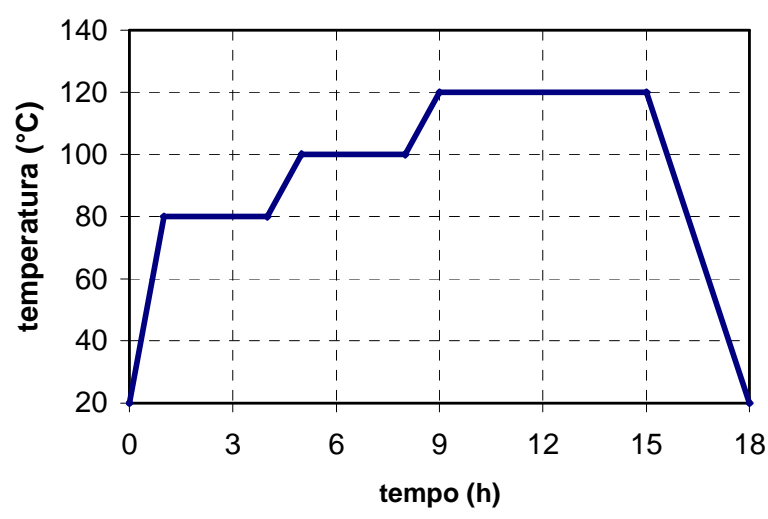

Figura 4.3.2 - Gráfico do ciclo de cura da matriz.

O ciclo de cura da matriz consistiu inicialmente de uma rampa de aquecimento com duração de uma hora, partindo-se da temperatura ambiente até a temperatura de $80^{\circ} \mathrm{C}$. Neste patamar, inicialmente ocorre a redução da viscosidade da matriz por causa do aumento de temperatura, permitindo ainda que $o$ ar introduzido no processo ou os voláteis presentes na matriz sejam 
liberados. Porém, a partir desta temperatura, inicia-se efetivamente o processo de polimerização com conseqüente aumento da viscosidade.

Após três horas a $80^{\circ} \mathrm{C}$, inicia-se outra rampa de aquecimento, com duração de uma hora, até que a temperatura de $100^{\circ} \mathrm{C}$ seja atingida. Nesta temperatura a polimerização da matriz continua a ocorrer lentamente por mais três horas, aumentando o número de ligações entre as cadeias poliméricas e promovendo a formação de ligações cruzadas, evitando que contrações elevadas pudessem trincar a matriz.

A terceira etapa de subida da temperatura é feita em uma hora atingindo-se a temperatura de $120^{\circ} \mathrm{C}$, permanecendo nesta temperatura por mais seis horas. Nesta temperatura ocorre o término da polimerização, permitindo que a matriz atinja a máxima temperatura de transição vítrea possível para o sistema utilizado.

A fase final do ciclo corresponde ao resfriamento gradual do cilindro, por seis horas, ainda dentro da estufa. Terminada a cura, o molde foi retirado da estufa e o cilindro removido e armazenado para a fase de corte.

Após a fabricação de cada cilindro, o molde era novamente preparado seguindo as etapas de limpeza e de aplicação de nova película de desmoldante.

O corte das extremidades dos cilindros, para ajuste de um comprimento adequado ao dispositivo de ensaio hidrostático, foi executado utilizando-se uma retificadora com disco rotativo diamantado acoplada a um torno universal. $\mathrm{O}$ detalhe do corte é mostrado na Fig. 4.3.2. A necessidade de utilização de ferramenta de corte diamantada deve-se à característica abrasiva do material compósito produzido.

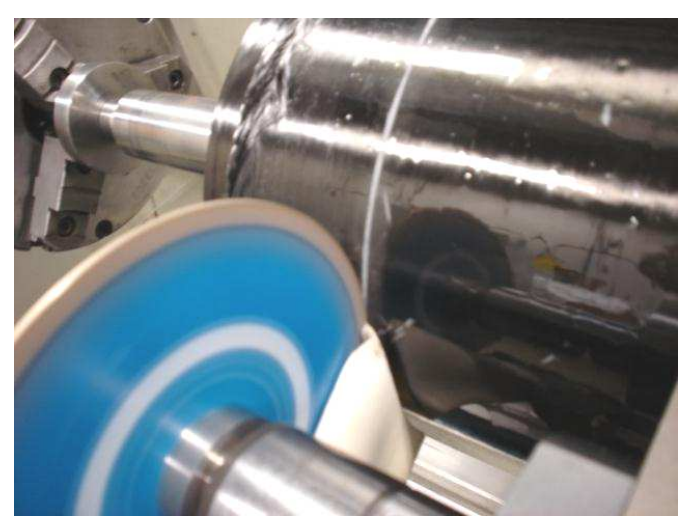

Figura 4.3.2 - Detalhe do disco diamantado iniciando o corte do cilindro. 


\subsection{Determinação das frações volumétricas}

Para a determinação das frações de massa de fibra e matriz dos cilindros foi utilizado o processo de calcinação em forno, que promove a queima da matriz presente no compósito contido em um cadinho de porcelana previamente tarado, obtendo-se como material residual a fibra de carbono. Esta operação foi realizada num forno EDG modelo Five1-A com atmosfera inerte de nitrogênio ultra puro à pressão de $5 \mathrm{cmHg}$, temperatura entre 25 e $700^{\circ} \mathrm{C}$ e taxa de aquecimento de $15^{\circ} \mathrm{C} \cdot \mathrm{min}^{-1}$, utilizando-se amostras retiradas dos cilindros com massa aproximada de $1,5 \mathrm{~g}$. As frações em massa de fibra foram obtidas tomando-se por base a pesagem das amostras calcinadas. Processo semelhante foi utilizado por Tarakçioglu et al. (2001).

A densidade de cada cilindro foi determinada pela técnica de deslocamento de líquido, conforme descrição na norma ASTM D 792 (1983), tomando-se por base três amostras cortadas com geometria retangular e massa de aproximadamente $0,3 \mathrm{~g}$. Para esta determinação, utilizou-se uma balança com precisão de 0,1 mg equipada com um kit para determinação da densidade, composto de um suporte que foi fixado à balança e de um termômetro para medir a temperatura da água contida no béquer localizado sob o suporte, conforme Fig. 4.4.1. O suporte possui dois pequenos pratos para a colocação da amostra, sendo um superior para a pesagem ao ar e um outro inferior para a pesagem da amostra totalmente submersa. A pesagem ao ar foi feita colocando-se a amostra no primeiro prato acima do béquer e zerada a balança com a amostra no prato superior. Em seguida, a amostra foi colocada no segundo prato, submerso, anotando-se os dois valores de massa obtidos da seqüência realizada. $\mathrm{Na}$ pesagem submersa, eventuais bolhas de ar aderidas à amostra foram removidas.

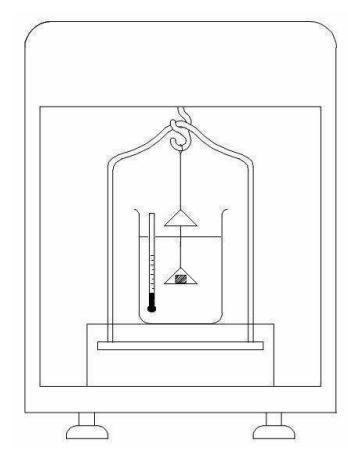

Figura 4.4.1 - Esquema da balança, com kit para determinação da densidade do compósito, ilustrando a pesagem da amostra submersa. 
Para o cálculo da densidade do compósito $d_{c}$ utilizou-se a equação (4.4.1)

$$
d_{c}=\left(m_{a} / m_{a}-m_{s}\right) \cdot d_{l}
$$

na qual $\left(m_{a}\right)$ é o peso da amostra ao $a r ;\left(m_{s}\right)$ é o peso da amostra submersa e $d_{1}$ é a densidade da água à temperatura lida no termômetro durante a pesagem.

As frações volumétricas de fibra $\left(v_{\mathrm{f}}\right)$, de matriz $\left(\mathrm{v}_{\mathrm{m}}\right)$ e o volume de vazio $\left(v_{v}\right)$ são obtidos das equações (4.4.2), (4.4.3) e (4.4.4), sendo respectivamente, $f_{m f}, f_{m m}$ as frações em massa de fibra e matriz e $d_{f}, d_{m}$ e $d_{c}$ respectivamente, as massas específicas de fibra, de matriz e do compósito.

$$
\begin{aligned}
& v_{f}=f_{m f} \cdot d_{c} / d_{f} \\
& v_{m}=f_{m m} \cdot d_{c} / d_{m} \\
& v_{v}=100-d_{c} \cdot\left(f_{m m} / d_{m}+f_{m f} / d_{f}\right)
\end{aligned}
$$

\subsection{Determinação das deformações nos cilindros}

Para determinação das propriedades elásticas do compósito, strain gauges foram colados na superfície externa dos cilindros e posicionados na metade do comprimento, tanto do grupo simétrico quanto do grupo assimétrico, nas direções circunferencial e longitudinal. A aquisição de dados da pressão e das deformações foram realizadas durante os ensaios hidrostáticos até que ocorresse o colapso. Este procedimento também foi adotado por Martens \& Ellyin (2000) e por Huang et al. (2002) em seus respectivos trabalhos. O sistema de aquisição de dados, composto de oito canais interligados a uma placa de aquisição de dados, permitiu que fossem obtidos um número 200 a 300 registros para cada direção durante os ensaios.

Na Fig. 4.5.1 é mostrado o detalhe da região onde os strain gauges foram colados em um dos cilindros ensaiados, sendo o strain gauge indicado por (a) o que está posicionado na direção circunferencial e o indicado por (b) o que está na posição longitudinal, que obtém, respectivamente, a expansão do diâmetro e o encurtamento do comprimento. 


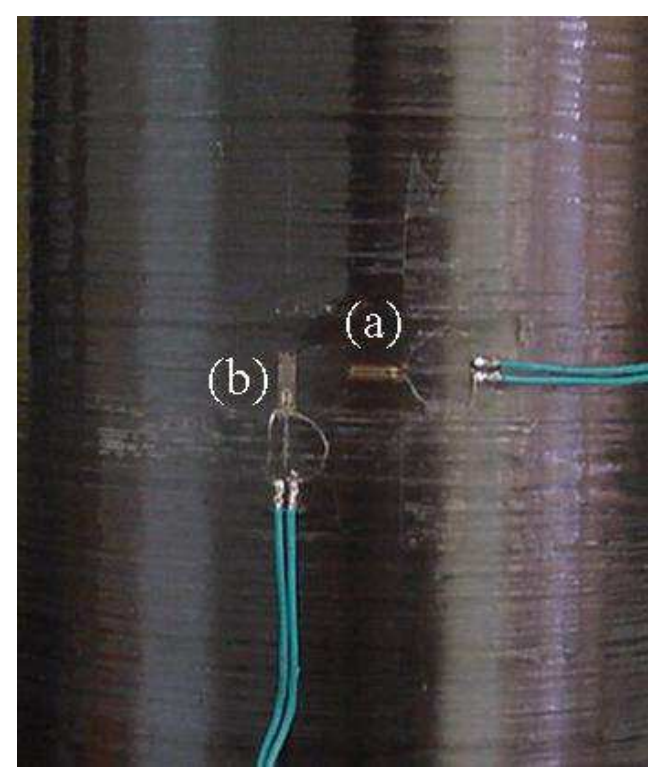

Figura 4.5.1 - Detalhe da região de colagem dos strain gauges nos cilindros ensaiados: (a) strain gauge posicionado na direção circunferencial, (b) strain gauge posicionado na direção longitudinal.

\subsection{Ensaio hidrostático}

Os dois grupos de cilindros foram submetidos a ensaios hidrostáticos à temperatura ambiente e o ensaio consistiu na aplicação de uma carga monotônica com taxa de $55 \mathrm{kPa} / \mathrm{s}$ de pressão interna até que se atingisse o colapso. A unidade de pressurização utilizada está equipada com uma bomba hidráulica com capacidade de até $100 \mathrm{MPa}$. O dispositivo de fixação do cilindro consiste de um tubo central com anéis de vedação nas extremidades que fazem o contato com o cilindro a ser ensaiado. Antes de iniciar a pressurização o cilindro foi preenchido pelo óleo solúvel, utilizado como fluido hidráulico, para evitar a presença de ar na câmara interna, espaço entre o cilindro e o dispositivo de ensaio. A pressurização foi feita por intermédio de uma entrada situada na base do dispositivo (Marinucci, 2001).

Como o óleo solúvel é incompressível, no caso de teste hidráulico a taxa de pressurização pode ser superior a que se utiliza em teste pneumático. Por razões de segurança, o dispositivo utilizado foi montado dentro de uma sala com dimensões de 2,0 x 2,0 x 2,0 m feita com placas de divisória recobertas com chapas de aço, permanecendo do lado externo apenas o painel de controle com a bomba e o sistema utilizado na aquisição de dados. 
$\mathrm{Na}$ Fig. 4.6.1 é mostrado um esquema do dispositivo de ensaio hidrostático.

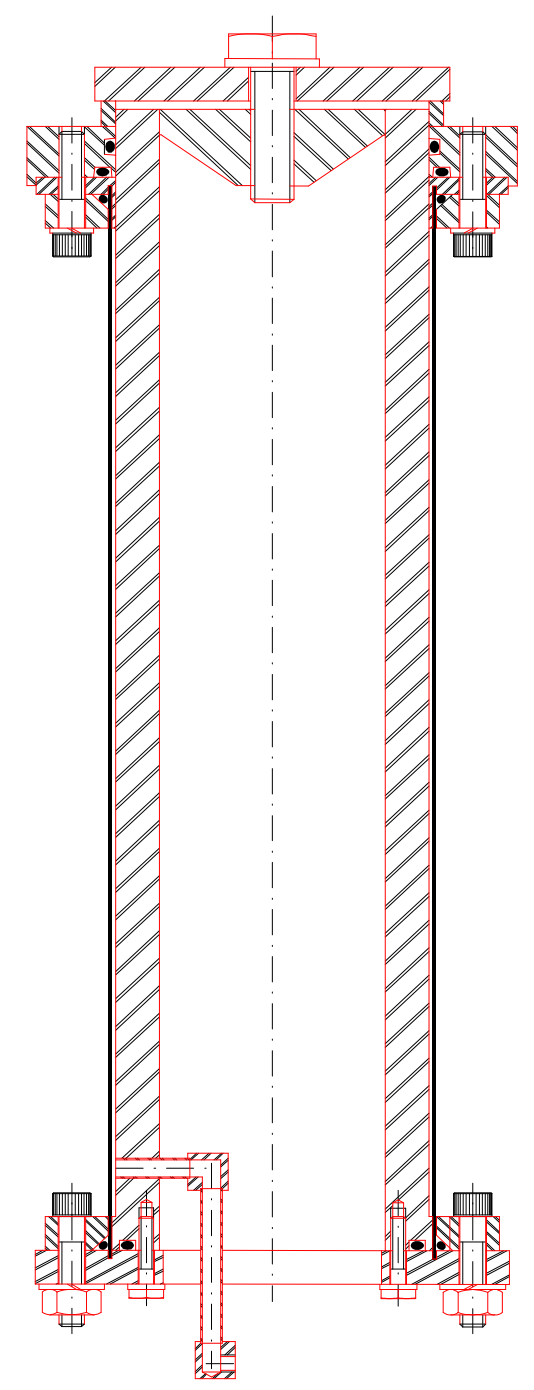

Figura 4.6.1 - Esquema do dispositivo de ensaio hidrostático (Marinucci, 2001).

\subsection{Análise térmica}

Existem alguns equipamentos que são normalmente utilizados para determinar o grau de cura de sistemas de matrizes termofixas. Um dos mais empregados é o calorímetro exploratório diferencial (DSC). Segundo Wisanrakkit \& Gillham (1990) e Gillham \& Wang (1992), a temperatura de transição vítrea ( $\left.T_{g}\right)$ pode ser um parâmetro sensível e prático para determinar o grau de conversão de sistemas de matriz termofixa. A avaliação do grau de cura pode ser feita ainda 
utilizando-se um analisador dinâmico-mecânico (DMA) ou um analisador termomecânico (TMA).

Neste trabalho, a verificação do grau de polimerização da matriz foi realizada tomando-se como referência a $T_{g}$ em um calorímetro exploratório diferencial (DSC), da marca Perkin Elmer modelo 7, com atmosfera inerte de nitrogênio ultra puro com razão de $120 \mathrm{~mL} \cdot \mathrm{min}^{-1}$, no intervalo de temperatura de 30 a $180^{\circ} \mathrm{C}$ com taxa de aquecimento de $20^{\circ} \mathrm{C} \cdot \mathrm{min}^{-1}$.

Neste método, baseado na norma ASTM D 3418 (1980), uma pequena amostra do compósito, da ordem de $50 \mathrm{mg}$, é colocada dentro de uma panela de alumínio selada, enquanto uma outra panela de referência é mantida vazia. As duas panelas são colocadas dentro da câmara de aquecimento do analisador, como é mostrado na Fig. 4.7.1, e a diferença do fluxo de calor entre as duas panelas é comparada, conforme a câmara do analisador é aquecida. Os valores do fluxo de calor versus temperatura são registrados e uma curva é obtida.

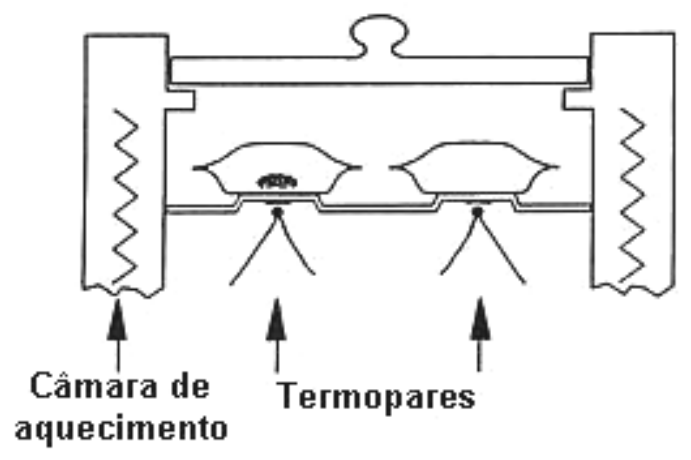

Figura 4.7.1 - Câmara de aquecimento do DSC (Shah, 1998).

Da curva do fluxo de calor versus temperatura, conforme mostrado na Fig. 4.7.2, obtém-se a temperatura de transição vítrea $\left(T_{g}\right)$, tomando-se por base a média entre as temperaturas do final da região na qual a matriz tem característica vítrea $\left(T_{f}\right)$ e o início da região na qual a matriz tem característica elástica $\left(T_{e}\right)$. 


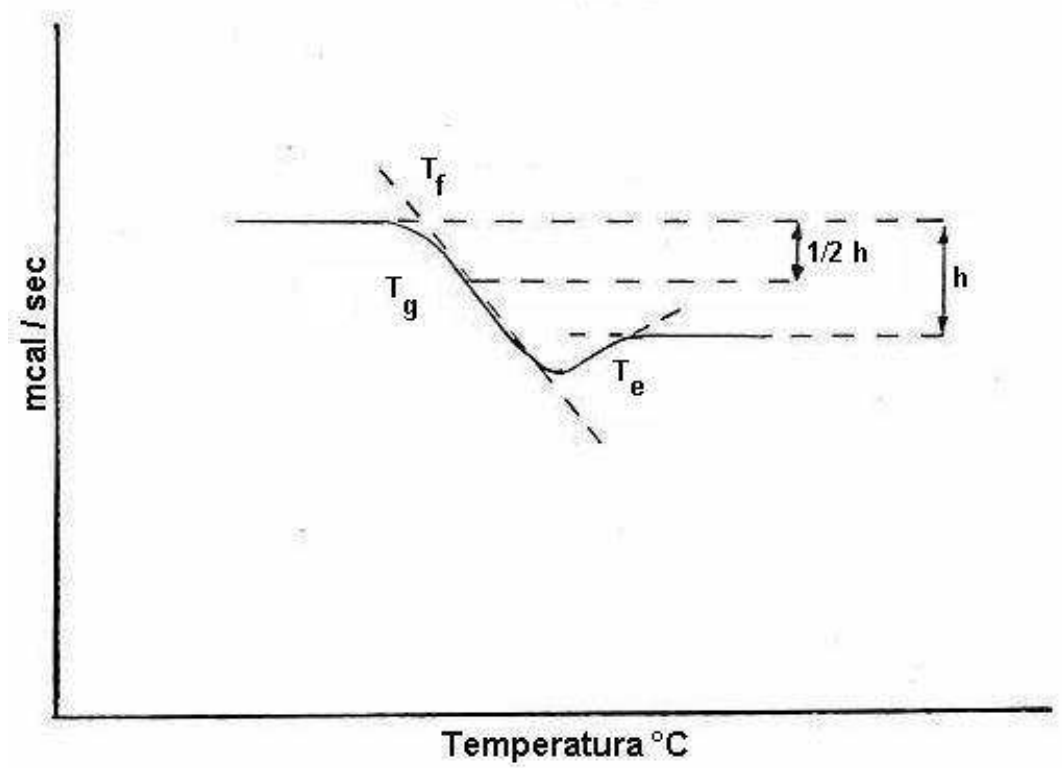

Figura 4.7.2 - Curva típica do fluxo de calor versus temperatura em DSC (ASTM D 3418, 1980).

A temperatura de transição vítrea pode ser interpretada como a temperatura limite na qual uma dada formulação pode manter sua integridade e como conseqüência evitando possíveis alterações no comportamento mecânico da matriz caso a sua utilização seja acima da $T_{g}$. No entanto, por segurança, considera-se como a temperatura máxima de trabalho para um material o valor de $10^{\circ} \mathrm{C}$ abaixo da $\mathrm{T}_{\mathrm{g}}$ registrada.

\subsection{Caracterização microestrutural}

O método de análise de imagens de amostras de compósitos pode ser utilizado para diversas finalidades, tais como, a determinação das frações volumétricas de fibra e resina, do volume de vazio, medida da espessura das camadas e a identificação de falhas. A aplicação deste método pode ser vista em Cohen et al. (2001) e Hagstrand et al. (2005).

No presente estudo, amostras retiradas de anéis da extremidade dos cilindros foram cortadas para análise da seção transversal do compósito. A preparação das amostras de material compósito seguiu as práticas metalográficas, destacando-se que em virtude da presença do material polimérico o embutimento é feito a frio. 
A obtenção de imagens das seções transversal e longitudinal das amostras foi realizada em um sistema de análise de imagens da marca Leco modelo 500. A análise das imagens tornou possível identificar as características do compósito pelos diferentes tons de cinza presentes na amostra.

\subsection{Análise das tensões}

Para avaliar o comportamento das tensões nas camadas dos cilindros, com configuração simétrica e assimétrica submetidos a pressão interna, utilizou-se o software de elementos finitos ANSYS.

Os dados de entrada para os cálculos foram as configurações de bobinagem de cada grupo de cilindros, as espessuras médias das camadas, as pressões médias de ruptura obtidas nos ensaios e as propriedades mecânicas típicas de um compósito unidirecional, conforme Daniel \& Ishai (1994), com 63\% de fração volumétrica de fibra. Os requisitos do ANSYS para as propriedades do compósito são: o módulo de elasticidade longitudinal $E_{1}$, o módulo de elasticidade transversal $E_{2}$, o módulo de cisalhamento $G_{12}$, o coeficiente de Poisson $v_{12}$ e o limite de resistência à tração $F_{1}$ na direção da fibra, cujo valor é de $2280 \mathrm{MPa}$.

O cálculo foi realizado para duas situações distintas. Na primeira delas, considerou-se a pressão média de ruptura obtida por meio dos ensaios hidrostáticos para cada grupo de cilindros, a fim de obter as tensões atuantes nesta condição. $\mathrm{Na}$ segunda situação, os cálculos foram realizados considerando-se o limite de resistência do compósito, a fim de obter a pressão de ruptura dos componentes para esta condição. 


\section{RESULTADOS E DISCUSSÃO}

\subsection{Frações volumétricas dos cilindros com bobinagens simétrica e assimétrica}

Nas Tab. 5.1.1 e 5.1.2 são mostrados respectivamente os valores de massa específica do compósito $\left(d_{c}\right)$ determinados pelo método do deslocamento de líquido e os valores de frações volumétricas de fibra de carbono $\left(\mathrm{v}_{\mathrm{f}}\right)$, matriz $\left(v_{m}\right)$ e volume de vazio $\left(v_{v}\right)$ obtidos para os grupos de cilindros simétrico e assimétrico.

Tabela 5.1.1 - Valores de massa específica do compósito, frações volumétricas de fibra e matriz e volume de vazio dos cilindros simétricos.

\begin{tabular}{ccccc}
\hline Cilindro & $\begin{array}{c}\text { Massa } \\
\text { específica } \\
\mathbf{d}_{\mathbf{c}}\left(\mathbf{g} \cdot \mathbf{c m}^{-3}\right)\end{array}$ & $\begin{array}{c}\text { Fração } \\
\text { fibra } \\
\mathbf{v}_{\mathbf{f}}(\%)\end{array}$ & $\begin{array}{c}\text { Fração } \\
\text { matriz } \\
\mathbf{v}_{\mathbf{m}}(\%)\end{array}$ & $\begin{array}{c}\text { Volume } \\
\text { vazio } \\
\mathbf{v}_{\mathbf{v}}(\%)\end{array}$ \\
\hline 1-S & 1,56 & 65,6 & 33,2 & 1,2 \\
2-S & 1,56 & 65,1 & 33,9 & 1,0 \\
3-S & 1,56 & 65,8 & 32,9 & 1,3 \\
4-S & 1,55 & 65,2 & 33,0 & 1,8 \\
5-S & 1,56 & 65,5 & 33,3 & 1,2 \\
6-S & 1,56 & 65,9 & 32,8 & 1,3 \\
7-S & 1,56 & 65,7 & 33,0 & 1,3 \\
\hline Média & 1,56 & 65,5 & 33,2 & 1,3 \\
\hline Desvio & 0,00 & 0,3 & 0,4 & 0,2 \\
padrão & & & & \\
\hline
\end{tabular}


Tabela 5.1.2 - Valores de massa específica do compósito, frações volumétricas de fibra e matriz e volume de vazio dos cilindros assimétricos.

\begin{tabular}{ccccc}
\hline Cilindro & $\begin{array}{c}\text { Massa } \\
\text { específica } \\
\mathbf{d}_{\mathbf{c}}\left(\mathbf{g} \cdot \mathbf{c m}^{-\mathbf{3}}\right)\end{array}$ & $\begin{array}{c}\text { Fração } \\
\text { fibra } \\
\mathbf{v}_{\mathbf{f}}(\%)\end{array}$ & $\begin{array}{c}\text { Fração } \\
\text { matriz } \\
\mathbf{v}_{\mathbf{m}}(\%)\end{array}$ & $\begin{array}{c}\text { Volume } \\
\text { vazio } \\
\mathbf{v}_{\mathbf{v}}(\%)\end{array}$ \\
\hline 1-A & 1,56 & 65,0 & 34,2 & 0,8 \\
2-A & 1,57 & 66,5 & 32,7 & 0,8 \\
3-A & 1,57 & 66,2 & 33,1 & 0,7 \\
4-A & 1,57 & 65,9 & 33,5 & 0,6 \\
5-A & 1,56 & 65,7 & 33,0 & 1,3 \\
6-A & 1,56 & 66,7 & 31,5 & 1,8 \\
7-A & 1,57 & 67,3 & 31,4 & 1,3 \\
\hline Média & 1,57 & 66,2 & 32,8 & 1,0 \\
\hline Desvio & 0,01 & 0,7 & 1,0 & 0,4 \\
padrão & & & & \\
\hline
\end{tabular}

Inúmeros parâmetros necessitam ser controlados no processo de bobinamento filamentar para se obter compósitos estruturais. Tensionamento da fibra, posicionamento da fibra no ângulo determinado, temperatura e tempo de residência da fibra no banho (matriz) são algumas das variáveis que podem afetar a qualidade do compósito e contribuir para não se atingir as propriedades mecânicas desejadas. Por exemplo, as frações volumétricas de fibra, matriz e vazio são propriedades que comprometem o comportamento do cilindro e podem sofrer variação se os parâmetros do processo não forem adequadamente controlados.

Nas Tab. 5.1.1 e 5.1.2 verificou-se que as frações volumétricas de fibra e matriz nos dois grupos de cilindros apresentaram valores com pequeno desvio, permitindo inferir que seqüências diferentes de bobinagem não exerceram influência nestes parâmetros. Fração volumétrica de fibra em torno de $65 \%$ é um valor típico para fabricação de compósitos de alto desempenho (ASM, 1987).

$O$ volume de vazio pode comprometer a resistência do material, sendo importante obter valores inferiores a $2 \%$ (Almeida \& Nogueira, 1994). Nos cilindros fabricados para este estudo, o volume de vazio em todos os exemplares 
foi inferior ao valor de $2 \%$, caracterizando a excelente impregnação da fibra pela matriz durante a etapa de fabricação.

Vazios estão quase sempre presentes em compósitos poliméricos, sendo importante reduzir ao mínimo sua presença e conseqüentemente o seu efeito sobre o comportamento mecânico global do componente. Valores elevados de vazios conduzem ao maior aparecimento de trincas e a diminuição da resistência do compósito (Varna et al., 1995).

\subsection{Análise térmica}

Embora os ensaios hidrostáticos tenham sido realizados à temperatura ambiente, a cura do sistema de matriz epóxi, avaliada pela temperatura de transição vítrea medida no DSC, indicou que a matriz polimérica poderia garantir sua integridade estrutural para aplicações de até $90^{\circ} \mathrm{C}\left(10^{\circ} \mathrm{C}\right.$ a menos que a $\mathrm{Tg}$ registrada).

A principal razão de ter sido feita a determinação da $T_{g}$ em todos os exemplares fabricados foi garantir que a matriz apresentasse uma cura igual para todos os cilindros, eliminando, deste modo, qualquer possível dúvida que pudesse recair sobre a matriz polimérica.

Na Fig. 5.2.1 é mostrada uma curva DSC típica, a partir da qual se obtém a temperatura de transição vítrea da matriz utilizada na fabricação dos cilindros.

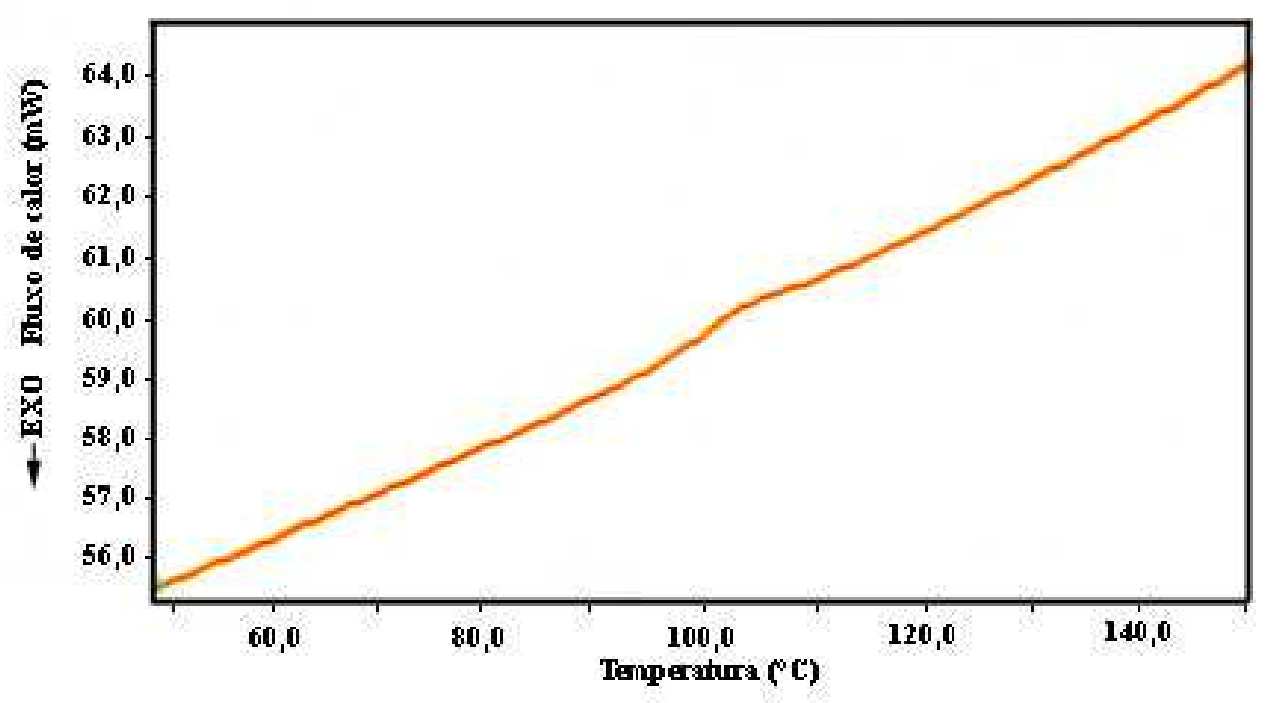

Figura 5.2.1 - Curva típica de análise em DSC do cilindro simétrico 6-S. 
Conforme pode ser observado na figura, a transição registrada é tênue devido à pequena massa de matriz presente na amostra de compósito analisada, ou seja, apenas cerca de $25 \%$ da massa da amostra de $50 \mathrm{mg}$. O cálculo da temperatura de transição vítrea $\left(\mathrm{T}_{\mathrm{g}}\right)$ foi realizado de acordo com o descrito no item 4.7 , resultando no valor de aproximadamente $100^{\circ} \mathrm{C}$ para a matriz utilizada neste estudo.

\subsection{Relação entre pressão e deformações circunferencial e longitudinal}

Os resultados a seguir referem-se a aquisição de dados realizada em quatro cilindros de cada grupo, nos quais foram aplicadas as técnicas de extensiometria.

Nos gráficos de pressão versus deformações, observa-se a plotagem de duas curvas. A curva do lado positivo da abcissa representa o comportamento da deformação circunferencial $\left(\varepsilon_{c}\right)$, que é resultante do carregamento de pressão interna e a curva do lado negativo representa o comportamento da deformação longitudinal $\left(\varepsilon_{\mathrm{z}}\right)$, que é conseqüência da deformação circunferencial, resultando na contração longitudinal dos cilindros. A representação gráfica individualizada por cilindro da pressão versus deformações, objetiva uma melhor visualização dos resultados obtidos durante os ensaios de cada grupo.

Nas curvas foram assinalados parte dos valores obtidos na aquisição de dados, visto que em razão ao elevado número de registros uma plotagem mais detalhada tornaria as curvas de difícil visualização. Os valores máximos de pressão e deformações circunferencial e longitudinal não estão representados devido à elevada interferência (ruído) verificada nos registros próximos da ruptura dos cilindros durante a aquisição de dados.

Os valores das deformações máximas mostrados nas Tab. 5.3.1.1 e 5.3.2.1 foram obtidos através da substituição da pressão de ruptura, lida diretamente no manômetro do dispositivo de ensaio hidrostático, nas respectivas equações das retas dos gráficos $P$ versus $\varepsilon$.

As deformações circunferenciais podem ser representadas por uma equação típica da forma $P=15,3 . \varepsilon_{c}$, enquanto que as deformações longitudinais são representadas pela equação $P=-47,4 . \varepsilon_{z}$. As deformações circunferenciais, 
para uma mesma pressão, são cerca de 3 vezes maior que as deformações longitudinais. Isto resulta do fato que todo o carregamento atua na direção circunferencial, situação definida pela própria construção dos cilindros que foram fabricados com extremidades abertas.

O colapso dos cilindros ocorreu com deformação circunferencial em torno de $1,4 \%$ e deformação longitudinal cerca de $0,45 \%$, lembrando que o limite de resistência da fibra ocorre com deformação de 1,5\%.

O aumento do diâmetro seria de especial interesse caso houvesse uma montagem e o cilindro fosse um dos elementos de um conjunto, pois a expansão causada pela pressão interna poderia provocar interferências neste conjunto, o que limitaria a aplicação de pressão.

\subsubsection{Cilindros simétricos}

$\mathrm{Na}$ Tab. 5.3.1.1 estão mostrados os valores de pressão de ruptura $\left(P_{\text {rup }}\right)$ e deformações circunferencial $\left(\varepsilon_{\mathrm{c}}\right)$ e longitudinal $\left(\varepsilon_{\mathrm{z}}\right)$ máximas dos cilindros simétricos 3-S, 4-S, 5-S e 6-S.

Tabela 5.3.1.1 - Valores da pressão de ruptura e deformações circunferencial e longitudinal máximas de cilindros simétricos.

\begin{tabular}{cccc}
\hline $\begin{array}{c}\text { Cilindros } \\
\text { simétricos }\end{array}$ & $\begin{array}{c}\text { Pressão de } \\
\text { ruptura } \\
\mathbf{P}_{\text {rup }}(\mathrm{MPa})\end{array}$ & $\begin{array}{c}\text { Deformação } \\
\text { circunferencial } \\
\boldsymbol{\varepsilon}_{\mathrm{c}} \text { máxima }\end{array}$ & $\begin{array}{c}\text { Deformação } \\
\text { longitudinal } \\
\boldsymbol{\varepsilon}_{\mathbf{z}} \text { máxima }\end{array}$ \\
\hline 3-S & 23,0 & 1,50 & 0,51 \\
4-S & 21,5 & 1,40 & 0,43 \\
5-S & 21,5 & 1,43 & 0,42 \\
6-S & 23,0 & 1,47 & 0,47 \\
\hline
\end{tabular}

Nas Fig. 5.3.1.1, 5.3.1.2, 5.3.1.3 e 5.3.1.4 são mostrados, respectivamente, os gráficos de pressão $(P)$ versus deformações circunferencial $\left(\varepsilon_{\mathrm{c}}\right)$ e longitudinal $\left(\varepsilon_{\mathrm{z}}\right)$ tomando-se por base os resultados obtidos da aquisição de dados realizada durante ensaio hidrostático nos cilindros simétricos 3-S, 4-S, 5-S e 6-S. 


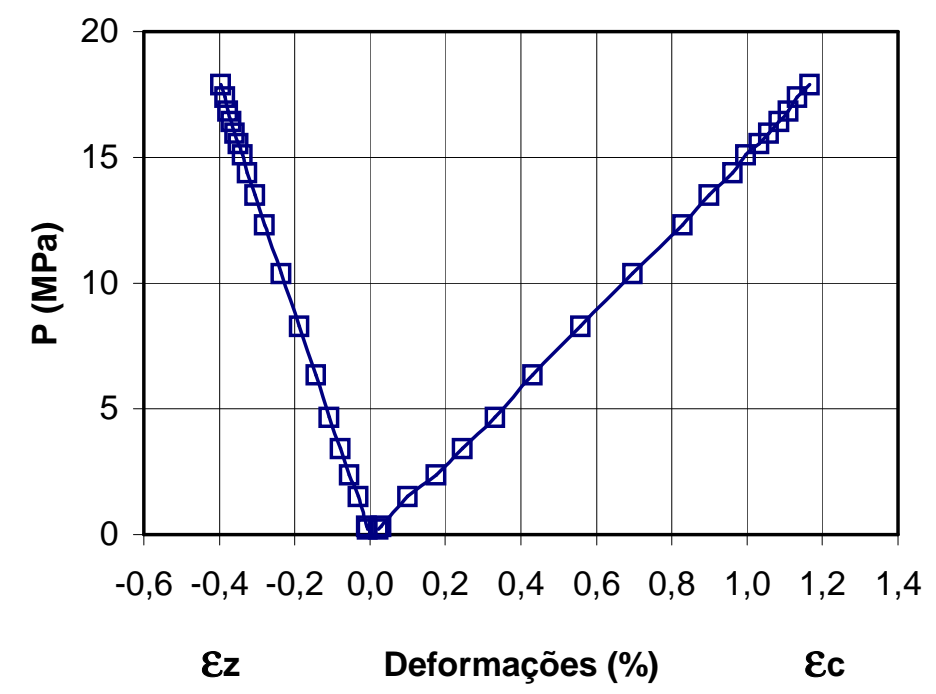

Figura 5.3.1.1 - Gráfico de pressão $(P)$ x deformações circunferencial $\left(\varepsilon_{c}\right)$ e longitudinal $\left(\varepsilon_{\mathrm{z}}\right)$ para o cilindro simétrico $3-\mathrm{S}$.

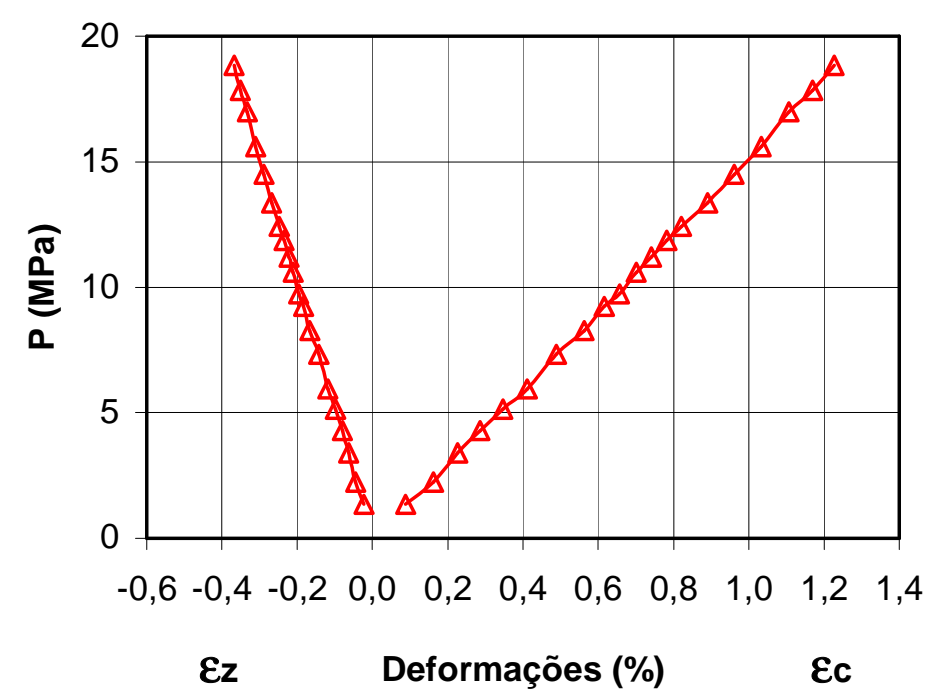

Figura 5.3.1.2 - Gráfico de pressão $(P) x$ deformações circunferencial $\left(\varepsilon_{c}\right)$ e longitudinal $\left(\varepsilon_{\mathrm{z}}\right)$ para o cilindro simétrico 4-S. 


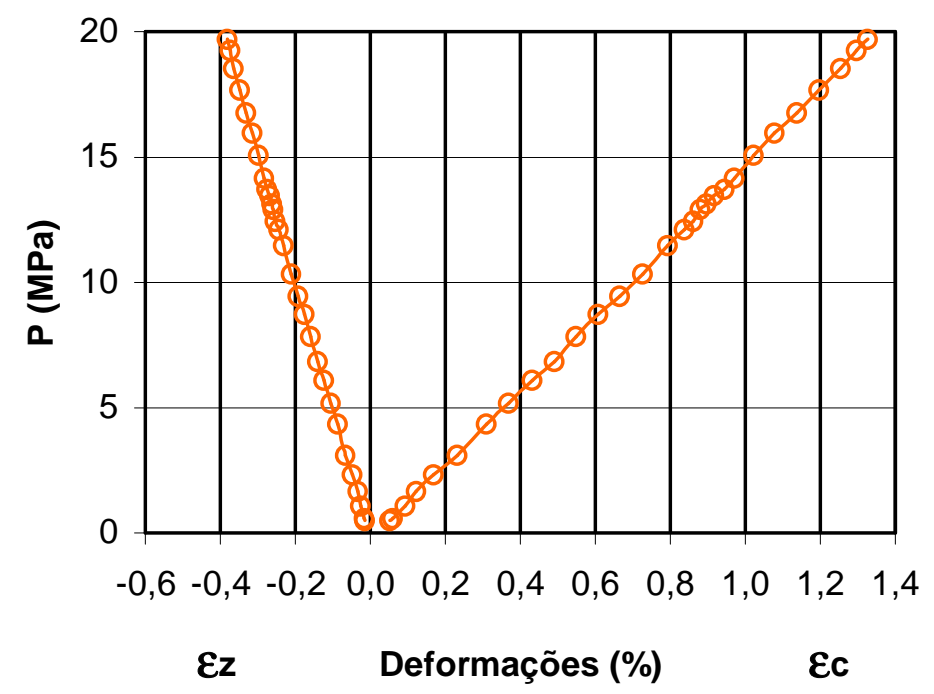

Figura 5.3.1.3 - Gráfico de pressão $(P)$ x deformações circunferencial $\left(\varepsilon_{c}\right)$ e longitudinal $\left(\varepsilon_{z}\right)$ para o cilindro simétrico 5 -S.

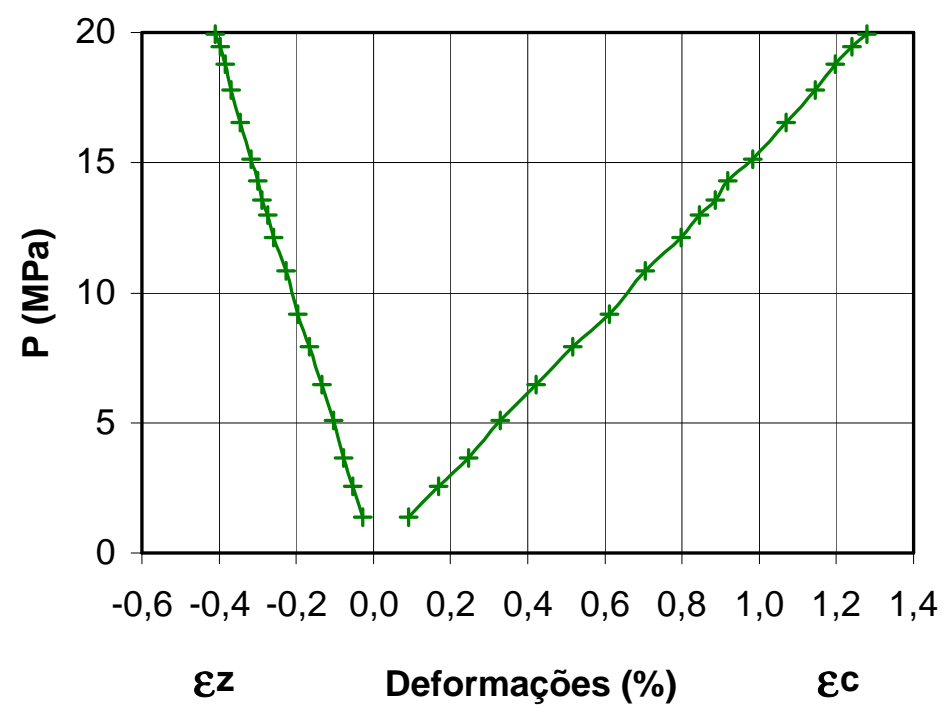

Figura 5.3.1.4 - Gráfico de pressão $(P) \times$ deformações circunferencial $\left(\varepsilon_{c}\right)$ e longitudinal $\left(\varepsilon_{\mathrm{z}}\right)$ para o cilindro simétrico 6-S.

\subsubsection{Cilindros assimétricos}

Na Tab. 5.3.2.1 estão mostrados os valores de pressão de ruptura $\left(P_{\text {rup }}\right)$ e deformações circunferencial $\left(\varepsilon_{c}\right)$ e longitudinal $\left(\varepsilon_{z}\right)$ máximas dos cilindros assimétricos 4-A, 5-A, 6-A e 7-A. 
Tabela 5.3.2.1 - Valores da pressão de ruptura e deformações circunferencial e longitudinal máximas de cilindros assimétricos.

\begin{tabular}{cccc}
\hline $\begin{array}{c}\text { Cilindros } \\
\text { assimétricos }\end{array}$ & $\begin{array}{c}\text { Pressão de } \\
\text { ruptura } \\
\mathbf{P}_{\text {rup }}(\mathrm{MPa})\end{array}$ & $\begin{array}{c}\text { Deformação } \\
\text { circunferencial } \\
\boldsymbol{\varepsilon}_{\mathrm{c}} \text { máxima }\end{array}$ & $\begin{array}{c}\text { Deformação } \\
\text { longitudinal } \\
\boldsymbol{\varepsilon}_{\mathbf{z}} \text { máxima }\end{array}$ \\
\hline 4-A & 21,5 & 1,38 & 0,48 \\
5-A & 21,0 & 1,36 & 0,49 \\
6-A & 22,0 & 1,45 & 0,43 \\
7-A & 20,0 & 1,30 & 0,44 \\
\hline
\end{tabular}

Nas Fig. 5.3.2.1, 5.3.2.2, 5.3.2.3 e 5.3.2.4 são mostrados, respectivamente, os gráficos de pressão versus deformações circunferencial $\left(\varepsilon_{c}\right)$ e longitudinal $\left(\varepsilon_{\mathrm{z}}\right)$ tomando-se por base os resultados obtidos da aquisição de dados realizada durante ensaio hidrostático nos cilindro assimétricos 4-A, 5-A, 6-A e 7-A.

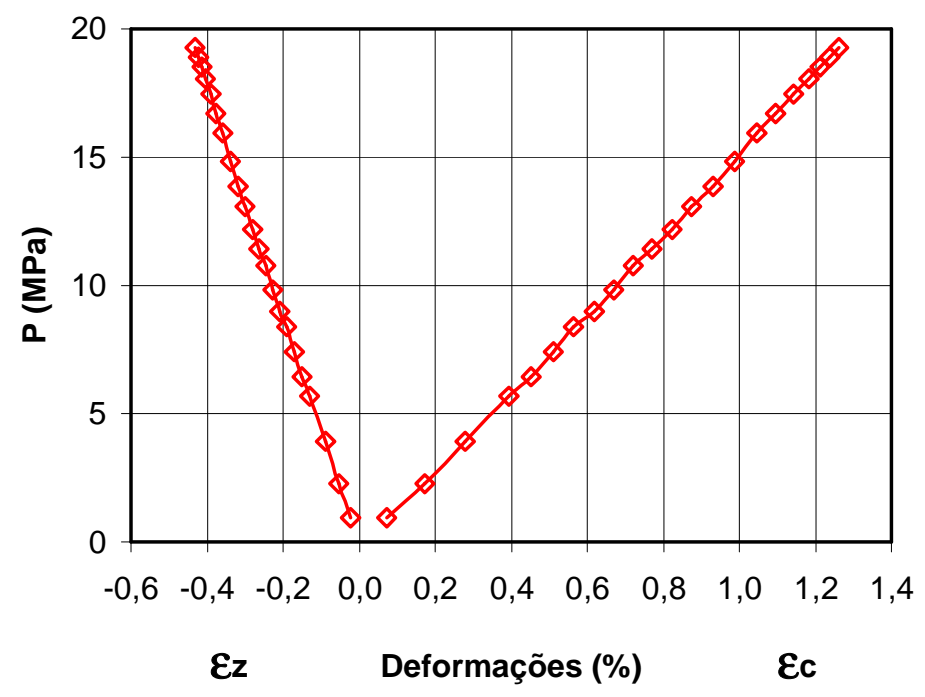

Figura 5.3.2.1 - Gráfico de pressão $(P)$ x deformações circunferencial $\left(\varepsilon_{c}\right)$ e longitudinal $\left(\varepsilon_{\mathrm{z}}\right)$ para o cilindro assimétrico $4-A$. 


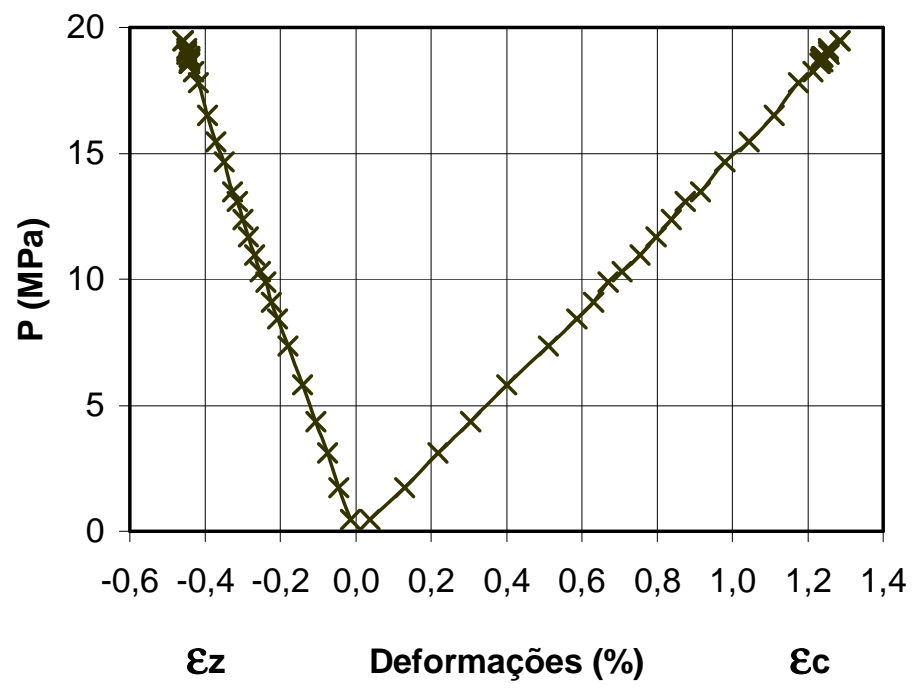

Figura 5.3.2.2 - Gráfico de pressão $(P)$ x deformações circunferencial $\left(\varepsilon_{c}\right)$ e longitudinal $\left(\varepsilon_{\mathrm{z}}\right)$ para o cilindro assimétrico $5-\mathrm{A}$.

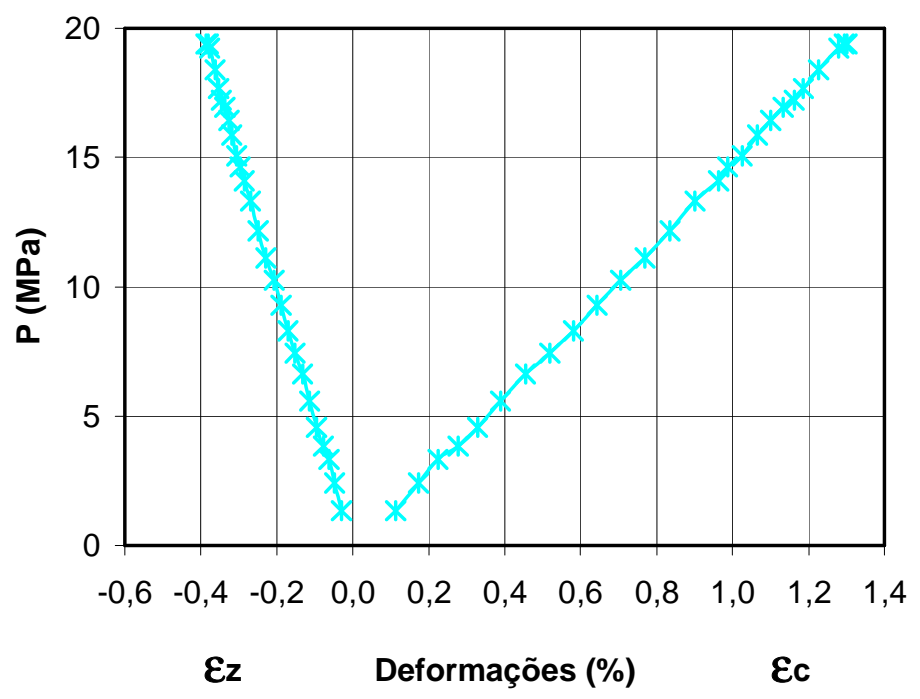

Figura 5.3.2.3 - Gráfico de pressão $(P)$ x deformações circunferencial $\left(\varepsilon_{c}\right)$ e longitudinal $\left(\varepsilon_{\mathrm{z}}\right)$ para o cilindro assimétrico $6-\mathrm{A}$. 


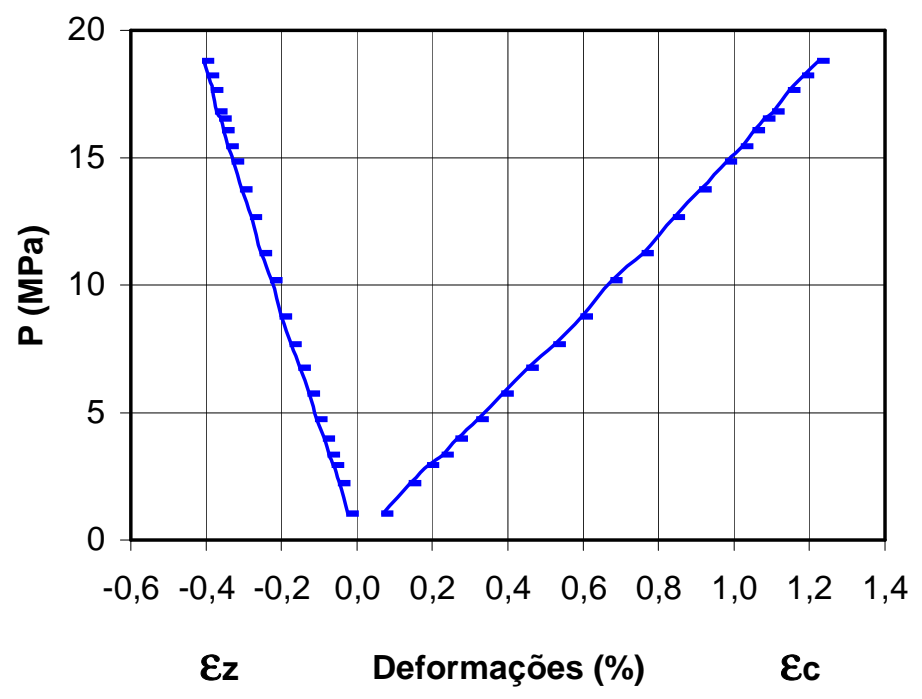

Figura 5.3.2.4 - Gráfico de pressão $(P) x$ deformações circunferencial $\left(\varepsilon_{c}\right)$ e longitudinal $\left(\varepsilon_{\mathrm{z}}\right)$ para o cilindro assimétrico 7-A.

5.3.3 Comparação entre pressão e deformações circunferencial e longitudinal nos cilindros simétricos e assimétricos

Nas Fig. 5.3.3.1 e 5.3.3.2 são mostrados, respectivamente, os gráficos de pressão versus deformações circunferencial $\left(\varepsilon_{\mathrm{c}}\right)$ e longitudinal $\left(\varepsilon_{\mathrm{z}}\right)$ com as 4 curvas obtidas da aquisição de dados realizada durante ensaio hidrostático nos cilindros simétricos 3-S, 4-S, 5-S e 6-S e assimétricos 4-A, 5-A, 6-A e 7-A. 


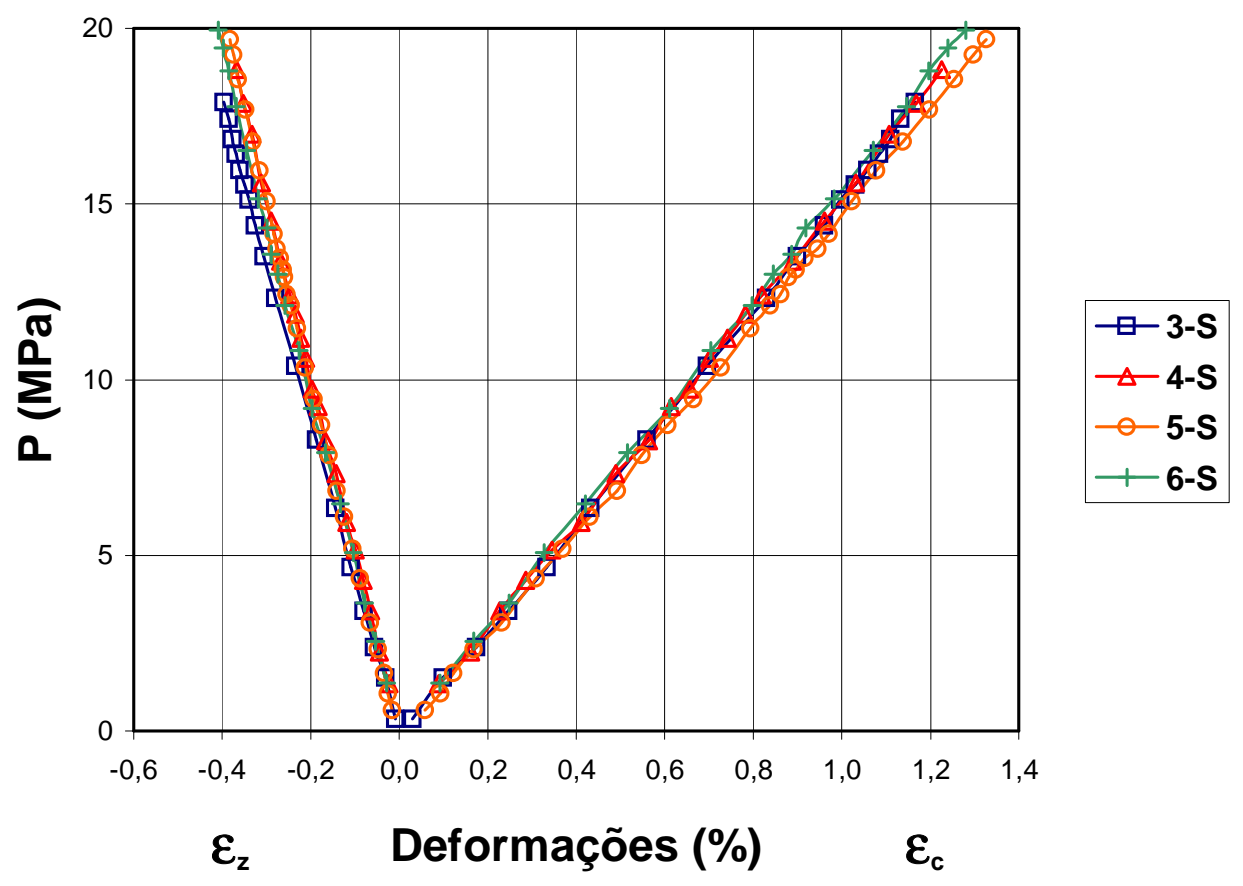

Figura 5.3.3.1 - Gráfico de pressão $(P) \times$ deformações circunferencial $\left(\varepsilon_{c}\right)$ e longitudinal $\left(\varepsilon_{z}\right)$ para os cilindros simétricos 3-S, 4-S, 5-S e 6-S.

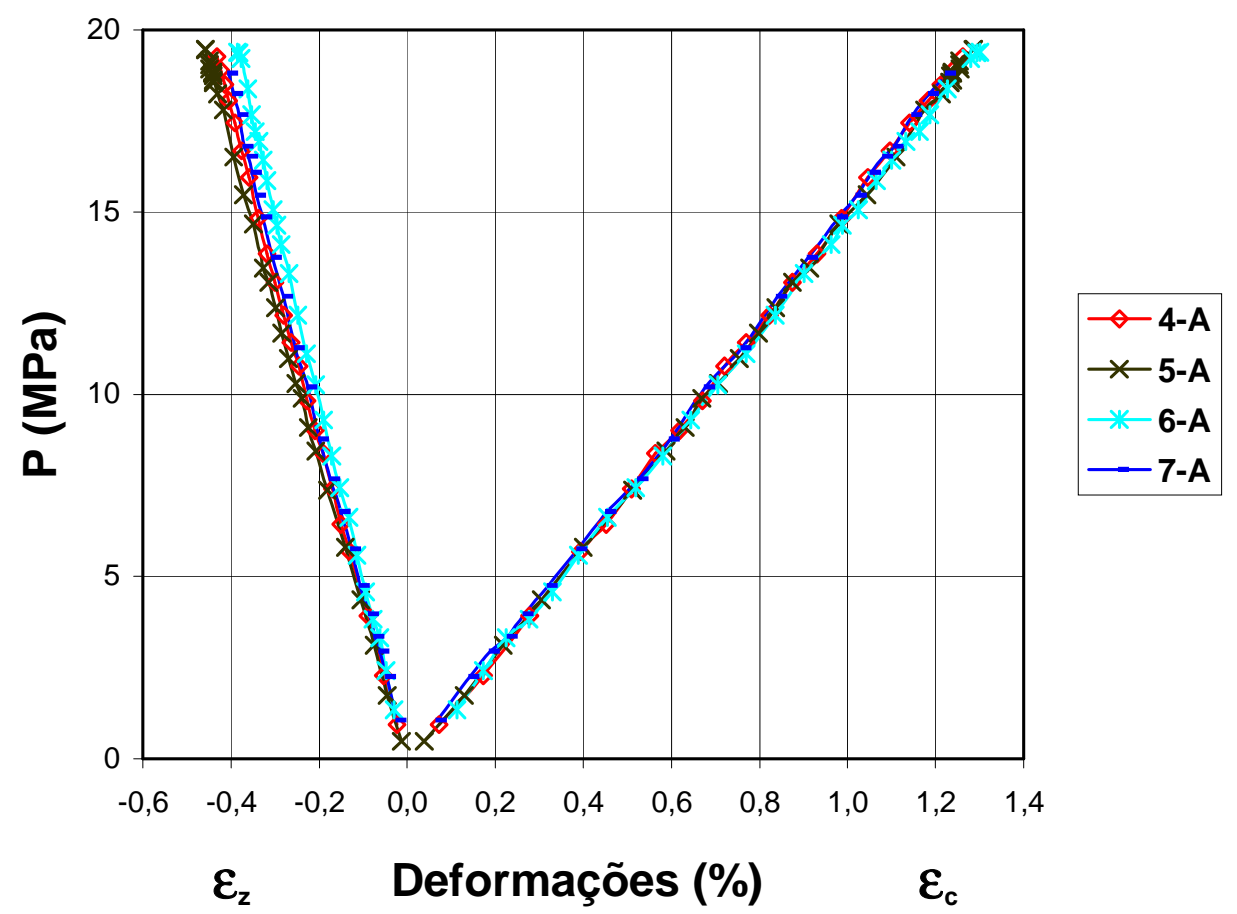

Figura 5.3.3.2 - Gráfico de pressão $(P)$ x deformações circunferencial $\left(\varepsilon_{c}\right)$ e longitudinal $\left(\varepsilon_{\mathrm{z}}\right)$ para os cilindros assimétricos 4-A, 5-A, 6-A e 7-A. 
Estruturas de compósitos poliméricos têm deformações que são dependentes das propriedades da fibra, das frações volumétricas e da configuração de bobinagem.

Da análise dos gráficos das Fig. 5.3.3.1 e 5.3.3.2 se observa que os cilindros tanto com configuração simétrica quanto com configuração assimétrica tiveram comportamento semelhantes quando submetidos à pressão interna. $\mathrm{A}$ plotagem de todas as curvas em um mesmo gráfico tornaria difícil a identificação de cada grupo de cilindros ensaiado, por causa da sobreposição das curvas em uma mesma região.

\subsection{Relação entre deformações circunferencial e longitudinal}

Nos gráficos de deformação circunferencial vesus deformação longitudinal apresentados a seguir observa-se que a abcissa, de valores positivos, representa o comportamento da deformação circunferencial $\left(\varepsilon_{c}\right)$ e a ordenada, de valores negativos, representa o comportamento da deformação longitudinal $\left(\varepsilon_{z}\right)$.

Novamente os pontos assinalados na curva não representam todos os valores obtidos na aquisição de dados, porém são iguais aos que representam as deformações nos gráficos pressão versus deformações, do item 5.3, para os dois grupos de cilindros.

A relação entre $\varepsilon_{z}$ e $\varepsilon_{c}$ permite obter 0 coeficiente de Poisson $(v)$ dos cilindros fabricados de acordo com as duas configurações apresentadas neste trabalho. O valor de $v$ é dado por:

$$
v=-\varepsilon_{\mathrm{z}} / \varepsilon_{\mathrm{c}}
$$

Os valores dos coeficientes de Poisson foram obtidos da relação acima, que representa o coeficiente angular das retas dos gráficos de $\varepsilon_{\mathrm{c}}$ versus $\varepsilon_{\mathrm{z}}$,para os dois grupos de cilindros e foram tabulados para análise comparativa. 


\subsubsection{Cilindros simétricos}

$\mathrm{Na}$ Tab. 5.4.1.1 estão mostrados os valores do coeficiente de Poisson ( $v$ ) obtidos nas Fig. 5.4.1.1, 5.4.1.2, 5.4.1.3 e 5.4.1.4 para os cilindros com configuração simétrica.

Tabela 5.4.1.1 - Valores do coeficiente de Poisson dos cilindros simétricos.

\begin{tabular}{cc}
\hline $\begin{array}{c}\text { Cilindros } \\
\text { simétricos }\end{array}$ & $\begin{array}{c}\text { Coeficiente de } \\
\text { Poisson }(v)\end{array}$ \\
\hline 3-S & 0,34 \\
4-S & 0,30 \\
5-S & 0,29 \\
6-S & 0,32 \\
\hline Média & 0,31 \\
\hline Desvio-padrão & 0,02 \\
\hline
\end{tabular}

Nas Fig. 5.4.1.1, 5.4.1.2, 5.4.1.3 e 5.4.1.4 são mostrados, respectivamente, os gráficos da relação entre as deformações circunferencial $\left(\varepsilon_{\mathrm{c}}\right)$ e longitudinal $\left(\varepsilon_{z}\right)$ tomando-se por base os resultados obtidos da aquisição de dados realizada durante ensaio hidrostático nos cilindros simétricos 3-S, 4-S, 5-S e 6-S.

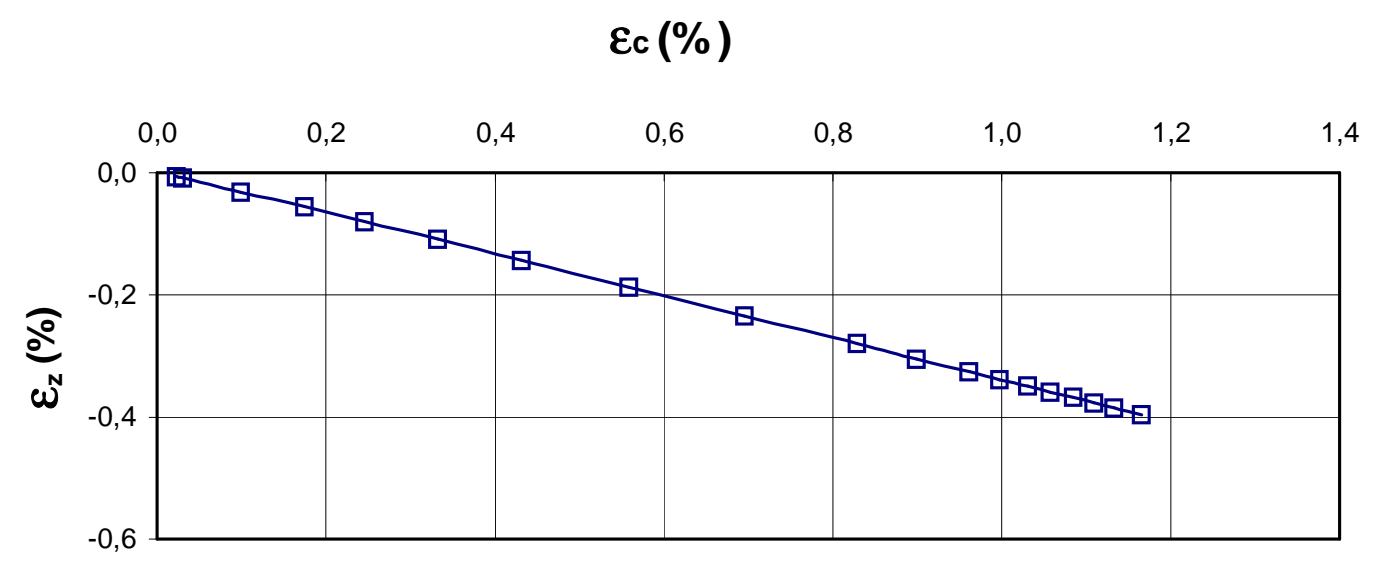

Figura 5.4.1.1 - Gráfico da relação entre as deformações $\varepsilon_{c}$ e $\varepsilon_{z}$ para o cilindro simétrico 3-S. 


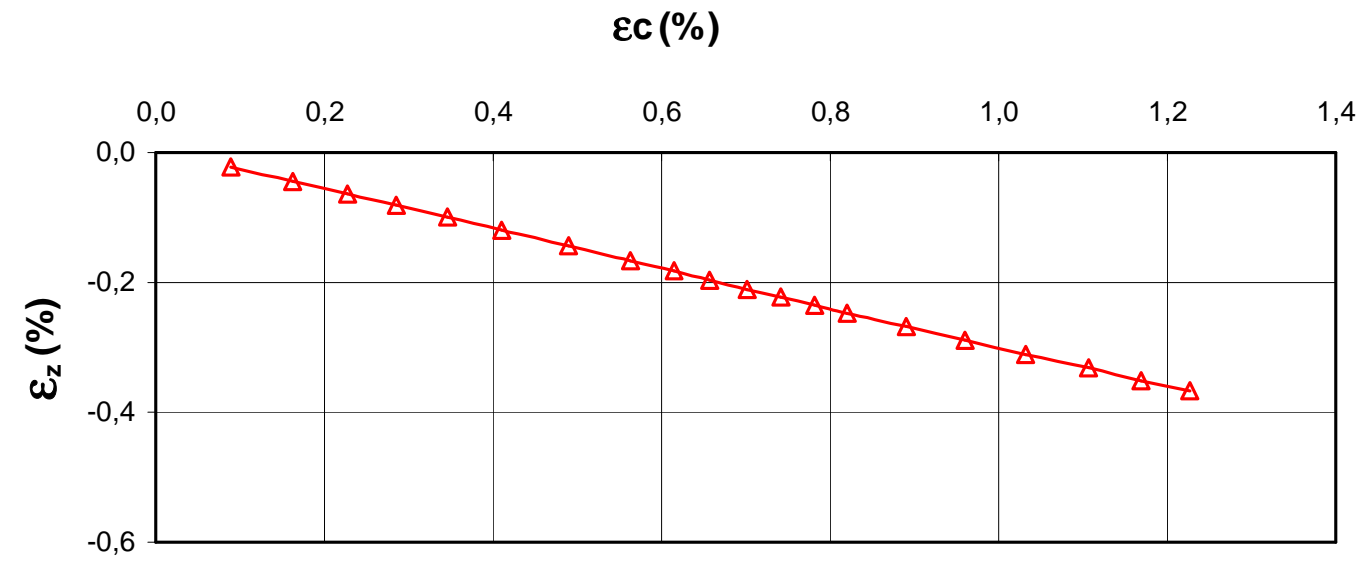

Figura 5.4.1.2 - Gráfico da relação entre as deformações $\varepsilon_{c}$ e $\varepsilon_{z}$ para o cilindro simétrico 4-S.

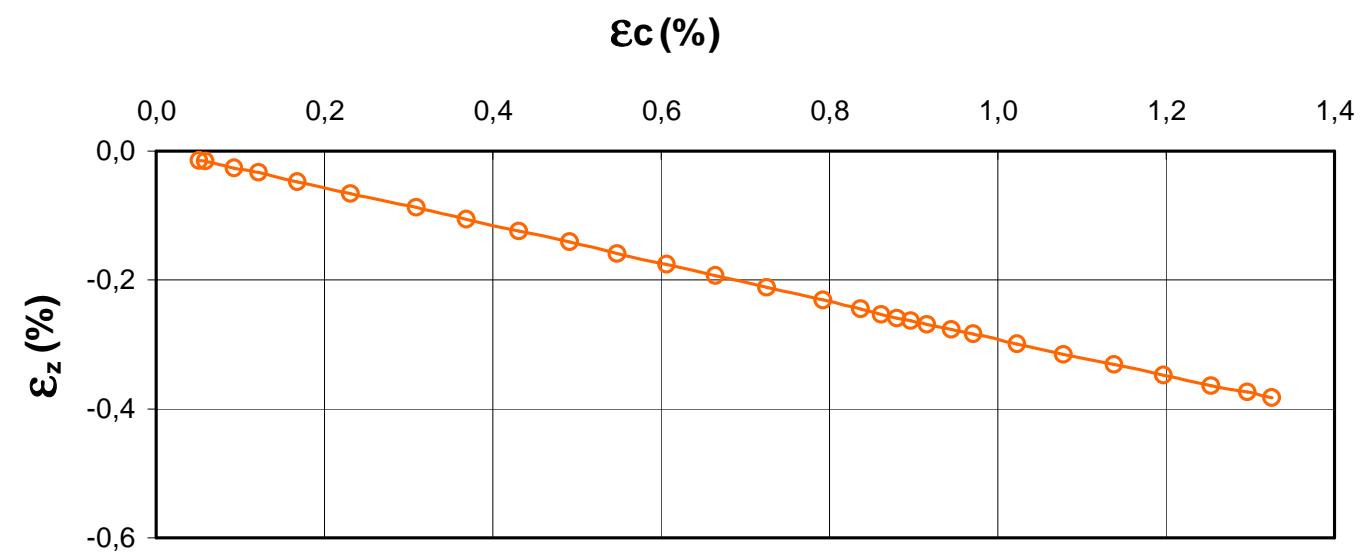

Figura 5.4.1.3 - Gráfico da relação entre as deformações $\varepsilon_{\mathrm{c}}$ e $\varepsilon_{\mathrm{z}}$ para o cilindro simétrico 5-S. 


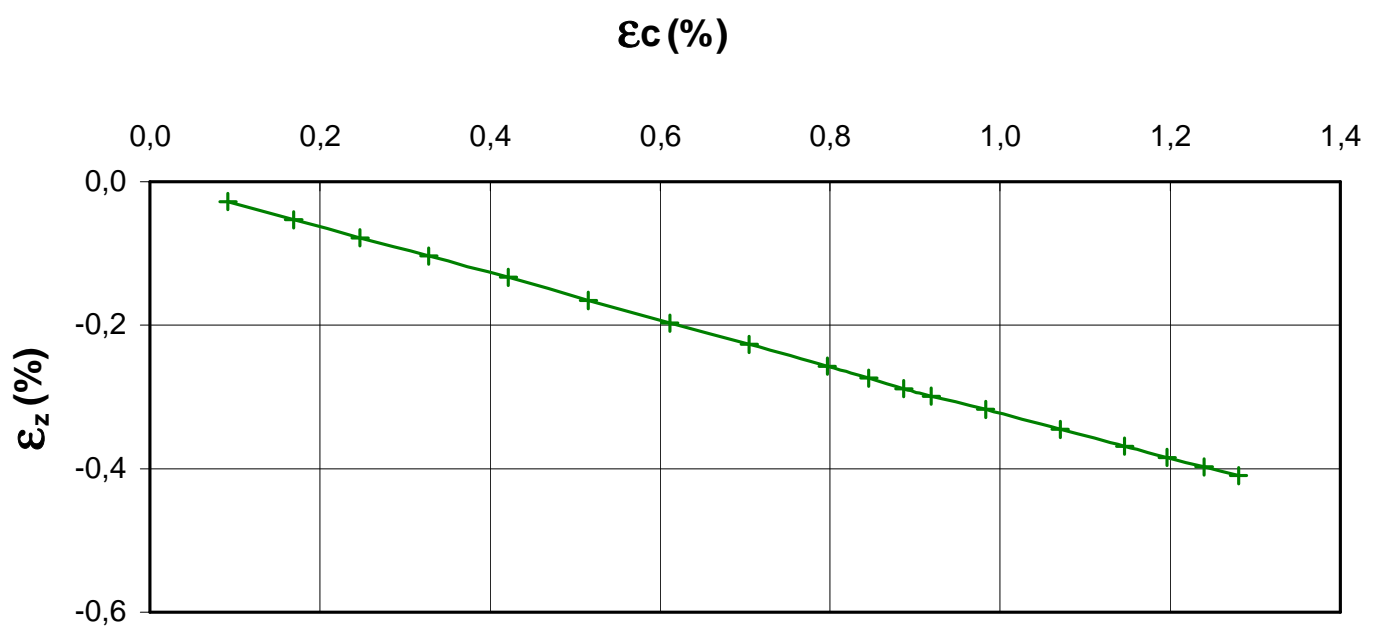

Figura 5.4.1.4 - Gráfico da relação entre as deformações $\varepsilon_{\mathrm{c}}$ e $\varepsilon_{\mathrm{z}}$ para o cilindro simétrico 6-S.

\subsubsection{Cilindros assimétricos}

$\mathrm{Na}$ Tab. 5.4.2.1 estão mostrados os valores do coeficiente de Poisson (v) obtidos das Fig. 5.4.2.1, 5.4.2.2, 5.4.2.3 e 5.4.2.4 para os cilindros com configuração assimétrica.

Tabela 5.4.2.1 - Valores do coeficiente de Poisson dos cilindros assimétricos.

\begin{tabular}{cc}
\hline $\begin{array}{c}\text { Cilindros } \\
\text { simétricos }\end{array}$ & $\begin{array}{c}\text { Coeficiente de } \\
\text { Poisson }(v)\end{array}$ \\
\hline 4-A & 0,34 \\
5-A & 0,35 \\
6-A & 0,30 \\
7-A & 0,33 \\
\hline Média & 0,33 \\
\hline Desvio-padrão & 0,02 \\
\hline
\end{tabular}

Nas Fig. 5.4.2.1, 5.4.2.2, 5.4.2.3 e 5.4.2.4 são mostrados, respectivamente, os gráficos da relação entre as deformações circunferencial $\left(\varepsilon_{\mathrm{c}}\right)$ e longitudinal $\left(\varepsilon_{z}\right)$ tomando-se por base os resultados obtidos da aquisição de 
dados realizada durante ensaio hidrostático nos cilindros assimétricos 4-A, 5-A, 6-A e 7-A.

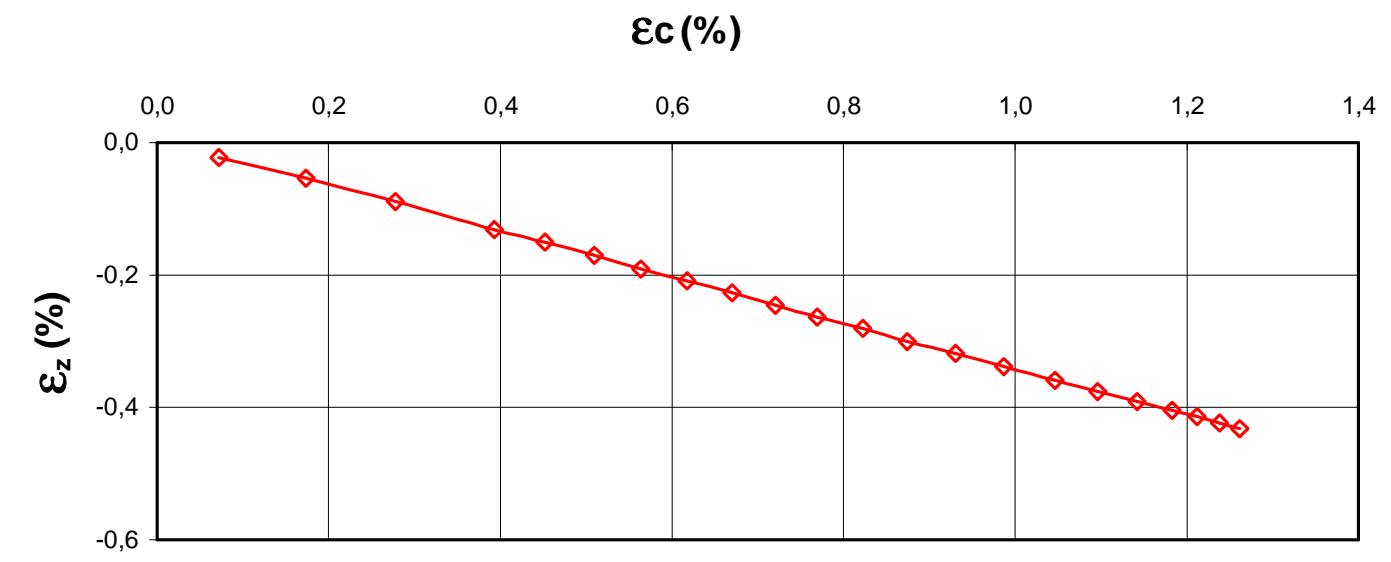

Figura 5.4.2.1 - Gráfico da relação entre as deformações $\varepsilon_{\mathrm{c}}$ e $\varepsilon_{\mathrm{z}}$ para o cilindro assimétrico 4-A.

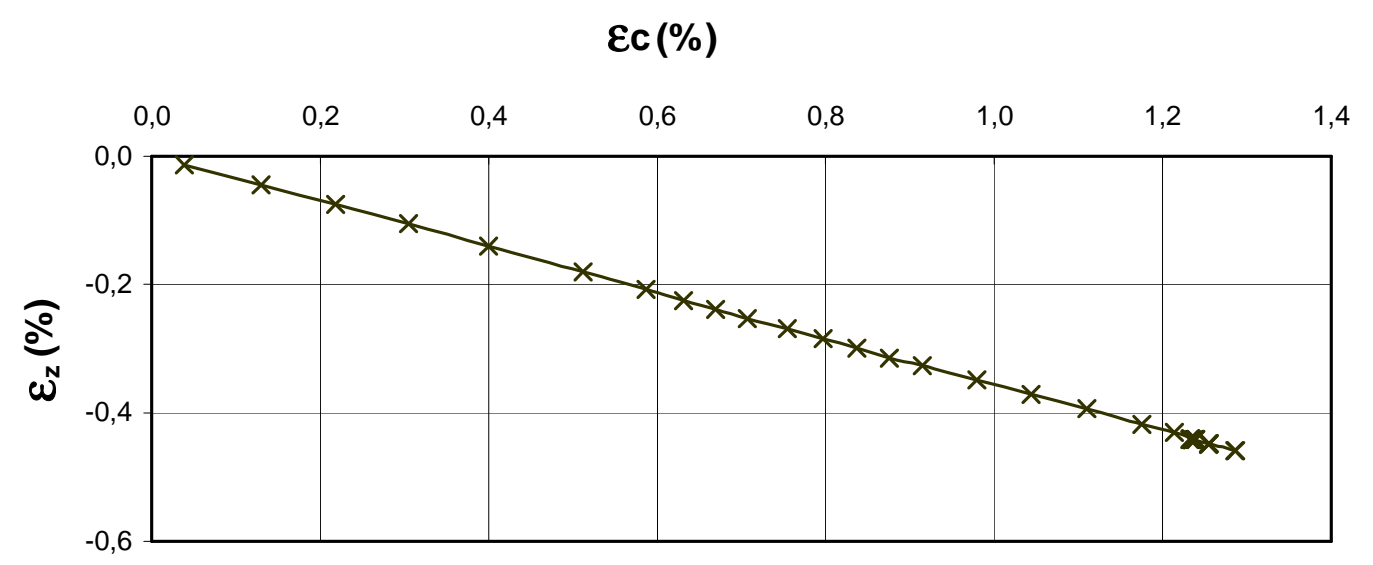

Figura 5.4.2.2 - Gráfico da relação entre as deformações $\varepsilon_{\mathrm{c}}$ e $\varepsilon_{\mathrm{z}}$ para o cilindro assimétrico 5-A. 


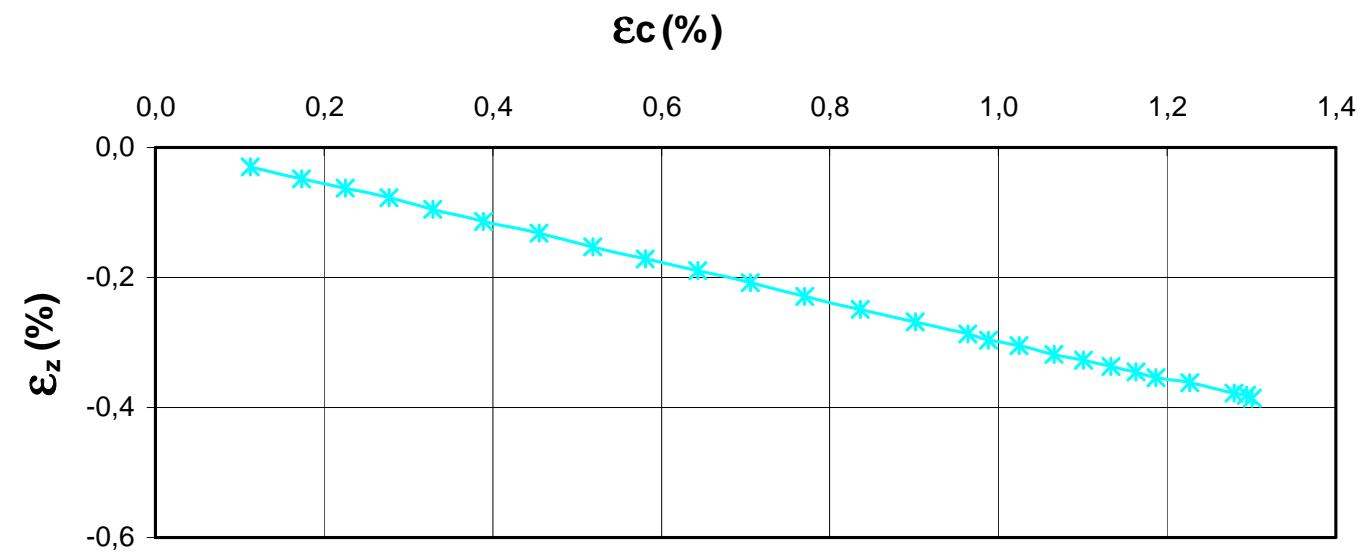

Figura 5.4.2.3 - Gráfico da relação entre as deformações $\varepsilon_{\mathrm{c}}$ e $\varepsilon_{\mathrm{z}}$ para o cilindro assimétrico 6-A.

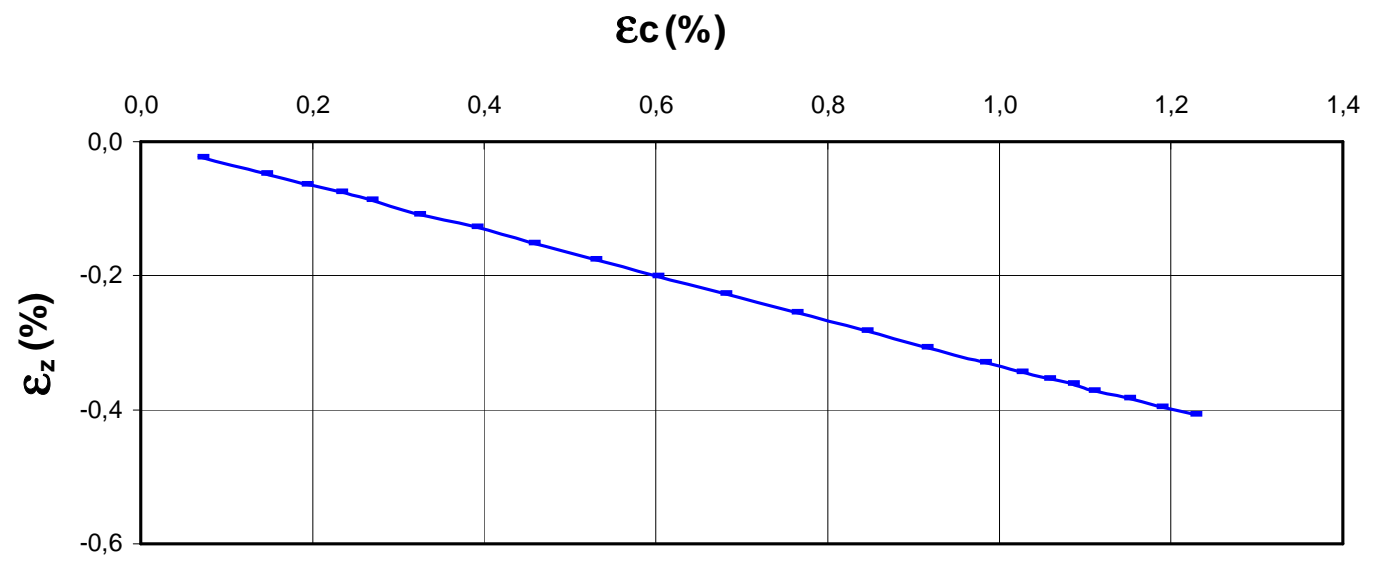

Figura 5.4.2.4 - Gráfico da relação entre as deformações $\varepsilon_{\mathrm{c}}$ e $\varepsilon_{\mathrm{z}}$ para o cilindro assimétrico 7-A.

\subsubsection{Comparação entre deformações circunferencial e longitudinal nos} cilindros simétricos e assimétricos

$\mathrm{Na}$ Tab. 5.4.3.1 estão mostrados os valores do coeficiente de Poisson ( $v$ ) tabulados anteriormente nas Tab. 5.4.1.1 e 5.4.2.1 para análise comparativa entre os cilindros com configuração simétrica e assimétrica. 
Tabela 5.4.3.1 - Valores dos coeficientes de Poisson para os cilindros simétricos e assimétricos.

\begin{tabular}{cccc}
\hline $\begin{array}{c}\text { Cilindros } \\
\text { simétricos }\end{array}$ & $\begin{array}{c}\text { Coeficientes de } \\
\text { Poisson }(v)\end{array}$ & $\begin{array}{c}\text { Cilindros } \\
\text { assimétricos }\end{array}$ & $\begin{array}{c}\text { Coeficientes de } \\
\text { Poisson }(v)\end{array}$ \\
\hline 3-S & 0,34 & 4-A & 0,34 \\
4-S & 0,30 & 5-A & 0,35 \\
5-S & 0,29 & 6-A & 0,30 \\
6-S & 0,32 & 7-A & 0,33 \\
\hline Média & 0,31 & Média & 0,33 \\
\hline Desvio-padrão & 0,02 & Desvio-padrão & 0,02 \\
\hline
\end{tabular}

Dos resultados da Tab. 5.4.3.1 se observa que a média do coeficiente de Poisson para o grupo de cilindros simétricos é cerca de $7 \%$ menor que o obtido para os cilindros com bobinagem assimétrica. Possivelmente uma interpretação inversa pudesse ocorrer se fosse analisada apenas as pressões de ruptura dos cilindros, cerca de $7 \%$ superior para os simétricos, que poderia provocar deformações maiores para os cilindros deste grupo. Contudo, para esta propriedade (Poisson) parece existir influência da configuração de bobinagem, favorecendo o arranjo simétrico, de sorte que as relações entre as deformações nas duas direções sofram influência da disposição das camadas na construção do compósito.

Nas Fig. 5.4.3.1 e 5.4.3.2 são mostrados, respectivamente, os gráficos da relação entre as deformações circunferencial $\left(\varepsilon_{c}\right)$ e longitudinal $\left(\varepsilon_{z}\right)$ com as 4 curvas obtidas da aquisição de dados realizada durante ensaio hidrostático nos cilindros simétricos 3-S, 4-S, 5-S e 6-S e assimétricos 4-A, 5-A, 6-A e 7-A. 


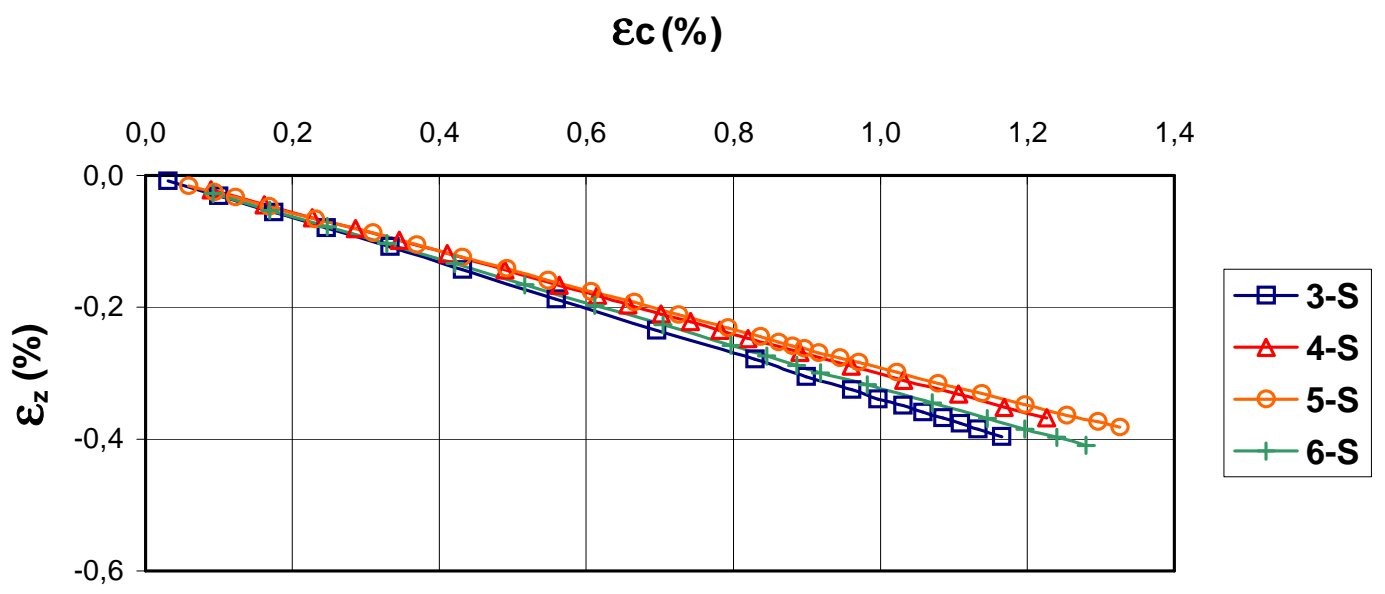

Figura 5.4.3.1 - Gráfico da relação entre as deformações $\varepsilon_{\mathrm{c}}$ e $\varepsilon_{\mathrm{z}}$ para os cilindros simétricos 3-S, 4-S, 5-S e 6-S.

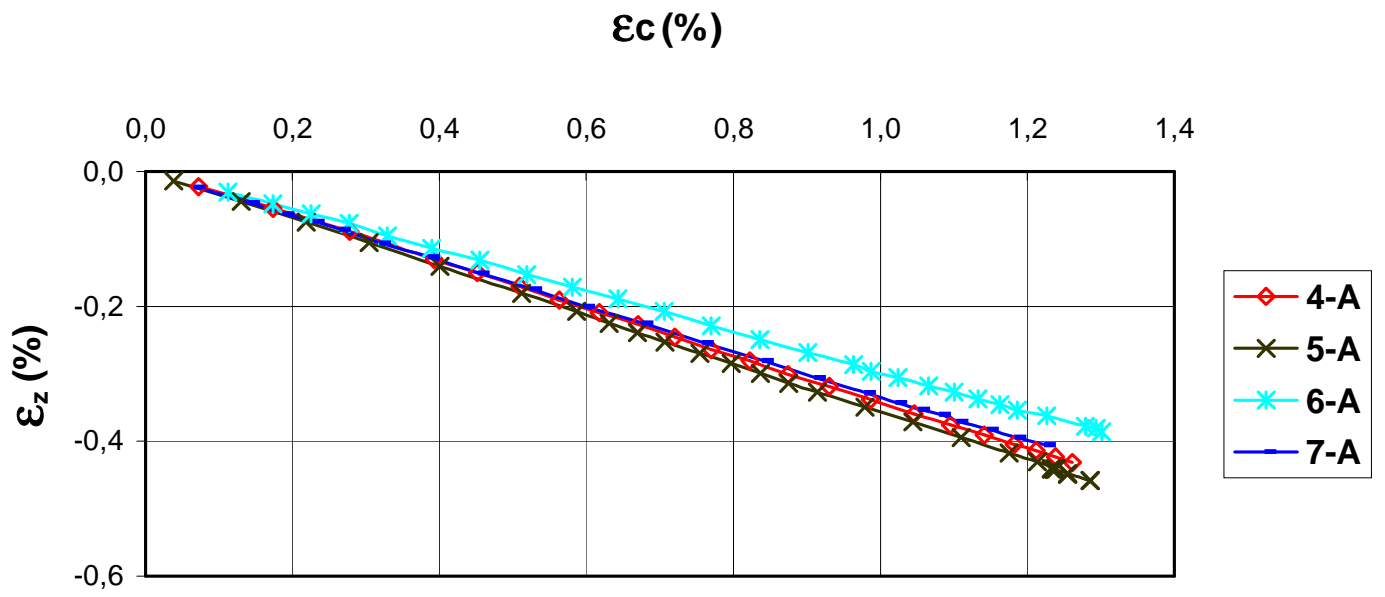

Figura 5.4.3.2 - Gráfico da relação entre as deformações $\varepsilon_{c}$ e $\varepsilon_{z}$ para os cilindros assimétricos 4-A, 5-A, 6-A e 7-A.

Da análise dos gráficos das Fig. 5.4.3.1 e 5.4.3.2 se observa que as curvas da relação entre as deformações obtidas para os cilindros assimétricos têm em média uma inclinação maior que as dos cilindros simétricos, confirmando o comportamento diferente das deformações dos cilindros quando submetidos ao carregamento hidrostático. 


\subsection{Ensaio hidrostático}

Nas Tab. 5.4.1 e 5.4.2 são mostrados, respectivamente, os valores da pressão de ruptura $\left(P_{\text {rup }}\right)$ dos cilindros submetidos ao ensaio hidrostático para os grupos simétrico e assimétrico.

Tabela 5.5.1 - Valores da pressão de ruptura dos cilindros simétricos.

\begin{tabular}{cc}
\hline Cilindros & $\begin{array}{c}\text { Pressão de } \\
\text { ruptura }\end{array}$ \\
simétricos & Prup (MPa) $^{\text {res }}$ \\
\hline 1-S & 22,5 \\
2-S & 22,5 \\
3-S & 23,0 \\
4-S & 21,5 \\
5-S & 21,5 \\
6-S & 23,0 \\
7-S & 23,5 \\
\hline Média & 22,5 \\
\hline Desvio & 0,8 \\
padrão &
\end{tabular}

Tabela 5.5.2 - Valores da pressão de ruptura dos cilindros assimétricos.

\begin{tabular}{|c|c|}
\hline $\begin{array}{c}\text { Cilindros } \\
\text { assimétricos }\end{array}$ & $\begin{array}{c}\text { Pressão de } \\
\text { ruptura } \\
\text { Prup (MPa) }\end{array}$ \\
\hline $1-A$ & 21,0 \\
\hline $2-A$ & 20,5 \\
\hline 3-A & 20,5 \\
\hline 4-A & 21,5 \\
\hline $5-A$ & 21,0 \\
\hline $6-A$ & 22,0 \\
\hline $7-A$ & 20,0 \\
\hline Média & 20,9 \\
\hline $\begin{array}{l}\text { Desvio } \\
\text { padrão }\end{array}$ & 0,7 \\
\hline
\end{tabular}


$\mathrm{Na}$ Fig. 5.5.1 é mostrado o gráfico com os resultados dos ensaios hidrostáticos, no qual a ruptura ocorreu para pressão média de 22,5 $\mathrm{MPa}$, representado pela linha cheia, para os cilindros simétricos e para a pressão média de 20,9 MPa, representado pela linha traço-dois-pontos, para os cilindros assimétricos. Os pontos correspondentes aos valores de pressão de ruptura dos cilindros com configuração simétrica e assimétrica estão assinalados, respectivamente, pelo símbolos losango e quadrado.

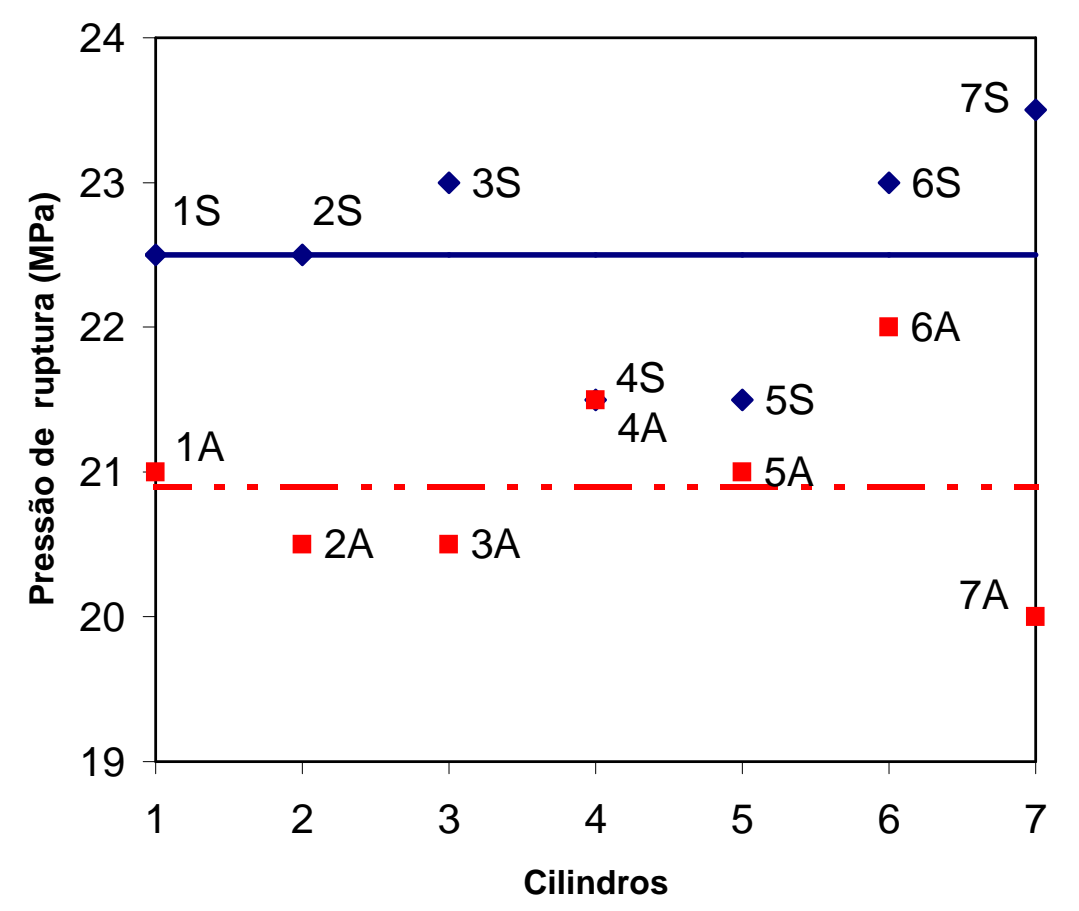

— PRESSÃO MÉDIA DE RUPTURA DE 22,5 MPa PARA OS CILINDROS SIMÉTRICOS
- PRESSÃO MÉDIA DE RUPTURA DE 20,9 MPa PARA OS CILINDROS ASSIMÉTRICOS

Figura 5.5.1 - Gráfico dos resultados dos ensaios hidrostáticos dos cilindros simétricos e assimétricos.

Dos resultados das pressões de ruptura das Tab. 5.5.1 e 5.5.2 obtidas nos colapsos dos cilindros e do gráfico da Fig. 5.5.1, observa-se que a capacidade de suportar o carregamento hidrostático é diferente em cada grupo de cilindros e está relacionada com a característica de simetria dos componentes.

Numa comparação entre as pressões médias de ruptura verifica-se que os cilindros assimétricos possuem média $7 \%$ inferior à média obtida para os cilindros simétricos. 
Para analisar se os dois valores médios de pressão de ruptura obtidos pertencem a mesma população ou a populações distintas em razão da diferença de configurações de bobinagem, utilizou-se o teste de hipóteses, que compara parâmetros equivalentes das populações envolvidas, nas quais têm-se duas ou mais amostras em princípio de populações distintas. O objetivo desta análise é avaliar se a diferença dos resultados obtidos está associada ao fato dos dois grupos de cilindros terem sido fabricados com configurações de bobinagem distintas.

As hipóteses a serem testadas são : $\mathrm{H}_{0}, \mu_{\mathrm{s}}=\mu_{\mathrm{a}}$ ou $\mathrm{H}_{1}, \mu_{\mathrm{s}} \neq \mu_{\mathrm{a}}$, sendo $\mu_{\mathrm{s}} \mathrm{e}$ $\mu_{\mathrm{a}}$ as médias das pressões de ruptura das populações de cilindros fabricados com configuração simétrica e assimétrica, respectivamente. Os desvios-padrão das duas populações são desconhecidos, mas admiti-se que sejam iguais, ou seja, $\sigma_{\mathrm{s}}=\sigma_{\mathrm{a}}$.

Neste caso, deve-se substituir o desvio-padrão desconhecido por uma estimativa $\mathrm{Sp}^{2}$ (média ponderada das variâncias amostrais). As hipóteses então podem ser testadas usando-se a distribuição $\boldsymbol{t}$ de Student relacionada com a estimativa $s_{p}^{2}$, a qual tem $\left(n_{s}+n_{a}-2\right)$ graus de liberdade, sendo $n_{s}$ e $n_{a}$ o número de elementos das amostras das populações de cilindros com configuração simétrica e assimétrica, respectivamente. A estatística $t$ é calculada pela relação: $\boldsymbol{t}=\left(\mathrm{x}_{\mathrm{s}}-\mathrm{x}_{\mathrm{a}}\right) /\left(\mathrm{s}_{\mathrm{p}} \cdot\left(1 / \mathrm{n}_{\mathrm{s}}+1 / \mathrm{n}_{\mathrm{a}}\right)^{1 / 2}\right)$, sendo $\mathrm{x}_{\mathrm{s}}$ e $\mathrm{x}_{\mathrm{a}}$ as médias das pressões de ruptura das amostras de cilindros fabricados com configuração simétrica e assimétrica, respectivamente e $s_{p}$ a média ponderada dos desvios-padrão das amostras, a qual é dada por: $s_{p}=\left(\left(\left(n_{s}-1\right) \cdot s_{s}^{2}+\left(n_{a}-1\right) \cdot s_{a}^{2}\right) /\left(n_{s}+n_{a}-2\right)\right)^{1 / 2}$, sendo $s_{s}$ e $s_{a}$ os desvios-padrão das amostras dos cilindros simétricos e assimétricos, respectivamente (Costa Neto, 1977).

Para testar as hipóteses que $\mathrm{H}_{0}, \mu_{\mathrm{s}}=\mu_{\mathrm{a}}$ ou $\mathrm{H}_{1}, \mu_{\mathrm{s}} \neq \mu_{\mathrm{a}}$, utiliza-se a equação da estatística $\boldsymbol{t}$, obtendo-se o valor de $\boldsymbol{t}$ igual a 3,991. Da tábua de valores da distribuição $\boldsymbol{t}$ de Student, para o nível de significância de 1\%, ou seja, um erro de $1 \%$ e 12 graus de liberdade, o valor crítico de $t$ é 2,681.

Como o valor crítico é inferior ao calculado, rejeita-se a hipótese $\mathrm{H}_{0}$ que considerava a média das pressões de ruptura das duas amostras iguais, em favor de $\mathrm{H}_{1}$ que as considerava diferentes. Portanto, os dois grupos de cilindros 
possuem valores médios diferentes da pressão de ruptura e pertencentes a populações distintas.

Como admitiu-se anteriormente que os desvios-padrão das populações eram iguais, realizou-se um teste que permite analisar se tal suposição é válida com base nas variâncias das duas amostras.

O teste da igualdade das variâncias das duas populações pode ser realizado aplicando-se a distribuição $\boldsymbol{F}$ de Snedecor. Para testar a hipótese $\mathrm{H}_{0}$, $\sigma_{\mathrm{s}}{ }^{2}=\sigma_{\mathrm{a}}{ }^{2}$, utiliza-se a relação $\boldsymbol{F}_{\mathrm{ns}-1, \mathrm{na}-1}=\mathrm{s}_{\mathrm{s}}{ }^{2} / \mathrm{s}_{\mathrm{a}}{ }^{2}$, obtendo-se o valor de $\boldsymbol{F}$ igual a 1,31. Da tábua de valores da distribuição $\boldsymbol{F}$ de Snedecor, para o nível de significância de 1\% e 6 graus de liberdade, uma vez que cada grupo de cilindros possui sete elementos, o valor crítico de $\boldsymbol{F}$ é 8,47. Como o valor crítico é superior ao calculado, a hipótese de que $\sigma_{\mathrm{s}}{ }^{2}=\sigma_{\mathrm{a}}{ }^{2}$ é válida (Costa Neto, 1977).

\subsection{Análise macroscópica da fratura}

Os dois grupos de cilindros ensaiados foram levados ao colapso, sem que fosse observado qualquer vazamento de fluido durante a pressurização, tanto nas regiões de vedação entre o cilindro e o dispositivo de ensaio hidrostático, quanto pelo corpo do cilindro. Esse comportamento permitiu que os ensaios fossem realizados sem prejuízo nos dados de pressão de ruptura e deformações obtidos que um vazamento prematuro de fluido poderia causar. 


\subsubsection{Cilindros simétricos}

Nas figuras a seguir são mostrados detalhes da fratura de cilindros com bobinagem simétrica após o ensaio hidrostático.

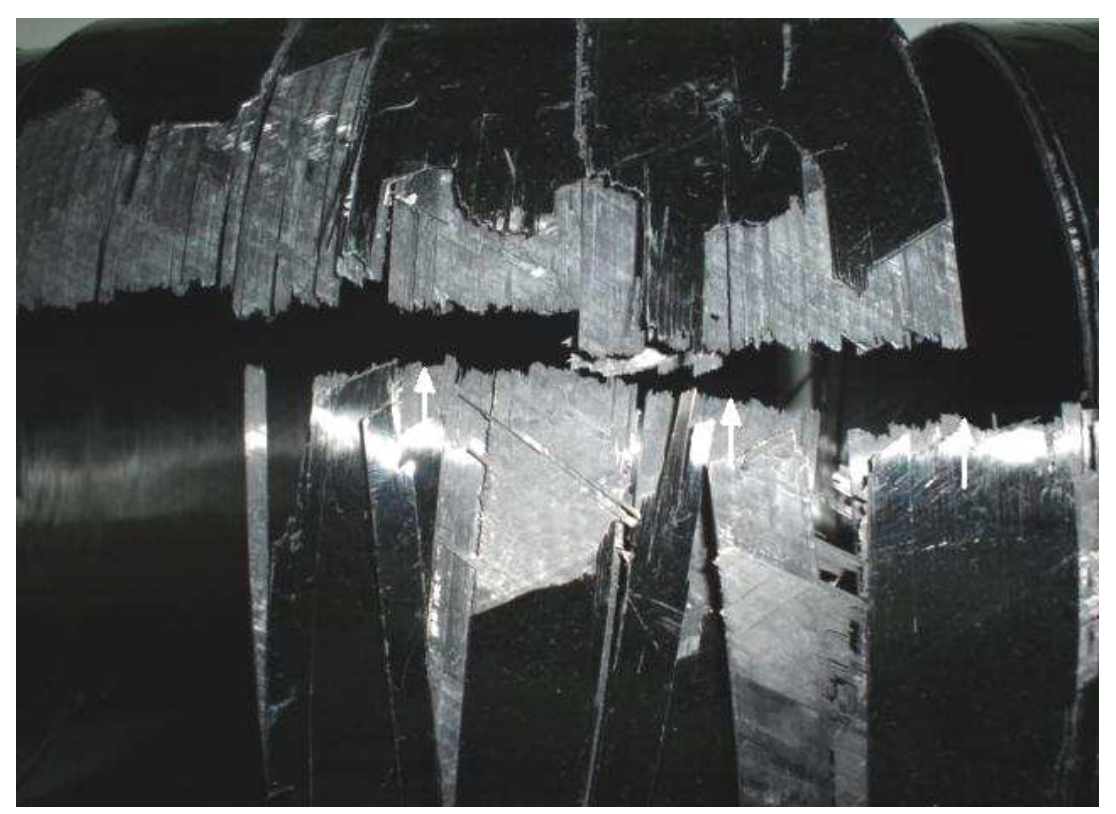

Figura 5.6.1.1 - Aspecto final do cilindro 1-S após o ensaio hidrostático.

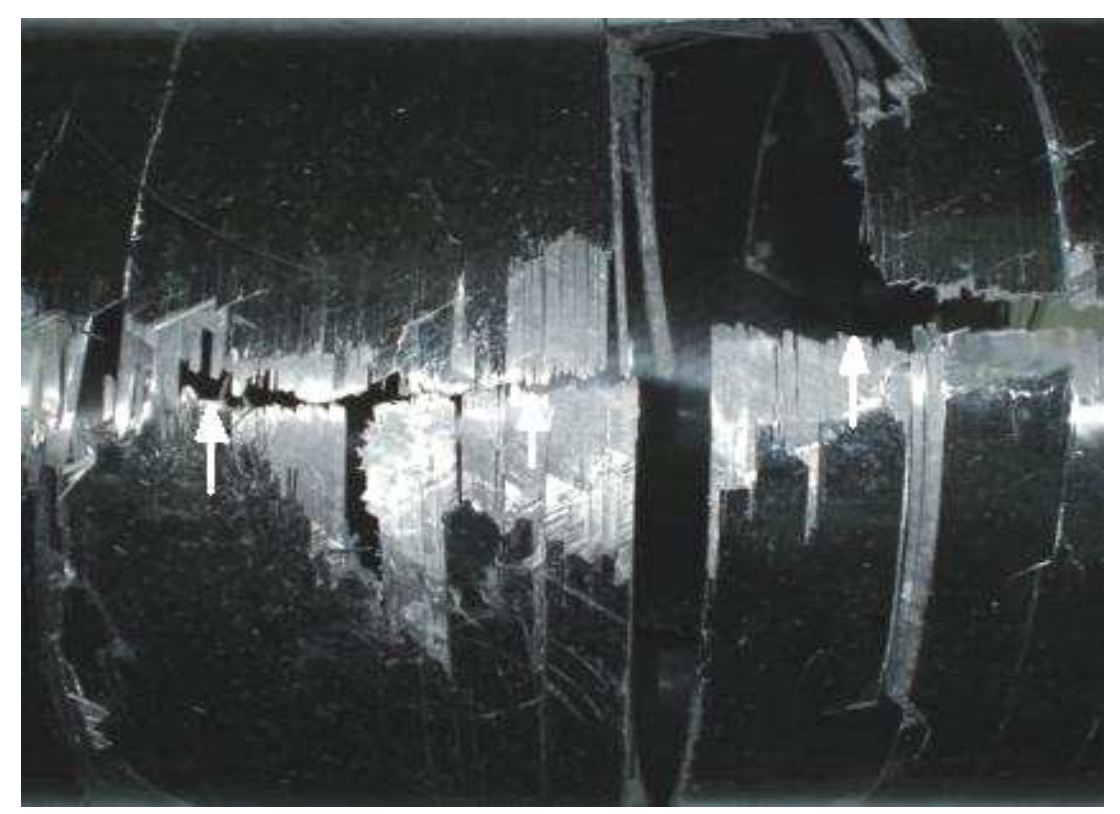

Figura 5.6.1.2 - Aspecto final do cilindro 2-S após o ensaio hidrostático. 


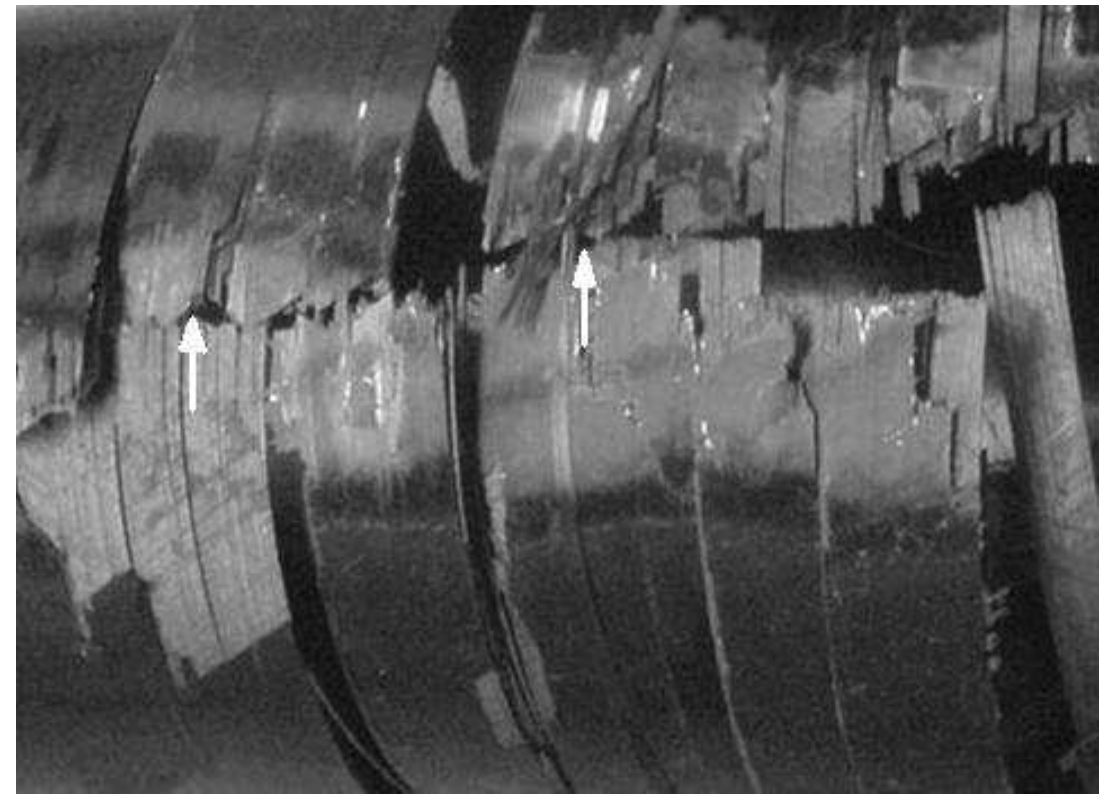

Figura 5.6.1.3 - Aspecto final do cilindro 3-S após o ensaio hidrostático.

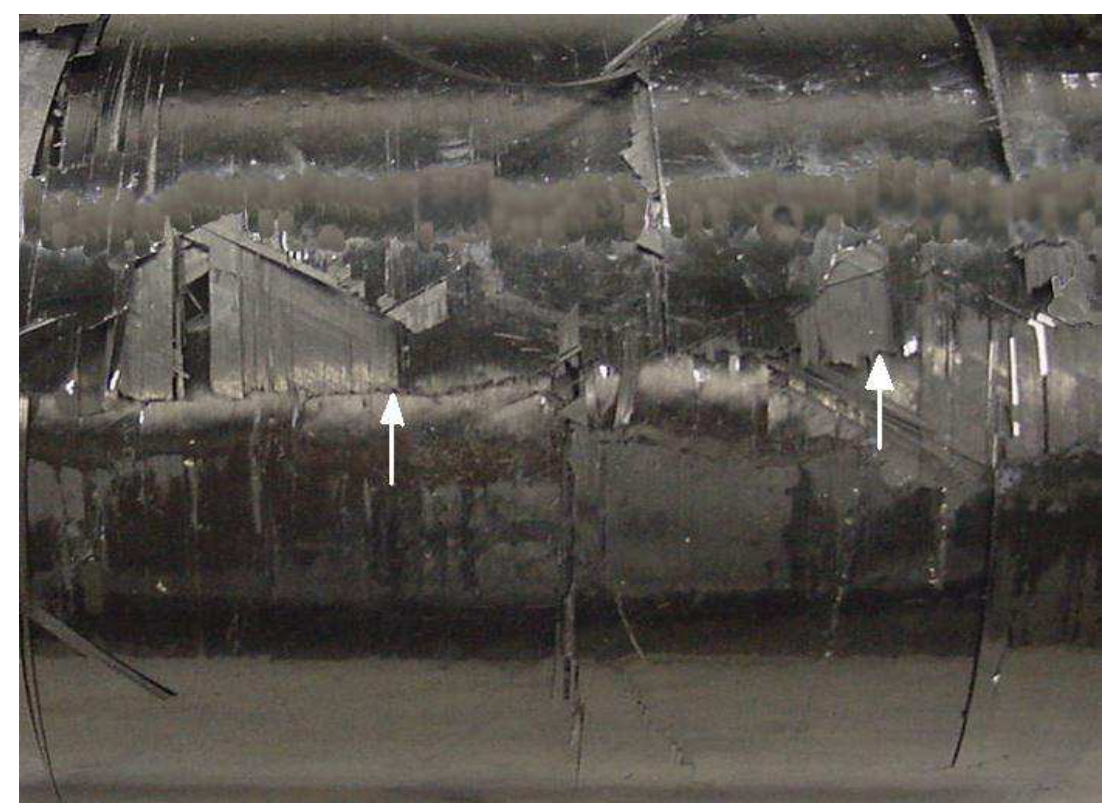

Figura 5.6.1.4 - Aspecto final do cilindro 4-S após o ensaio hidrostático. 


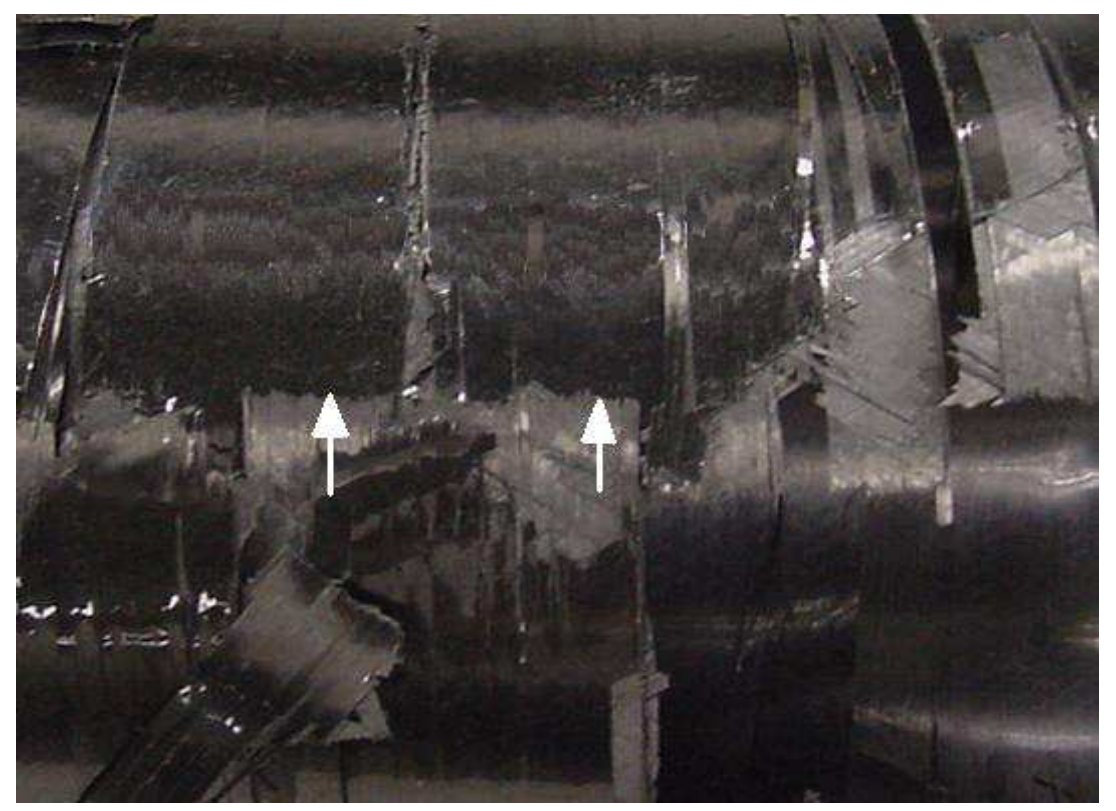

Figura 5.6.1.5 - Aspecto final do cilindro 6-S após o ensaio hidrostático.

Observa-se nas figuras que os aspectos macroscópicos das falhas nos cilindros com configuração simétrica apresentaram uma trinca principal longitudinal (indicada por setas), característica de ensaio hidrostático, e trincas transversais secundárias produzindo elevada delaminação das camadas circunferenciais, que surgem como conseqüência da trinca longitudinal.

O fato de ocorrer, como principal conseqüência da fratura, a trinca longitudinal, vem da construção da estrutura cilíndrica escolhida para este estudo. Como os cilindros possuem extremidades abertas não ocorre o estado bidirecional de tensões, como a que ocorre em vasos de pressão, por exemplo, surgindo apenas a tensão circunferencial que causa a trinca longitudinal. 


\subsubsection{Cilindros assimétricos}

Nas figuras a seguir são mostrados detalhes da fratura de cilindros com bobinagem assimétrica após o ensaio hidrostático.

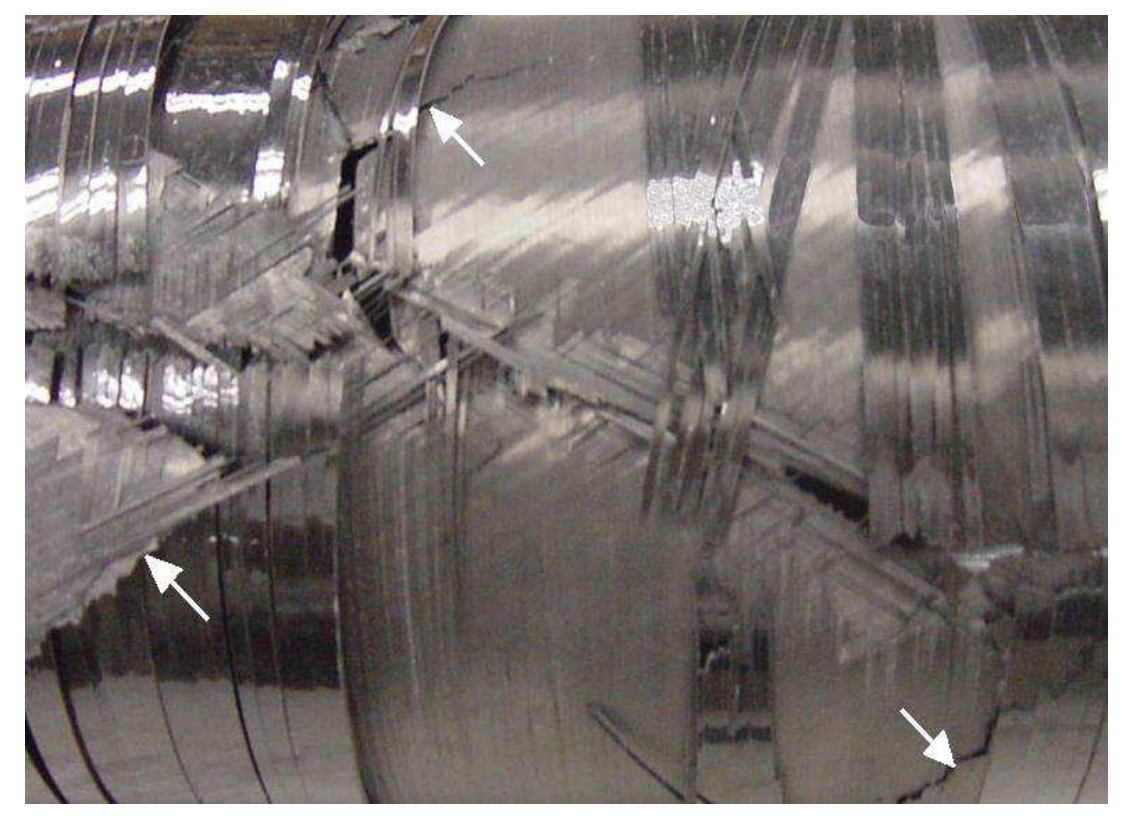

Figura 5.6.2.1 - Aspecto final do cilindro 2-A após ensaio hidrostático.

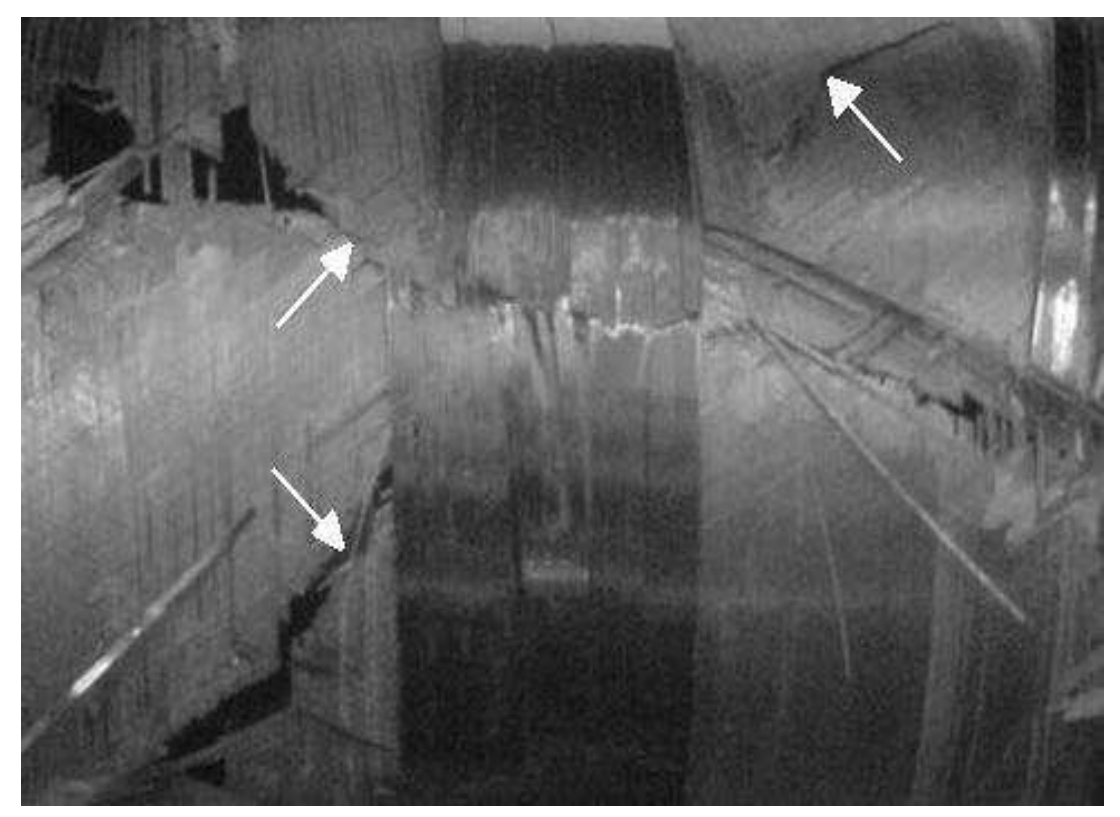

Figura 5.6.2.2 - Aspecto final do cilindro 4-A após ensaio hidrostático. 


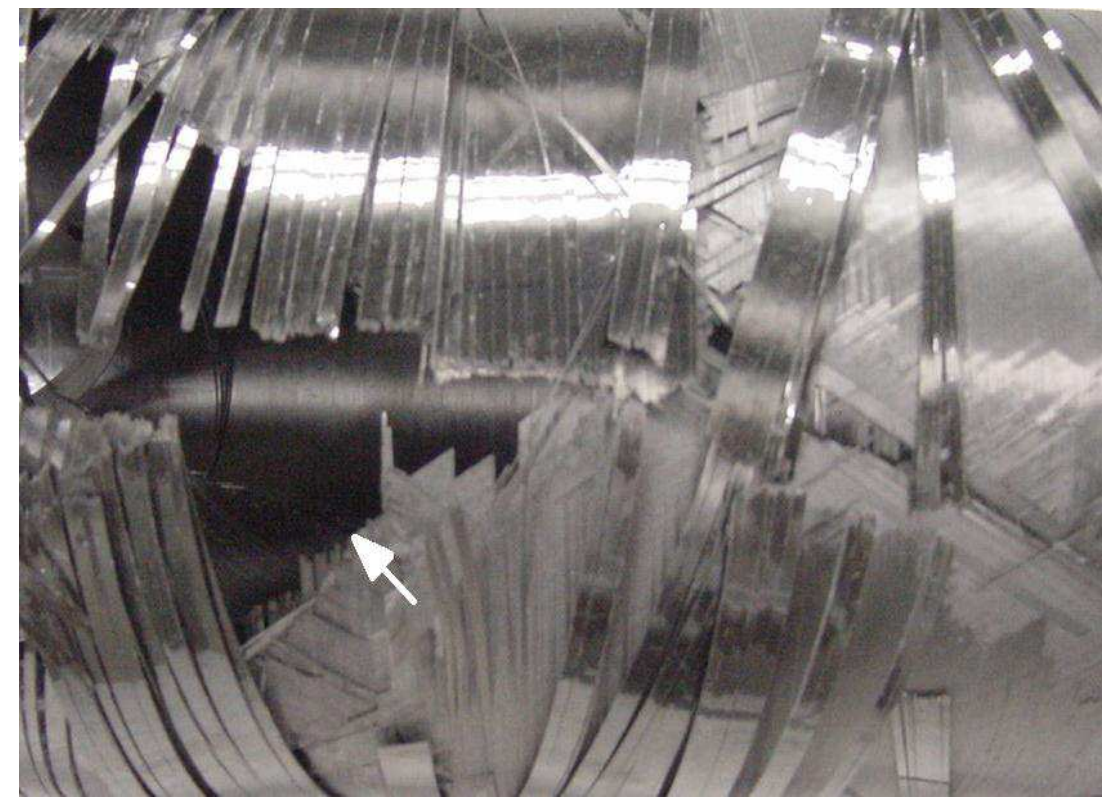

Figura 5.6.2.3 - Aspecto final do cilindro 5-A após ensaio hidrostático.

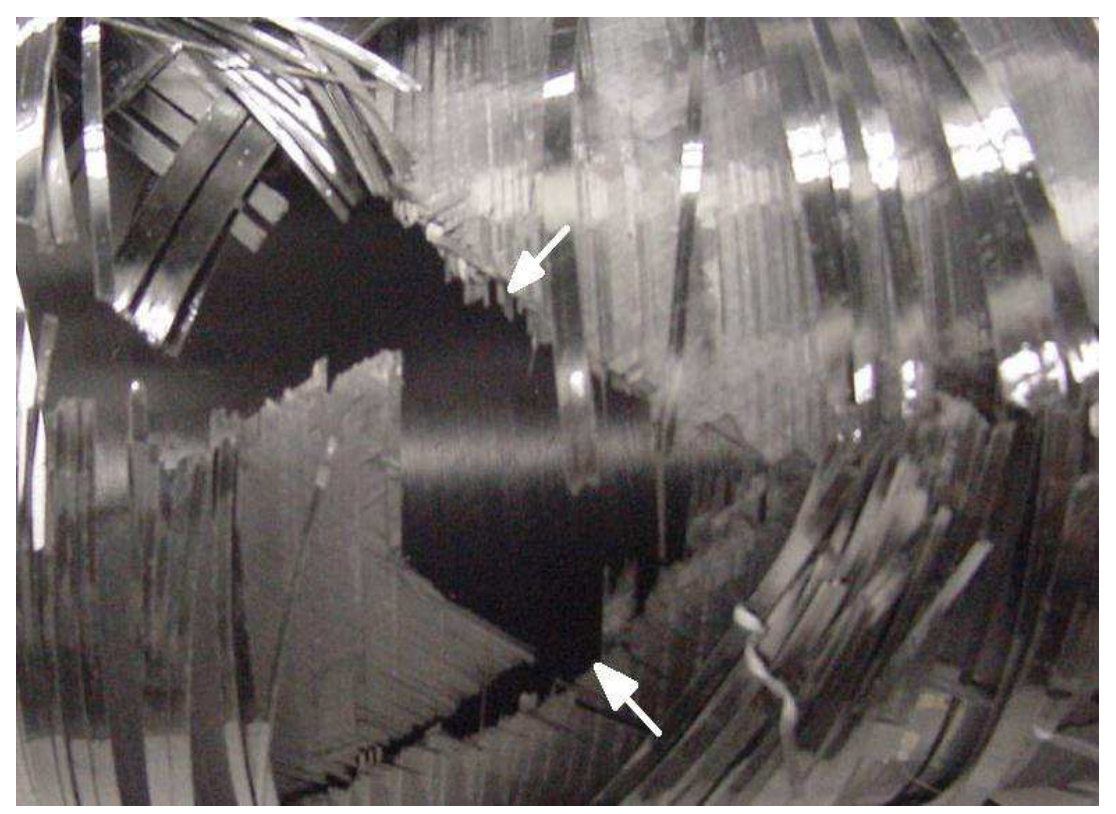

Figura 5.6.2.4 - Aspecto final do cilindro 6-A após ensaio hidrostático. 


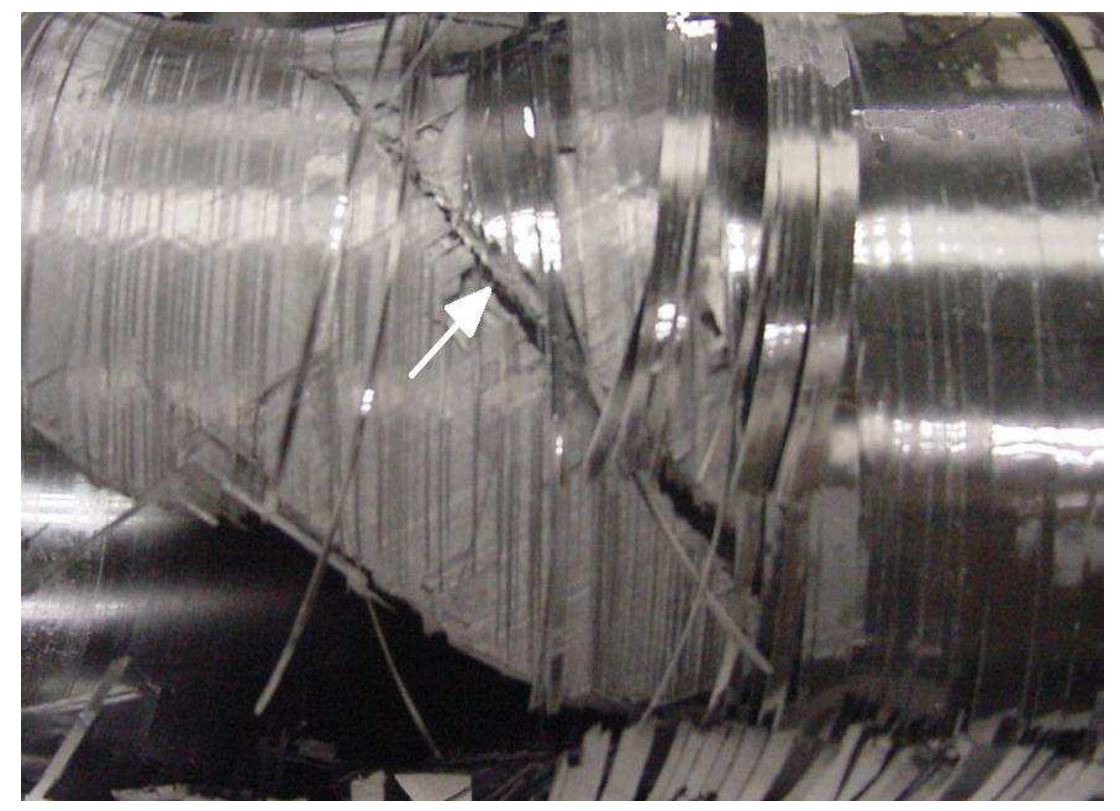

Figura 5.6.2.5 - Aspecto final do cilindro 7-A após ensaio hidrostático.

Observa-se nas Fig. 5.6.2.1, 5.6.2.2, 5.6.2.3, 5.6.2.4 e 5.6.2.5, que os cilindros com configuração assimétrica apresentaram trincas diagonais (indicadas por setas) e delaminação das camadas circunferenciais mais externas. Verificou-se que as trincas diagonais não obedeceram um caminho preferencial dado possivelmente pelo ângulos de $-30^{\circ}$ e $+30^{\circ}$ utilizados na bobinagem helicoidal como poderia se deduzir. $\mathrm{O}$ ângulo relativo ao eixo longitudinal dos cilindros assimétricos aproximou-se de $45^{\circ}$ por causa do surgimento de cisalhamento.

\subsubsection{Comparação macroscópica das fraturas}

Assim como relatado por Mertiny et al. (2003), no qual foram estudados cilindros com dois tipos diferentes de configurações assimétricas, comparando-se as figuras que indicam as falhas dos cilindros com bobinagem simétrica com aquelas dos cilindros com bobinagem assimétrica, observa-se que as diferentes configurações exibem comportamentos diferentes da falha sob as mesmas condições de carregamento.

Por causa da configuração assimétrica, o laminado possui tensões residuais que induzem torsões nas camadas (Hoover et al., 1997; Hudson et al., 1998). No presente estudo, estas torsões provocaram o aparecimento de tensões interlaminares que podem ter contribuído para que os cilindros assimétricos 
sofressem colapso em pressões inferiores e com um modo característico de falha que apresentou trincas em ângulos próximos de $45^{\circ}$, indicando a presença de cisalhamento. A trinca longitudinal observada nos dois tipos de configuração é característica de ensaio hidrostático em cilindros de extremidades abertas.

Evidências obtidas dos experimentos mostraram que as configurações de bobinagem de cada grupo possuem relação direta com suas respectivas pressões de ruptura e modos de falha.

\subsection{Caracterização microestrutural}

Os cilindros fabricados para o estudo do presente trabalho fazem uso de tecnologia que produz compósitos estruturais de alto desempenho e que necessitam portanto de uma avaliação da microestrutura para análise dos materiais constituintes. Observações que envolvem a impregnação e a homogeneidade desta impregnação são registros que devem ser feitos. Presença de vazios, suas localizações e morfologia é outra característica que determina a qualidade do compósito, além da avaliação da interface entre as camadas, especialmente em relação àquelas que possuem ângulos diferentes, como as camadas circunferencial e helicoidal.

Nas Fig. 5.7.1 e 5.7.2 são mostradas, respectivamente, micrografias das seções transversal e longitudinal de cilindro com configuração de bobinagem simétrica, e nas Fig. 5.7 .3 e 5.7.4, respectivamente, micrografias da seção transversal e longitudinal de cilindro com configuração de bobinagem assimétrica. 


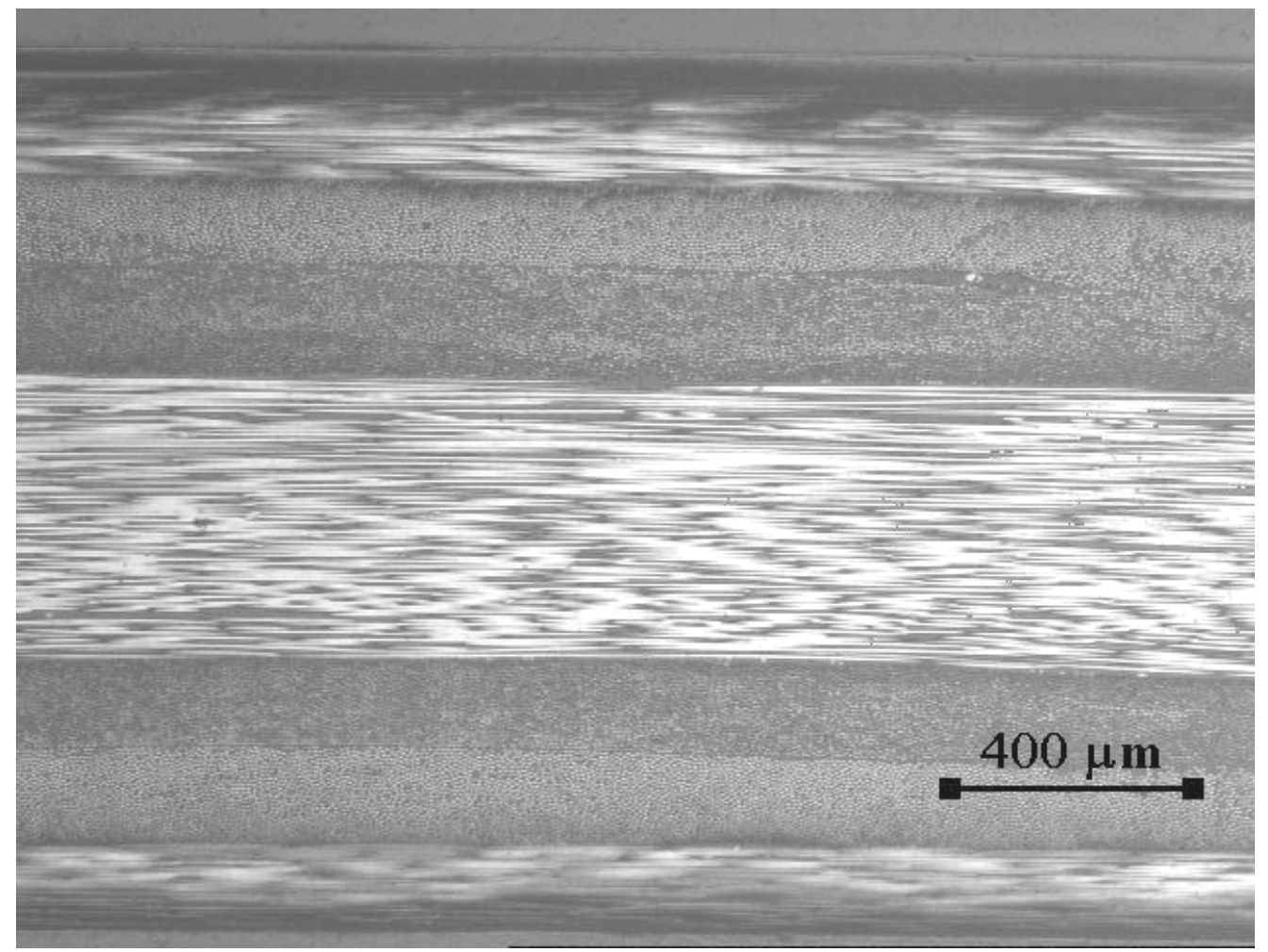

Figura 5.7.1 - Imagem típica da seção transversal de cilindro simétrico.

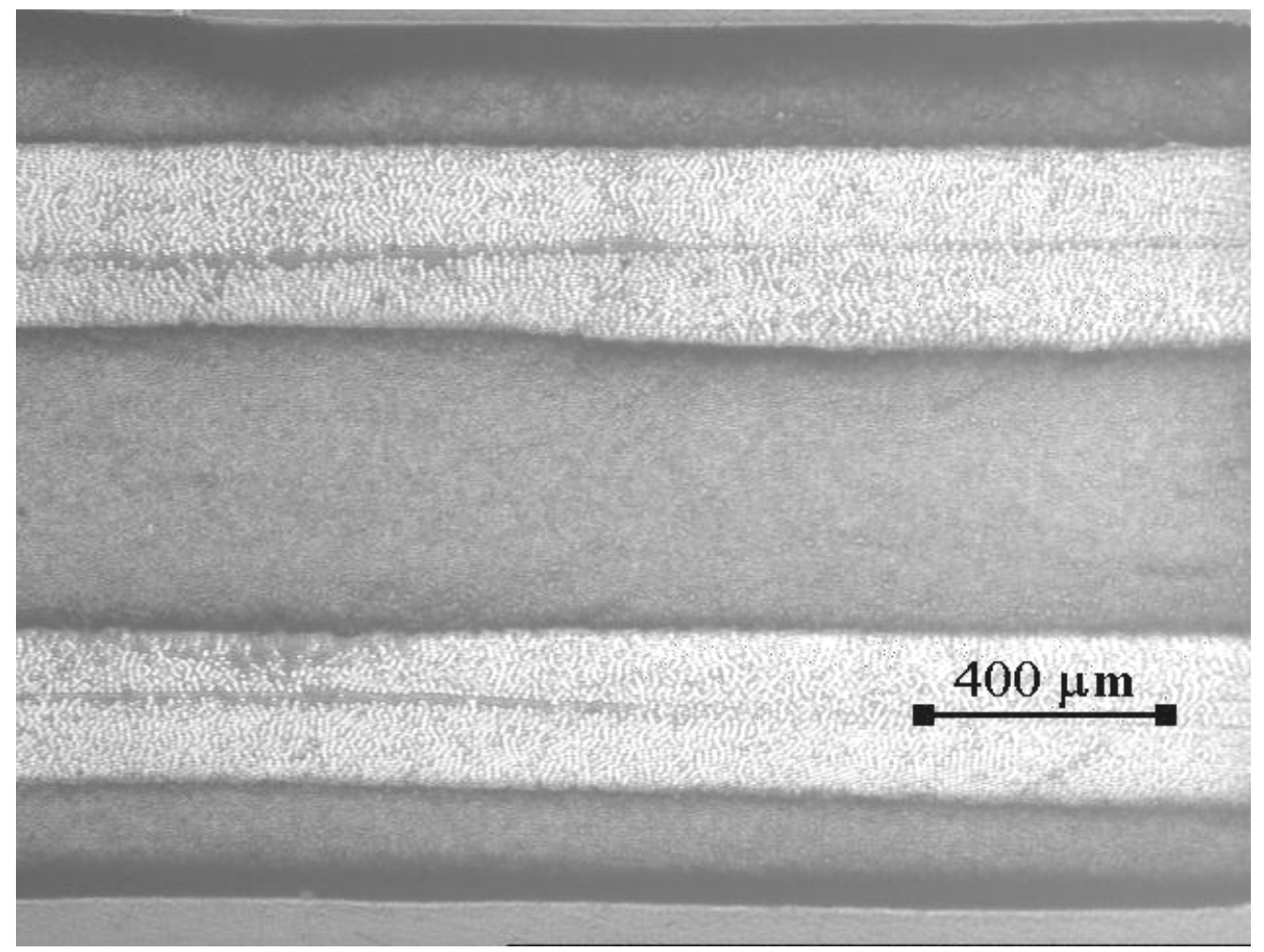

Figura 5.7.2 - Imagem típica da seção longitudinal de cilindro simétrico. 


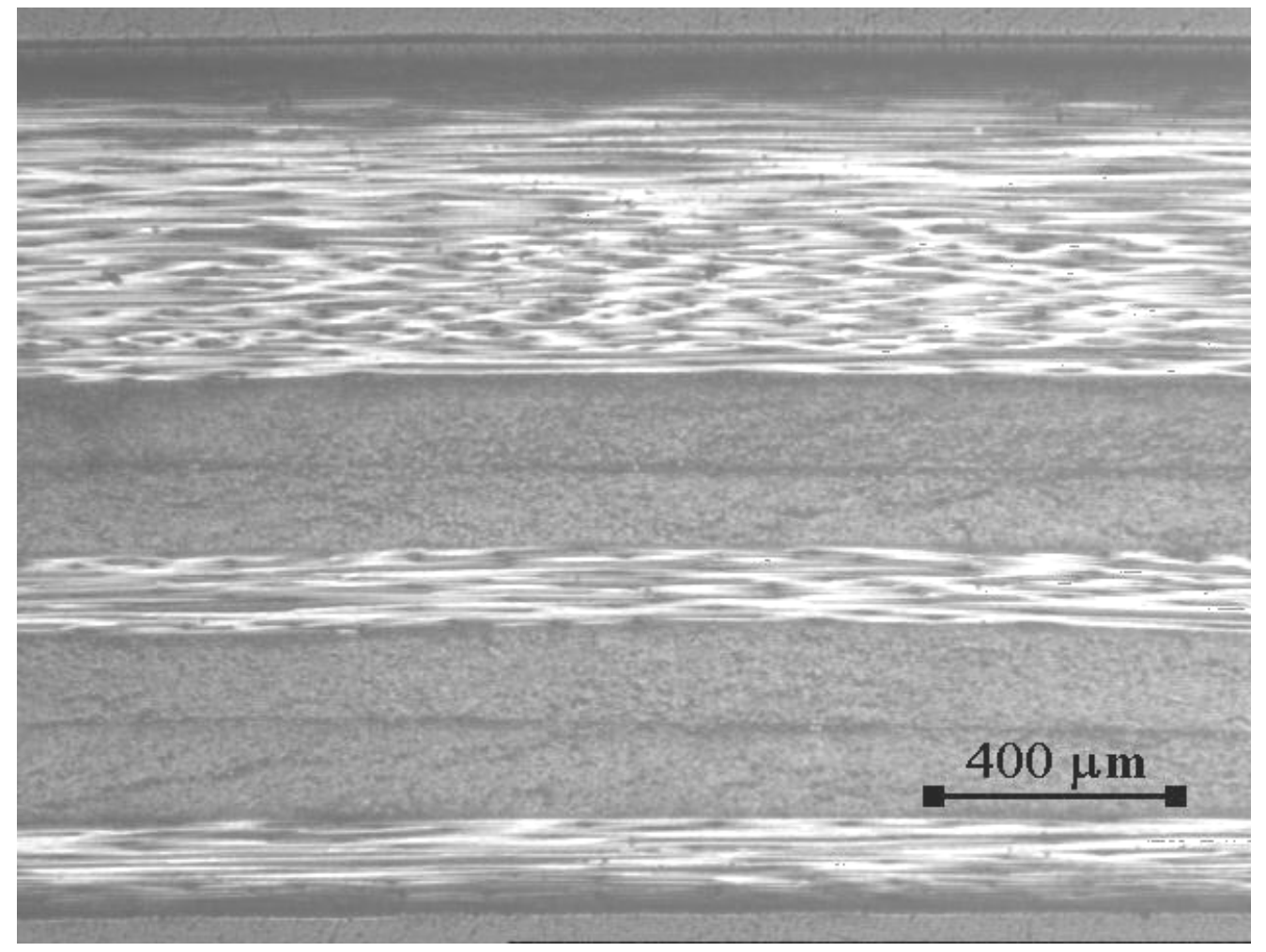

Figura 5.7.3 - Imagem típica da seção transversal de cilindro assimétrico.

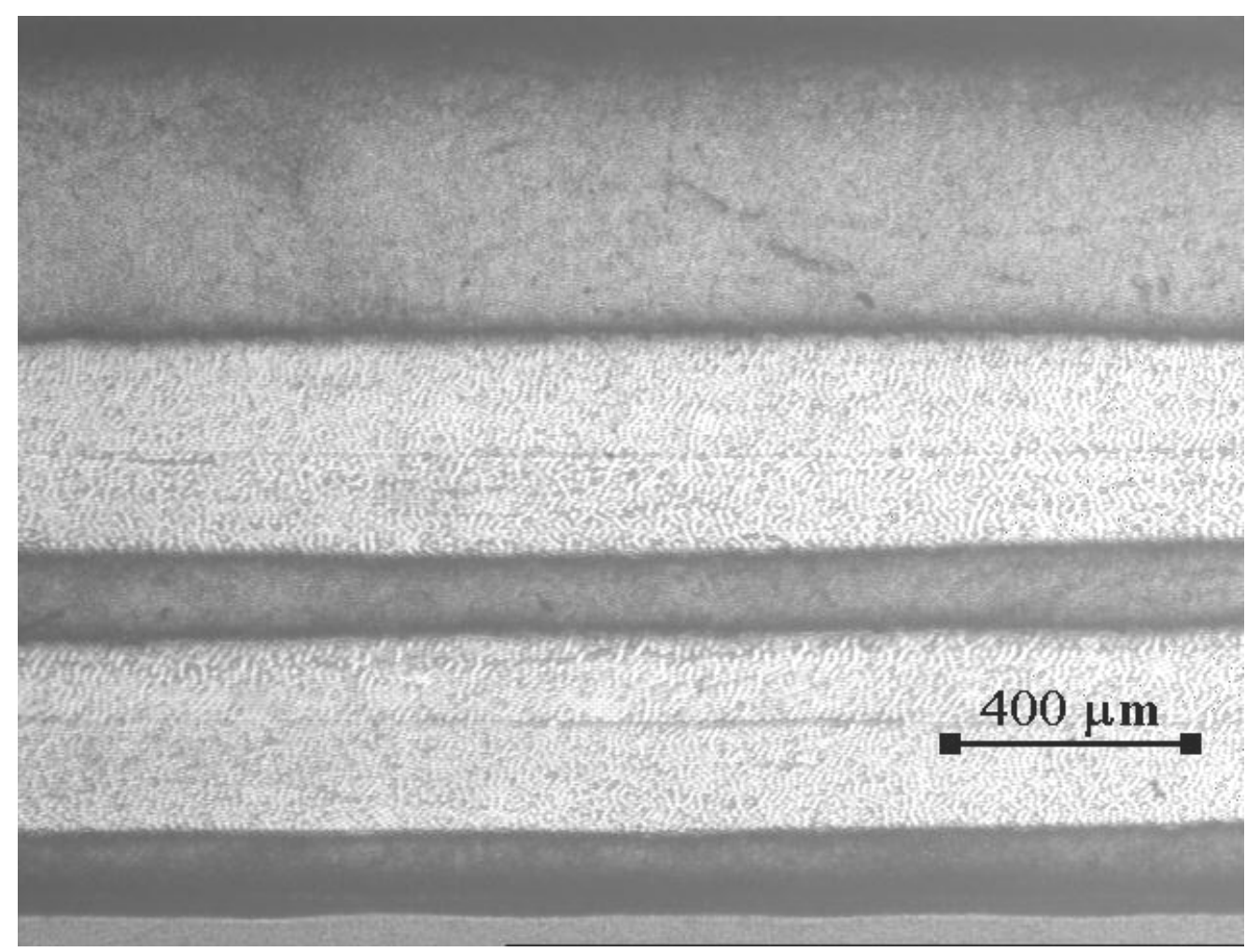

Figura 5.7.4 - Imagem típica da seção longitudinal de cilindro assimétrico. 
Analisando-se as Fig. 5.7.1 e 5.7.2 é possível verificar a distribuição das camadas conforme a configuração simétrica $\left[90 \% /-30 \%+30^{\circ} / 90^{\circ}{ }_{2}\right.$ s. A parte inferior de cada figura representa a primeira camada de fibra depositada sobre o molde durante a fabricação do cilindro, ou seja, a camada circunferencial mais interna. Entre as camadas se observa linhas que definem as interfaces, nas quais ocorrem a mudança de ângulo das fibras, excetuando-se a região central, de maior espessura, na qual estão posicionadas quatro camadas de fibra de mesmo ângulo que impossibilitam a formação da linha de interface.

Nas micrografias das Fig. 5.7.3 e 5.7.4 a assimetria é facilmente identificada observando-se as primeiras e as últimas camadas conforme a configuração assimétrica $\left[90 \% /-30 \%+30^{\circ} / 90^{\circ} /+30 \% /-30 \% / 90^{\circ}\right]_{\mathrm{T}}$. Novamente a parte inferior de cada figura representa a primeira camada de fibra depositada sobre o molde. Nestas imagens as regiões de maior espessura estão posicionadas mais externamente, representando as quatro camadas de fibra de ângulo $90^{\circ}$.

Nas Fig. 5.7.5 e 5.7.6 são mostradas imagens com detalhes das camadas helicoidais e circunferencial, respectivamente.

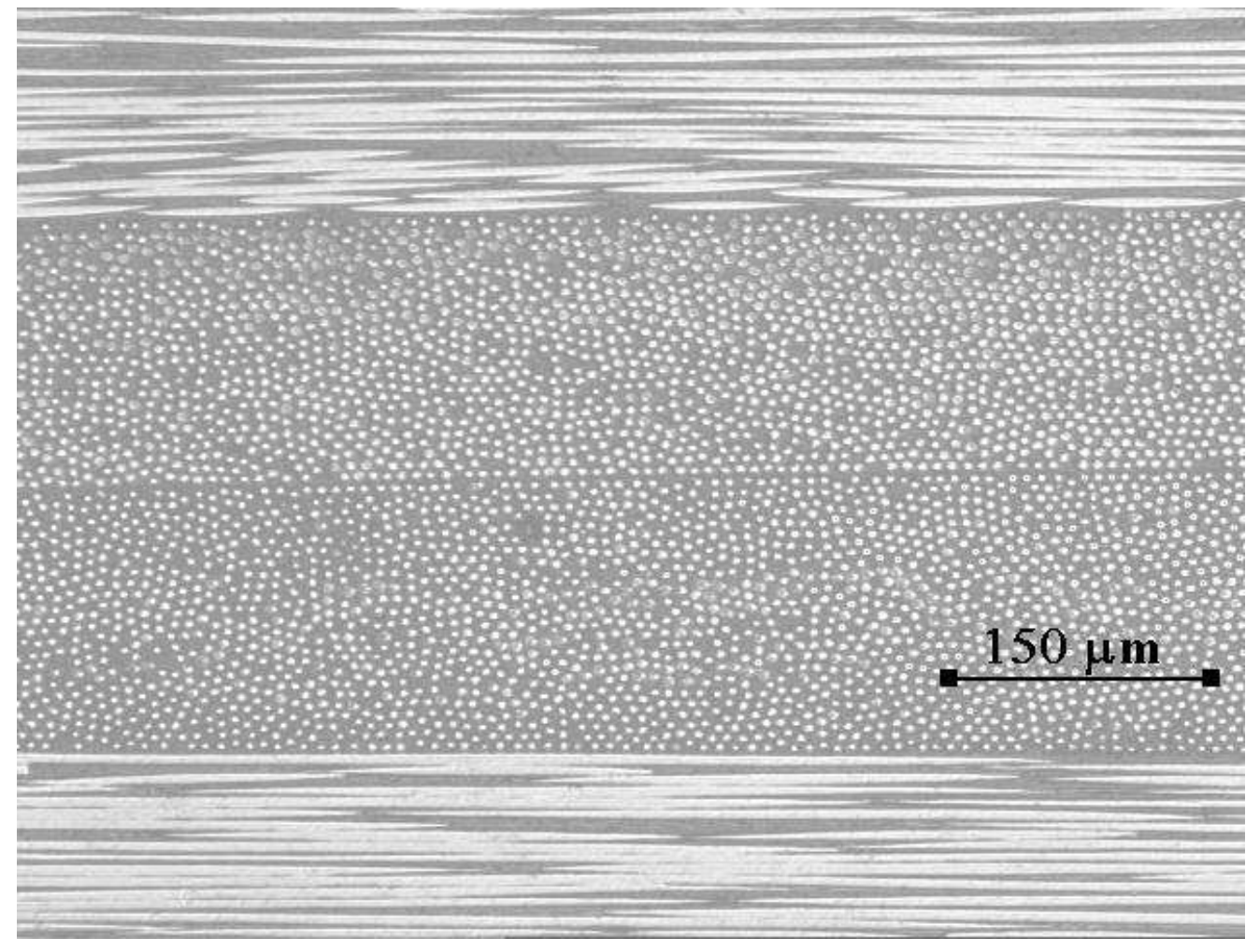

Figura 5.7.5 - Detalhe das camadas helicoidais no corte da seção transversal do cilindro. 


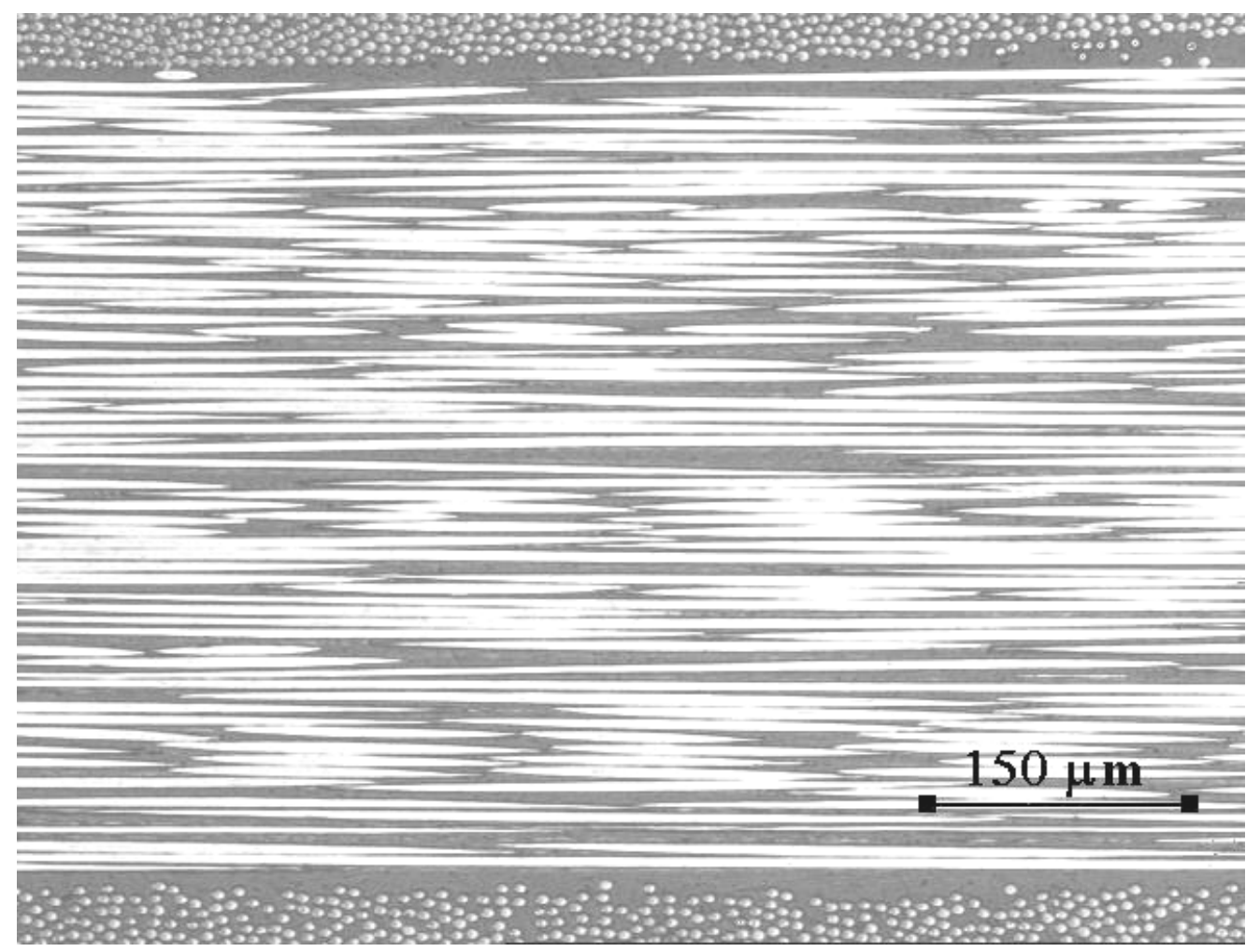

Figura 5.7.6 - Detalhe das camadas circunferenciais no corte da seção transversal do cilindro.

Nestas figuras é possível identificar uma excelente impregnação das fibras pela resina, caracterizadas pela cor cinza escuro envolvendo os filamentos de cor cinza mais claro, não havendo a presença de vazios nas regiões analisadas. Caso houvesse vazios, a característica que mais identifica a presença destas irregularidades é a formação de áreas escuras, próximo do preto, que dependendo da localização apresentariam morfologias diferentes, sendo esféricos quando localizados no interior das camadas (intralaminar) e alongados quando situados na interface das camadas (interlaminar) (Marinucci \& Andrade, 2003). A ausência de vazios nas amostras analisadas foi resultado do rigoroso controle dos parâmetros do processo de fabricação dos cilindros, confirmadas pelos resultados obtidos, que estão com valores médios próximos de 1,2\%.

Para determinação da relação raio-espessura $(r / t)$, foram feitas oito medidas de espessura para as camadas helicoidais e cinco medidas para as camadas circunferenciais, apoiadas, respectivamente, nas Fig. 5.7.5 e 5.7.6, obtendo-se nesta ordem os valores de $142 \pm 4 \mu \mathrm{m}$ e $108 \pm 3 \mu \mathrm{m}$. Portanto para o 
raio do cilindro objeto deste estudo, a relação $r / t$ foi de 80 , muito próxima do valor estimado de 75 , feita na definição da configuração de bobinagem no item 4.2.

\subsection{Análise das tensões}

Utilizando-se recursos do programa de elementos finitos ANSYS, analisou-se as tensões resultantes do carregamento das pressões médias de ruptura de 22,5 MPa e 20,5 MPa, respectivamente, dos cilindros com bobinagens simétrica e assimétrica. Os resultados são mostrados respectivamente pelos quadros das Fig. 5.8.1 e 5.8.2, que representam a seção transversal dos cilindros.

Neste cálculo, as tensões atuantes em determinados pontos da espessura do cilindro foram registradas para permitir uma melhor visualização do efeito que o carregamento hidrostático promove na estrutura e a comparação entre os dois tipos de configurações estudadas. 


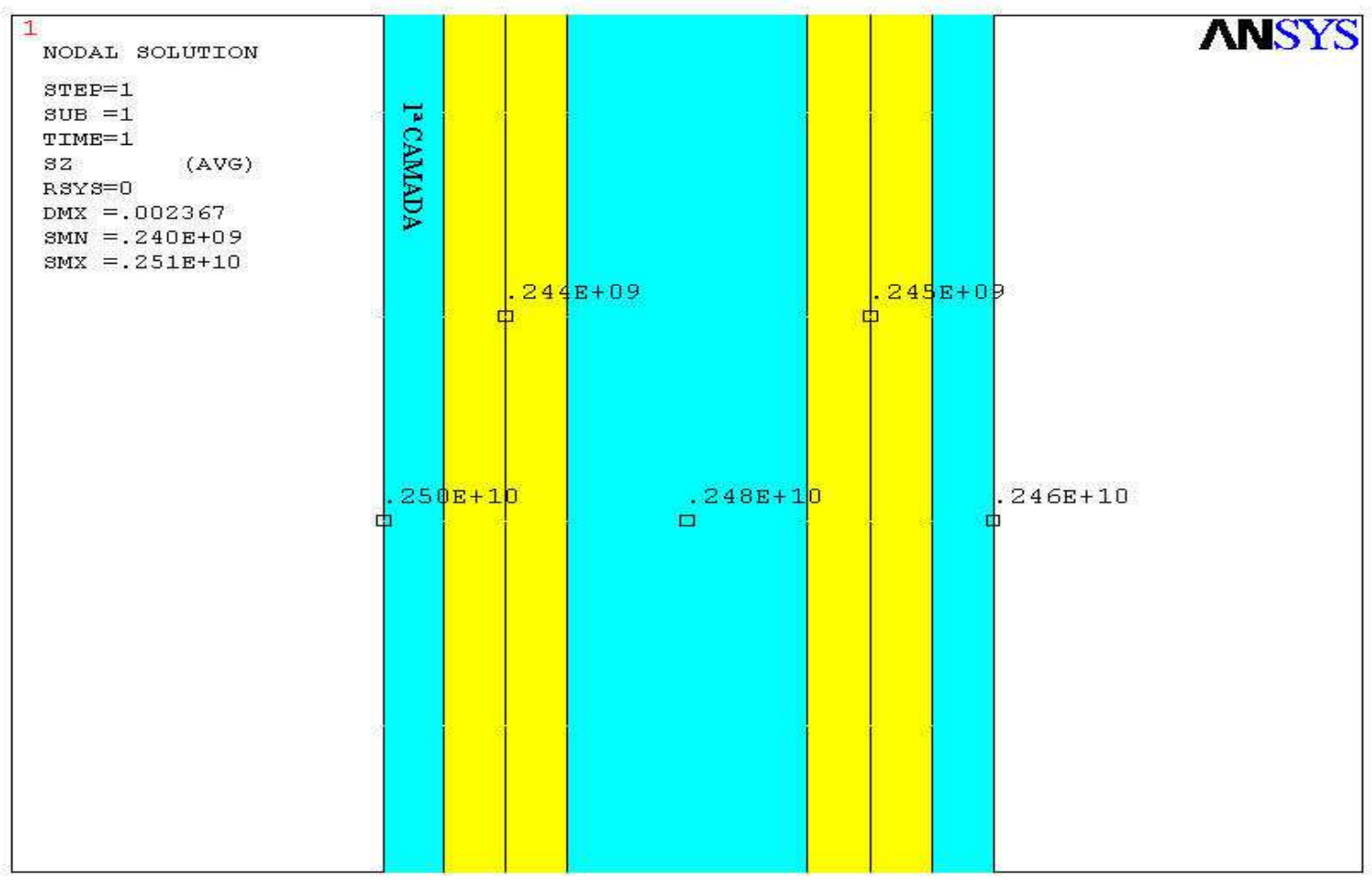

Figura 5.8.1 - Resultados da análise de tensões por elementos finitos em um cilindro com configuração simétrica submetido a pressão média de ruptura de 22,5 MPa.

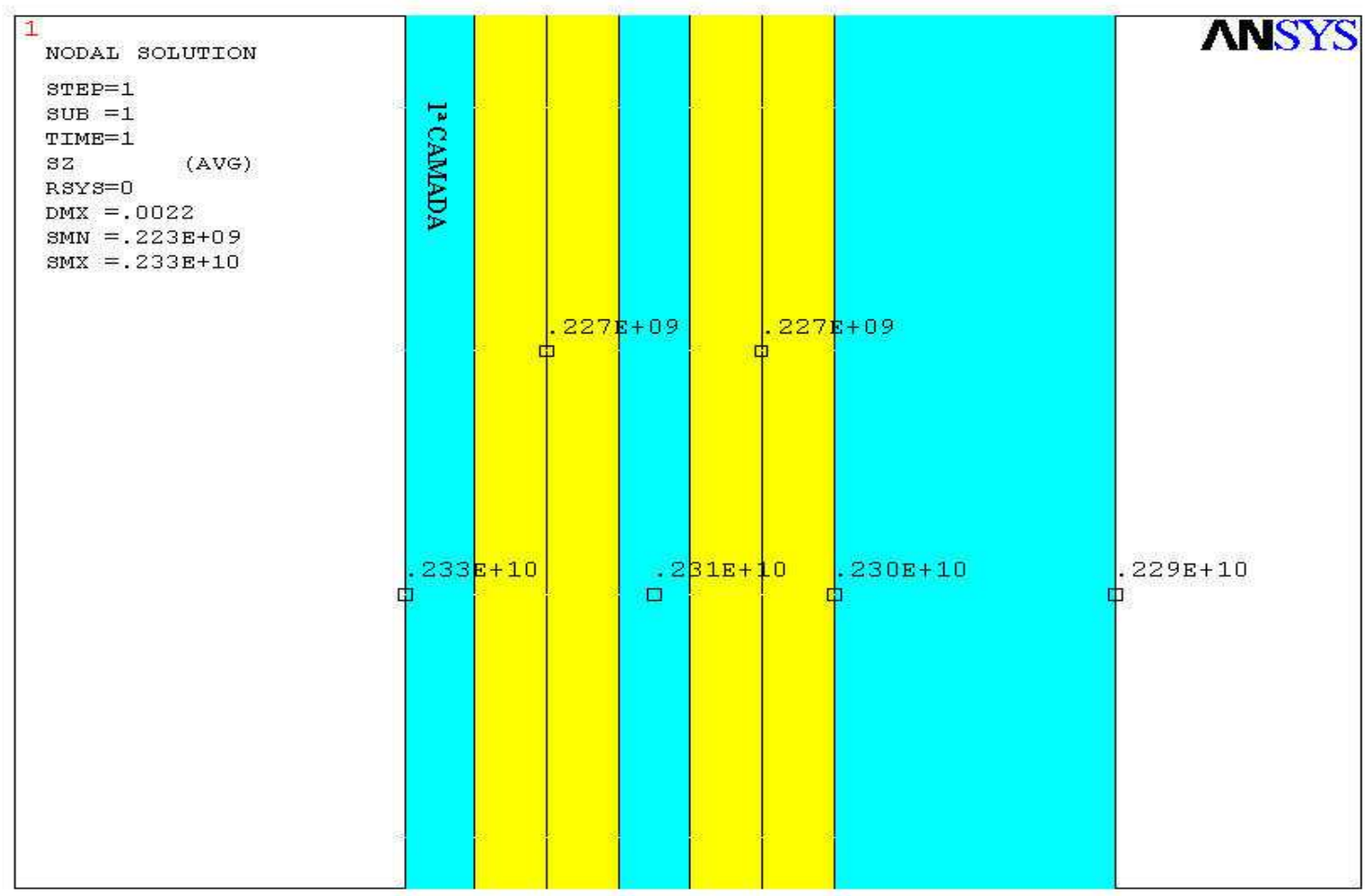

Figura 5.8.2 - Resultados da análise de tensões por elementos finitos em um cilindro com configuração assimétrica submetido a pressão média de ruptura de 20,9 MPa. 
Nas folhas de respostas do ANSYS, indicadas nas Fig. 5.8.1 e 5.8.2, as siglas DMX, SMN e SMX representam, respectivamente, o deslocamento resultante máximo e as tensões circunferenciais mínima e máxima obtidas no cálculo, em Pascal (Pa). Os valores assinalados sobre as figuras representam as tensões circunferenciais atuantes em determinados pontos da espessura dos cilindros, tomando-se por base a primeira camada, posicionada à esquerda nas figuras. Para maior compreensão, na Fig. 5.8.1 a tensão de $2500 \mathrm{MPa}$ $(0.255 E+10)$ representa a tensão circunferencial na primeira camada, enquanto que a tensão de $244 \mathrm{MPa}(0.244 \mathrm{E}+09)$ indica a tensão circunferencial no primeiro par de camadas helicoidais.

As tensões no cilindro com configuração simétrica são superiores às do cilindro com configuração assimétrica, como conseqüência da maior carga que foi aplicada na estrutura, porém, fato é que a distribuição das tensões nos dois cilindros apresentou valores muito próximos no cálculo do ANSYS.

Outro resultado que se obtém da análise é que as tensões nas camadas circunferenciais decrescem da camada mais interna para a camada mais externa, indicando que a falha teria maior possibilidade de ocorrer nesta seqüência, ou seja, a primeira camada circunferencial falhar antes que a última. Analisando-se as tensões nas camadas helicoidais verifica-se que elas são semelhantes para cada grupo de cilindros e dez vezes menor que as tensões nas camadas circunferenciais. Contudo, apesar de inferiores, estas tensões necessitam de uma análise mais rigorosa por não estarem atuando na direção da fibra, podendo ocorrer falha numa destas camadas mesmo antes de uma camada circunferencial falhar.

Da análise dos resultados das Fig. 5.8.1 e 5.8.2 não é possível afirmar que a posição das camadas de forma diferenciada em cada uma das configurações estudadas exerceu influência nas tensões obtidas após o carregamento considerando-se o cálculo do ANSYS.

Nas Fig. 5.8.3 e 5.8.4 a seguir, são mostrados os resultados obtidos no cálculo de elementos finitos do ANSYS, para o limite de resistência à tração na direção da fibra de $2280 \mathrm{MPa}$, conforme Daniel \& Ishai (1994), nos cilindros com configuração simétrica e assimétrica, respectivamente, submetidos ao carregamento de pressão interna. 


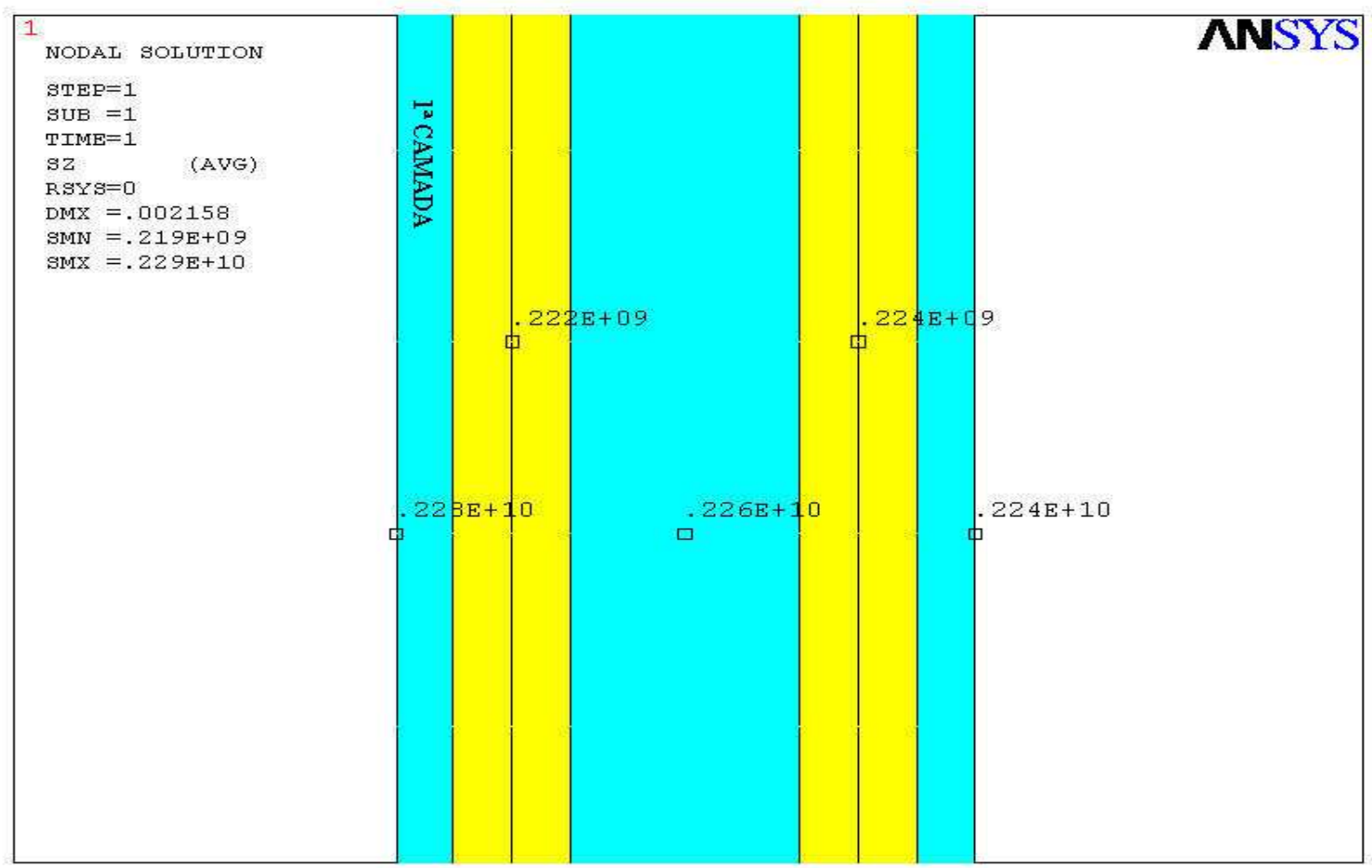

Figura 5.8.3 - Resultados da análise de tensões por elementos finitos em um cilindro com configuração simétrica, submetido à pressão interna, para o limite de resistência a tração na direção da fibra de $2280 \mathrm{MPa}$.

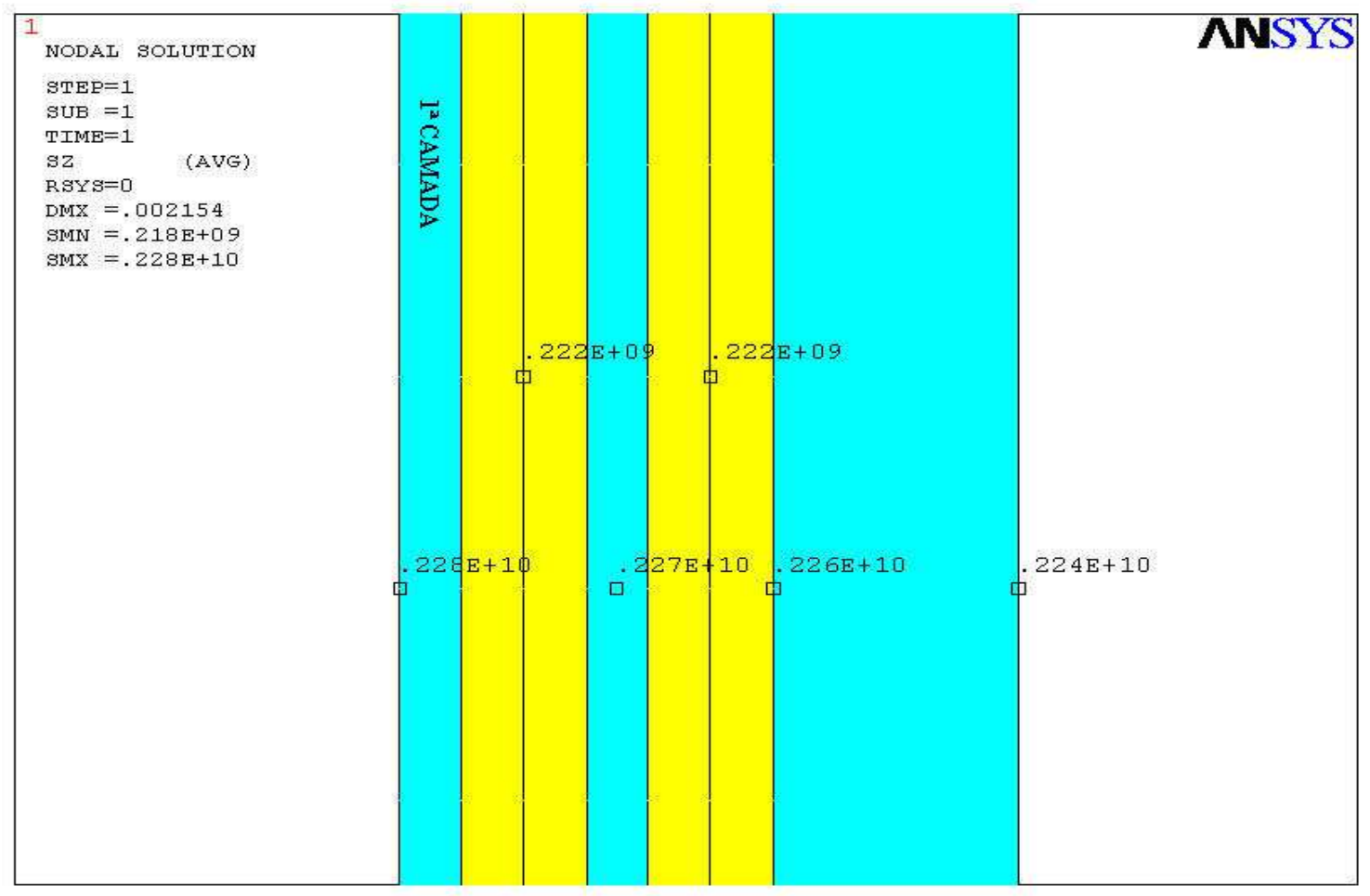

Figura 5.8.4 - Resultados da análise de tensões por elementos finitos em um cilindro com configuração assimétrica, submetido à pressão interna, para o limite de resistência a tração na direção da fibra de $2280 \mathrm{MPa}$. 
Para o cálculo utilizando-se o limite de resistência à tração na direção da fibra, foi adotado como procedimento a introdução de valores crescentes de pressão interna até que o valor de tensão de $2280 \mathrm{MPa}$, definido como limite de resistência do material compósito na direção das fibras, fosse atingido nas regiões analisadas em cada configuração. Os valores de tensão máxima atuantes no compósito, SMX, resultantes desse procedimento foram $2290 \mathrm{MPa}$ e $2280 \mathrm{MPa}$ para as configurações simétrica e assimétrica, respectivamente. $O$ valor de 2290 MPa, para SMX, na configuração simétrica ocorre fora da região analisada, na extremidade da malha de elementos devido ao efeito de borda, porém na região analisada obteve-se o valor máximo definido inicialmente.

Neste cálculo, além de permitir a análise das tensões atuantes ao longo da espessura e determinar o ponto no qual a tensão circunferencial atinge o valor máximo estipulado, foi possível também obter as máximas pressões teóricas para as quais a tensão máxima ocorre nas duas configurações estudadas. Para atingir o limite de tensão nas regiões analisadas, as pressões máximas de carregamento para as configurações simétrica e assimétrica foram, respectivamente, de 20,51 e 20,47 MPa.

Os valores das tensões ao longo da espessura nas Fig. 5.8.3 e 5.8.4 distribuem-se de forma semelhante para as duas configurações e observa-se novamente que a máxima tensão circunferencial ocorre na posição mais interna da parede do cilindro.

Da análise destes valores de pressão máxima obtidos, verifica-se que pelo cálculo realizado com o uso do programa ANSYS, também não é possível afirmar que a posição das camadas de forma diferenciada em cada uma das configurações estudadas exerceu influência na obtenção do limite de resistência a tração de $2280 \mathrm{MPa}$.

Como se observou nos cálculos anteriores, o ANSYS utilizado como ferramenta para o cálculo estrutural de compósitos está limitado a fornecer tensões e deformações atuantes nos eixos principais da estrutura, o que para os materiais anisotrópicos, como é o caso dos compósitos, não é suficiente. Nestes materiais, as tensões obtidas para o sistema de coordenadas dos eixos globais necessitam ser transferidas para o sistema de coordenadas dos eixos locais de cada camada, que corresponde a rotacionar o sistema principal no ângulo que corresponde ao ângulo da fibra de cada camada. Somente após este 
procedimento é que se pode analisar o efeito das tensões em cada camada. Como o ANSYS não executa este cálculo individualizado, a interpretação dos resultados depende principalmente da experiência do projetista, que muitas vezes não é um especialista neste tipo de material.

Dos resultados obtidos nos cálculos, observa-se que o ANSYS não fornece subsídios para concluir qual das duas configurações de bobinagem abordadas neste estudo possui vantagem do ponto de vista estrutural, deixando a decisão de qual configuração utilizar na estrutura a critério do projetista.

Portanto, uma das contribuições importantes que é dada por este estudo é mostrar que programas de elementos finitos, como o ANSYS, por exemplo, apesar de serem ferramentas poderosas para análise de tensões e deformações em materiais isotrópicos, não oferecem respostas satisfatórias para materiais que apresentam comportamento anisotrópico.

As dificuldades que o programa apresenta em converter tensões dos eixos globais para os eixos locais torna a tarefa do analista mais difícil, haja vista que os modos de falha do arranjo assimétrico, com indicação clara da ocorrência de tensões de cisalhamento, não podem ser previstas pelos quadros de respostas dadas pelo ANSYS, que estão mostrados nas páginas anteriores . 


\section{CONCLUSÕES}

No projeto de um componente estrutural em compósito polimérico, é possível até desconsiderar o posicionamento relativo das camadas do compósito em relação ao plano médio da espessura. No entanto, dependendo do arranjo das camadas na configuração de bobinagem, podem ocorrer efeitos inesperados, tal como tensões cisalhantes, que podem comprometer o desempenho da estrutura.

No presente estudo, dois grupos de cilindros foram produzidos com as mesmas matérias-primas, pelo mesmo processo e apresentaram resultados de frações volumétricas quase idênticos, o que permite concluir que quando submetidos ao ensaio hidrostático, a única variável que poderia influenciar no desempenho dos cilindros seria a configuração de bobinagem. Resultados dos ensaios hidrostáticos mostraram que a configuração de bobinagem assimétrica causou efeitos que produziram uma pressão média de ruptura $7 \%$ menor em relação aos cilindros simétricos e diferentes modos de falha.

O modo de falha observado nos cilindros com configuração simétrica foi caracterizado pela presença de uma trinca longitudinal que se estendeu de uma extremidade a outra do cilindro e diversas trincas circunferenciais ramificadas dessa trinca principal. Nos cilindros com configuração assimétrica o modo de falha observado apresentou, além da trinca longitudinal, trincas próximas de $45^{\circ}$, com forte evidência de tensões de cisalhamento provocadas pela assimetria.

O software ANSYS utilizado como ferramenta para análise de tensões nos cilindros com as configurações propostas no trabalho não forneceu resultados que permitiram concluir que cilindros fabricados com configuração assimétrica têm limite de resistência à ruptura inferior aos de configuração simétrica, inclusive não indicando a presença de tensões de cisalhamento geradas pela assimetria. 


\section{TRABALHOS FUTUROS}

- Mecanismo de fratura a partir da análise das fraturas utilizando microscópio eletrônico de varredura.

- Cálculo analítico para determinar as tensões de cisalhamento interlaminares que surgem em cilindros fabricados com configuração assimétrica.

- Comparação com outros laminados assimétricos de mesmo número de camadas e ângulos.

- Otimização do ciclo de cura da matriz utilizando-se análise cinética. 


\section{REFERÊNCIAS BIBLIOGRÁFICAS}

Almeida, S. F. M.; Nogueira Neto, Z. S. Effect of void content on the strength of composite laminates. Composite Structures, v. 28, p. 139-148, 1994.

Al-Salehi, F. A. R.; Al-Hassani, S. T. S.; Haftchenari, H. Temperature and rate effects on GRP tubes under tensile hoop loading. Applied Composite Materials, v. 8, p. 1-24, 2001.

Ashbee, K. Fundamental Principles of Fiber Reinforced Composites. Technomic Publishing Company, Inc., USA, p. 38-42, 165-167, 1989.

ASM International, Composites. Engineered Materials Handbook, v. 1, USA, p. $7,23,25,27,502-507,1987$.

ASTM Standards, D792 - 66 (1979) Standard Test Methods for Specific Gravity and Density of Plastics by Displacement, 08.01, USA, 1983.

ASTM Standards, D3418 - 75 Standard Test Method for Transition Temperatures of Polymers by Thermal Analysis, Part 35, USA, 1980.

Bader, M. G.; Smith, W.; Isham, A. B.; Rolston, J. A.; Metzner, A. B. Processing and Fabrication Technology. Technomic Publishing Company, Inc., USA, p. 193-200, 1990.

Carvalho, O.; Marinucci, G.; Rossi, J. L. Estudo do comportamento mecânico de cilindros de compósito polimérico com bobinagem simétrica e assimétrica. In: CONGRESSO BRASILEIRO DE ENGENHARIA E CIÊNCIA DOS MATERIAIS, XVI, 28 novembro a 02 dezembro, 2004, Porto Alegre. Proceedings...

Porto Alegre: CBECIMAT, 2004.

Chang, D. J. Burst tests of filament-wound graphite-epoxy tubes. Journal of Composite Materials, v. 37, n. 9, p. 811-829, 2003.

Cohen, D. Influence of filament winding parameters on composite vessel quality and strength. Composites Part A, v. 28A, p. 1035-1047, 1997.

Cohen, D.; Mantell, S. C.; Zhao, L. The effect of fiber volume fraction on filament wound composite pressure vessel strength. Composites Part B, v. 32, p. 413429, 2001. 
Corrêa, R. Tubos Estruturais em Material Composto para Motores de Foguetes: Estudos em Dimensionamento e Técnicas de Fabricação. Dissertação de Mestrado, São José dos Campos, p. 21-34, 1979.

Costa Neto, P. L. O. Estatística. Edgard Blücher, São Paulo, Brasil, p. 108-116, 250 e 254, 1977.

Daniel, I. M.; Ishai, O. Engineering Mechanics of Composite Materials. Oxford University Press, USA, p. 34, 1994.

Gillham, J. K.; Wang, X. Tg - temperature property. The Journal of Coatings Technology, v. 64, n. 807, p. 37-39, 1992.

Hagstrand, P. -O.; Bonjour, F.; Manson, J. -A. E. The influence of void content on the strutural flexural performance of unidirectional glass fibre reinforced polypropylene composites. Composites Part A, v. 36, p. 705-714, 2005.

Hoover, J. W.; Kujawski, D.; Ellyin, F. Transverse cracking of symmetric and unsymmetric glass-fibre/epoxy-resin laminates. Composites Science and Technology, v. 57, p. 1513-1526, 1997.

Huang, Y. K.; Frings, P. H.; Hennes, E. Exploding pressure vessel test on zylon/epoxy composite. Composites Part B, v. 33, p. 117-123, 2002.

Hudson, R. C.; Davidson, B. D.; Polaha, J. J. Effect of remote ply orientation on the perceived mode I and mode II toughness of $\theta / \theta$ and $\theta /-\theta$ interfaces. Applied Composite Materials, v. 5, p. 123-138, 1998.

Kaddour, A. S.; Hinton, M. J.; Soden, P. D. Behavior of $\pm 45^{\circ}$ glass/epoxy filament wound composite tubes under quasi-static equal biaxial tension-compression loading: experimental results. Composites Part B, v. 34, p. 689-704, 2003.

Marinucci, G. Desenvolvimento, Fabricação e Análise de Fratura de Cilindros de Fibra de Carbono Colapsados por Pressão Interna. Tese de Doutorado, São Paulo, p. 62-65, 87-90, 2001.

Marinucci, G.; Andrade, A. H. P. Microstructural study of polymeric composite cylinders. In: ENCONTRO DA SOCIEDADE BRASILEIRA DE PESQUISA EM MATERIAIS, II, 26 a 29 de outubro, 2003, Rio de Janeiro. Livro de resumos. Rio de Janeiro: SBPMat, 2003. p. 192.

Martens, M.; Ellyin, F. Biaxial monotonic behavior of a multidirectional glass fiber epoxy pipe. Composites Part A, v. 31, p. 1001-1014, 2000. 
Mertiny, P.; Ellyin, F.; Hothan, A. Stacking sequence effect of multi-angle filament wound tubular composite structures. Journal of Composite Materials, v. 38, n. 13, p. 1095-1113, 2004.

Peters, S. T. Filament winding composite structure fabrication. SAMPE, USA, p. 1-1, 3-6, 1989.

Rousseau, J.; Perreux, D.; Verdière, N. The influence of winding patterns on the damage behavior of filament-wound pipes. Composites Science and Technology, v. 59, p. 1439-1449, 1999.

Strong, Dr. A. B. Fundamentals of composites manufacturing: Materials, Methods, and Applications. Society of Manufacturing Engineers, USA, p. 5-6, 1989.

Shah, V. Handbook of plastics testing technology. John Wiley \& Sons, Inc., USA, $2^{\text {nd }}$ ed., p. 197, 1998.

Tarakçioglu, N.; Akdemir, A.; Avci, A. Strength of filament wound GRP pipes with surface crack. Composites Part B, v. 32, p. 131-138, 2001.

Tenax Fibers - Catálogo Técnico. 1991.

Vântico Ltda. - Catálogo Técnico. Maio, 2001.

Varna, J.; Joffe, R.; Berglund,; L. A. Lundström, T. S. Effect of voids on failure mechanisms in RTM laminates. Composites Science and Technology, v. 53, p. 241-249, 1995.

Wild, P. M.; Vickers, G. W. Analysis of filament-wound cylindrical shells under combined centrifugal, pressure and axial loading. Composite Part A, v. 28A, p. 47-55, 1997.

Wisanrakkit, G.; Gillham, J. K. The glass transition temperature $\left(T_{g}\right)$ as an index of chemical conversion for a high- $\mathrm{T}_{\mathrm{g}}$ amine/epoxy system: chemical and diffusioncontrolled reaction kinetics. Journal of Applied Polymer Science, v. 41, p. 28852929, 1990. 